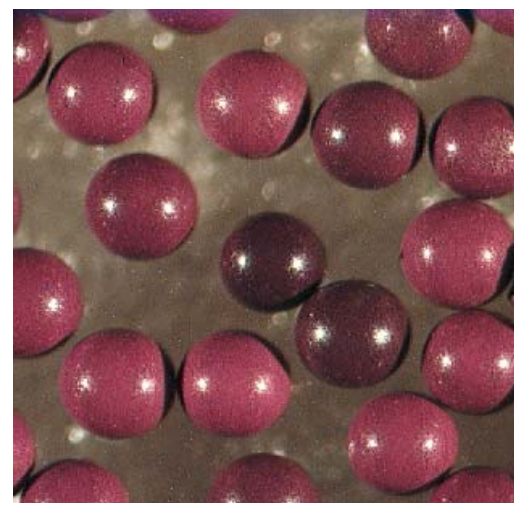

Spherical Resorcinol-Formaldehyde

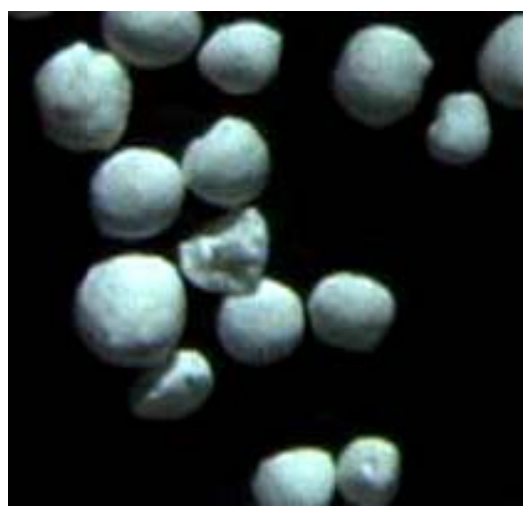

Engineered Crystalline Silicotitanate

\title{
Literature Reviews to Support Ion Exchange Technology Selection for Modular Salt Processing
}

Washington Savannah River Company

Savannah River Site

Aiken, SC 29808

Prepared for the U.S. Department of Energy under Contract No. DE-AC09-96SR18500

(B) 


\section{DISCLAIMER}

This report was prepared by the Washington Savannah River Corporation (WSRC) for the United States Department of Energy under Contract DE-AC09-96SR18500 and is an account of work performed under that Contract. Neither the United States, the United States Department of Energy, nor WSRC, nor any of their employees, makes any warranty, expressed or implied, or assumes any legal liability or responsibility for the accuracy, completeness, or usefulness of any information, apparatus, product, or process disclosed herein, or represents that its use will not infringe privately owned rights. Reference herein to any specific commercial product, process or service by trade name, mark, manufacturer, or otherwise does not necessarily constitute or imply endorsement, recommendation, or favoring of same by WSRC or by the United States Government or any agency thereof. The views and opinions of authors expressed herein do not necessarily state or reflect those of the United States Government or any agency thereof. 


\section{KEYWORDS:}

In-tank Column

Resorcinol-Formaldehyde Resin

Crystalline Silicotitanate

Cesium

RETENTION - Permanent

\section{Literature Reviews to Support Ion Exchange Technology Selection for Modular Salt Processing}

William D. King

Savannah River National Laboratory

Publication Date: November 2007

Washington Savannah River Company

Savannah River Site

Aiken, SC 29808

Prepared for the U.S. Department of Energy under Contract No. DE-AC09-96SR18500

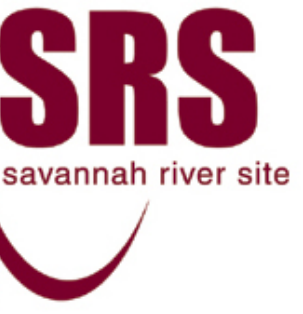


DOCUMENT: WSRC-STI-2007-00609

TITLE: Literature Reviews to Support Ion Exchange Technology Selection for Modular Salt Processing

\section{APPROVALS}

Date:

William D. King, Author,

Advanced Characterization and Process Research, SRNL

Date:

Daniel J. McCabe, Technical Reviewer,

Advanced Characterization and Process Research, SRNL

Date:

William R. Wilmarth, Level 4 Manager,

Advanced Characterization and Process Research, SRNL

Date:

Timothy Punch,

Technology Development and Tank Closure, SRS 


\section{TABLE OF CONTENTS}

1.0 INTRODUCTION.

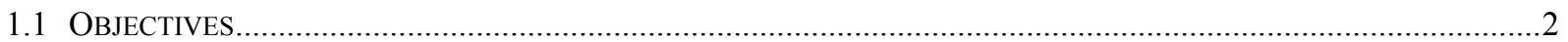

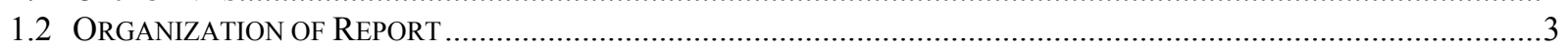

2.0 SUMMARY OF PRIMARY REFERENCES FOR IX TECHNOLOGY SELECTION AND SCIX

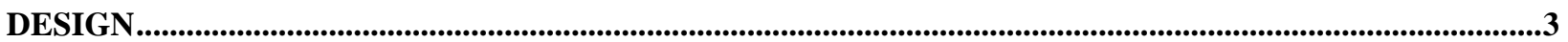

3.0 SPHERICAL RESORCINOL-FORMALDEHYDE RESIN .....................................................................

3.1 Spherical RF MANUfaCtURABILITY - Production SCALE AND REPRODUCIBILITY .....................................10

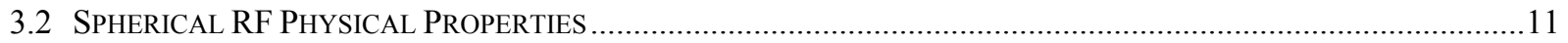

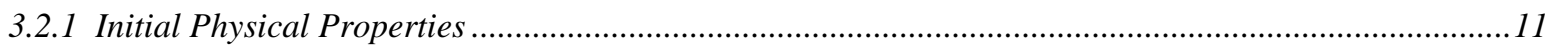

3.2.2 Physical Property Changes Associated with Chemical Cycling and Radiolysis .....................................11

3.2.3 Physical Property Changes Associated with Chemical Reactivity ............................................................12

3.2.4 Handling (Fluidization, Slurry Transport, and Settling Behavior) (........................................................13

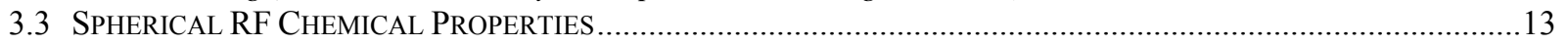

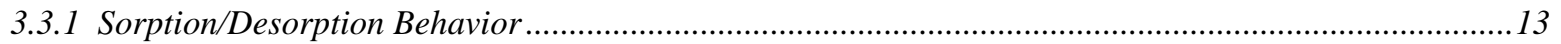

3.3.2 Chemical Reactivity and Impacts on Cesium Removal Performance .....................................................15

3.3.3 Radiolytic Effects on Cesium Removal Performance.................................................................................17

3.4 SPherical RF PERFORMANCE UNDER DYNAMIC Flow CONDITIONS IN COLUMN CONFIGURATION .................18

3.4.1 Hanford RPP-WTP Resin Pretreatment, Column Loading, and Column Processing Summary .............18

3.4.2 Cesium Loading/Elution Performance................................................................................................

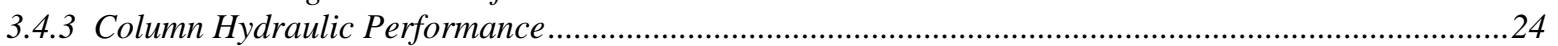

3.4.4 Column Testing using Actual Hanford Tank Supernates.....................................................................26

3.4.5 Anticipated RF Radiation Exposure and Resin Lifetime in the SCIX Packed Column Geometry ............27

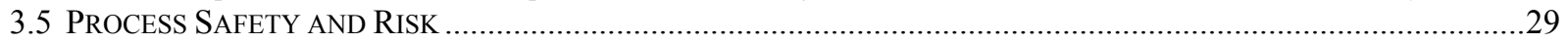

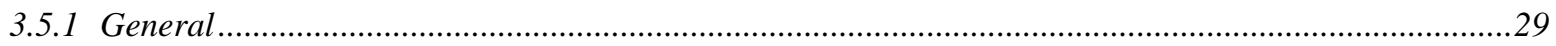

3.5.2 Risks Associated with Hydraulic Performance and Column Pluggage ...................................................30

3.5.3 Hazards Associated with Heat Sources ..............................................................................................30

3.5.4 Vessel Pressurization and Explosion Hazards Associated with Off-gassing from Chemical Reactions

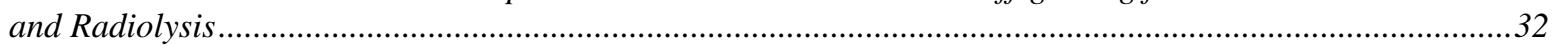

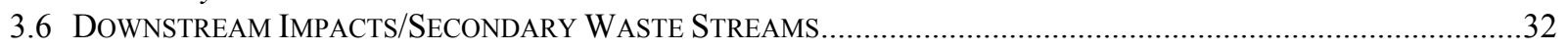

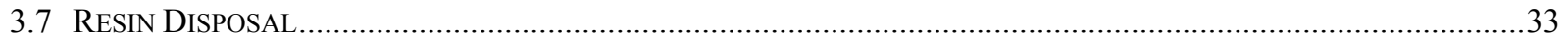

4.0 IONSIV IE-911 ENGINEERED CRYSTALLINE SILICOTITANATE......................................................40

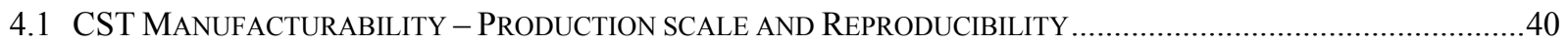

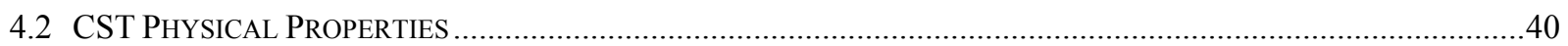

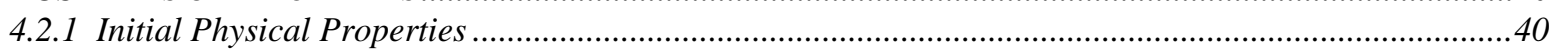

4.2.2 Physical Property Changes Associated with Chemical Reactivity and Radiation..................................41

4.2.3 Handling (Fluidization, Slurry Transport, Settling, Abrasion, and Grinding) ......................................42

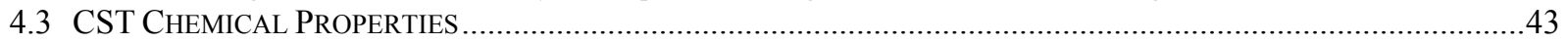

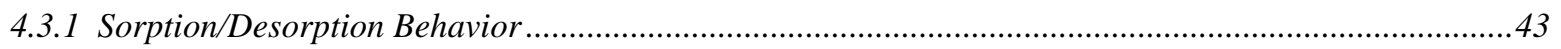

4.3.2 Chemical Reactivity and Impacts on Cesium Removal Performance .....................................................45

4.3.3 Radiolytic Effects on Cesium Removal Performance................................................................................46

4.4 CST PERFORMANCE UNDER DYNAMIC Flow CONDITIONS IN COLUMN CONFIGURATION ...............................46

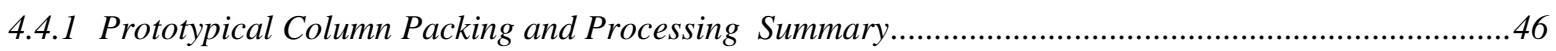

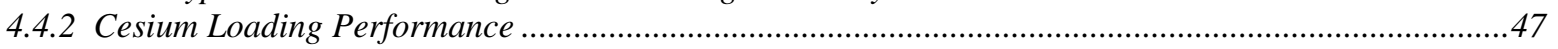

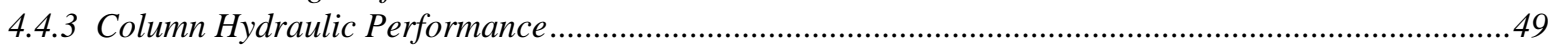

4.4.4 Column Testing using Actual SRS or Other Tank Waste Supernates .....................................................50

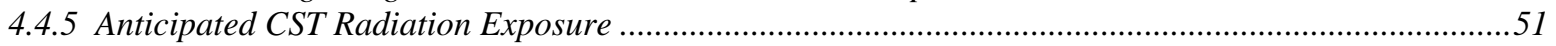

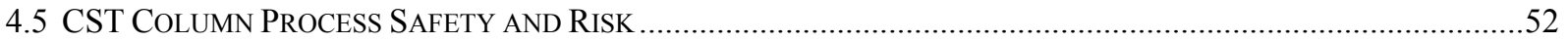

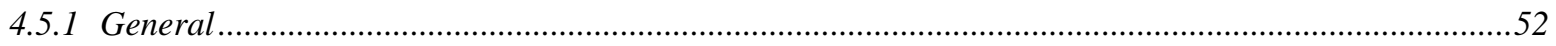

4.5.2 Risks Associated with Hydraulic Performance and Column Pluggage .................................................52

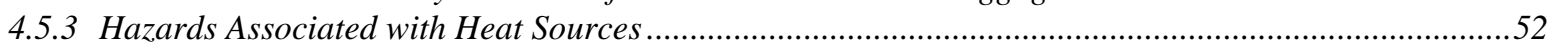


4.5.4 Vessel Pressurization and Explosion Hazards Associated with Off-gassing from Chemical Reactions

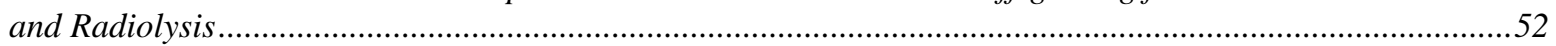

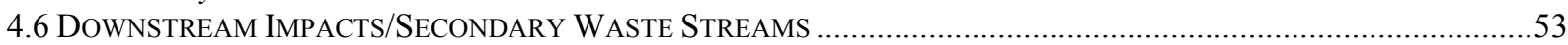

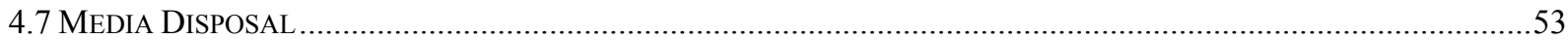

5.0 COMPARISONS OF SPHERICAL RF AND ENGINEERED CST ION EXCHANGE MEDIA FOR

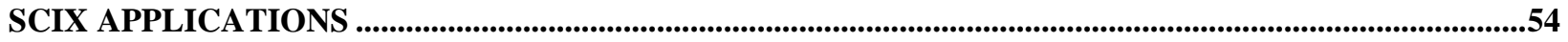

6.0 CURRENT TECHNOLOGY GAPS AND RECOMMENDATIONS FOR ADDITIONAL STUDIES FOR RF AND CST …..........................................................................................................................................58

7.0 CONCLUSIONS

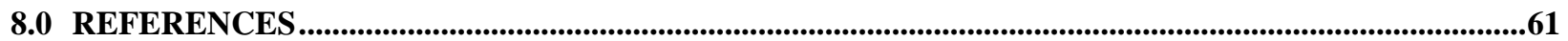




\section{LIST OF TABLES}

Table 2-1. Primary MSP References for RF and CST Ion Exchange Media. . .4

Table 3-1. Physical Property and Performance Data for Six Production Scale Spherical RF Resin Batches ..........36

Table 3-2. Estimations of RF Resin Radiation Dose and Lifetime for Tank 37 Processing....................................37

Table 3-3. Estimations of RF Resin Radiation Dose and Lifetime for Tank 3 Processing........................................38

Table 3-4. Fractional loading and time-averaged dose corrections used for the dose calculations for Tanks 37 and

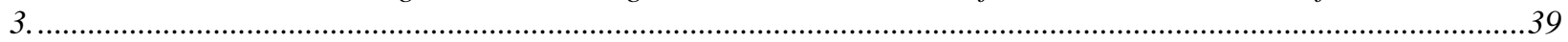

Table 5-1. Comparison of Selected Properties for Spherical RF and IONSIV IE-911 (CST)................................55

Table 5-2. Evaluations of Spherical RF and IONSIV IE-911 (CST) Technical Maturity ........................................56

Table 6-1. Gaps in the Characterization of Spherical RF and IONSIV IE-911 (CST) and Potential Additional

Testing..... .59

\section{LIST OF FIGURES}

None 


\subsection{Introduction}

This report summarizes the results of literature reviews conducted to support the selection of a cesium removal technology for application in a small column ion exchange (SCIX) unit supported within a high level waste tank. SCIX is being considered as a technology for the treatment of radioactive salt solutions in order to accelerate closure of waste tanks at the Savannah River Site (SRS) as part of the Modular Salt Processing (MSP) technology development program. Two ion exchange materials, spherical Resorcinol-Formaldehyde (RF) and engineered Crystalline Silicotitanate (CST), are being considered for use within the SCIX unit. Both ion exchange materials have been studied extensively and are known to have high affinities for cesium ions in caustic tank waste supernates. RF is an elutable organic resin and CST is a non-elutable inorganic material. Waste treatment processes developed for the two technologies will differ with regard to solutions processed, secondary waste streams generated, optimum column size, and waste throughput. Pertinent references, anticipated processing sequences for utilization in waste treatment, gaps in the available data, and technical comparisons will be provided for the two ion exchange materials to assist in technology selection for SCIX. The engineered, granular form of CST (UOP IE911) was the baseline ion exchange material used for the initial development and design of the SRS SCIX process (McCabe, 2005). To date, in-tank SCIX has not been implemented for treatment of radioactive waste solutions at SRS. Since initial development and consideration of SCIX for SRS waste treatment an alternative technology has been developed as part of the River Protection Project Waste Treatment Plant (RPP-WTP) Research and Technology program (Thorson, 2006). Spherical RF resin is the baseline media for cesium removal in the RPP-WTP, which was designed for the treatment of radioactive waste supernates and is currently under construction in Hanford, WA. Application of RF for cesium removal in the Hanford WTP does not involve in-riser columns but does utilize the resin in large scale column configurations in a waste treatment facility.

The basic conceptual design for SCIX involves the dissolution of saltcake in SRS Tanks 1-3 to give approximately $6 \mathrm{M}$ sodium solutions and the treatment of these solutions for cesium removal using one or two columns supported within a high level waste tank. Prior to ion exchange treatment, the solutions will be filtered for removal of entrained solids. In addition to Tanks 1-3, solutions in two other tanks (37 and 41) will require treatment for cesium removal in the SCIX unit. The previous SCIX design (McCabe, 2005) utilized CST for cesium removal with downflow supernate processing and included a CST grinder following cesium loading. Grinding of CST was necessary to make the cesium-loaded material suitable for vitrification in the SRS Defense Waste Processing Facility (DWPF). Because RF resin is elutable (and reusable) and processing requires conversion between sodium and hydrogen forms using caustic and acidic solutions more liquid processing steps are involved. The WTP baseline process involves a series of caustic and acidic solutions (downflow processing) with water washes between $\mathrm{pH}$ transitions across neutral. In addition, due to resin swelling during conversion from hydrogen to sodium form an upflow caustic regeneration step is required. Presumably, one of these basic processes (or some variation) will be utilized for MSP for the appropriate ion exchange technology selected. 
CST processing involves two primary waste products: loaded CST and decontaminated salt solution (DSS). RF processing involves three primary waste products: spent RF resin, DSS, and acidic cesium eluate, although the resin is reusable and typically does not require replacement until completion of multiple treatment cycles. CST processing requires grinding of the ion exchange media, handling of solids with high cesium loading, and handling of liquid wash and conditioning solutions. RF processing requires handling and evaporation of cesium eluates, disposal of spent organic resin, and handling of the various liquid wash and regenerate solutions used. In both cases, the DSS will be immobilized in a low activity waste form. It appears that both technologies are mature, well studied, and generally suitable for this application. Technology selection will likely be based on downstream impacts or preferences between the various processing options for the two materials rather than on some unacceptable performance property identified for one material. As a result, the following detailed technical review and summary of the two technologies should be useful to assist in technology selection for SCIX.

\section{$1.1 \quad$ Objectives}

The objective of this report is to provide the information listed below for RF and CST (though not necessarily in the order listed) as specified in SRNL Memo SRNL-CST-200700048, which was dated April 10, 2007.

- Manufacturability

o consistency

o production scale

- $\quad$ sorption behavior

o geometry effects on DF

o actinide adsorption

o cesium adsorption

o chemical/radiation stability (performance degradation)

- column behavior

o resin physical stability

o pressure drop data and flow performance

o design specifications

o channeling behavior

o cooling system requirements

o resin thermal characteristics

- $\quad$ safety

o emergency elution systems

o RF chemical reactivity

o acid handling

- handling

o hydrogen gas generation

o spent resin settling rates

o mixing requirements for spent resin suspension

o rheology of new and spent resin 


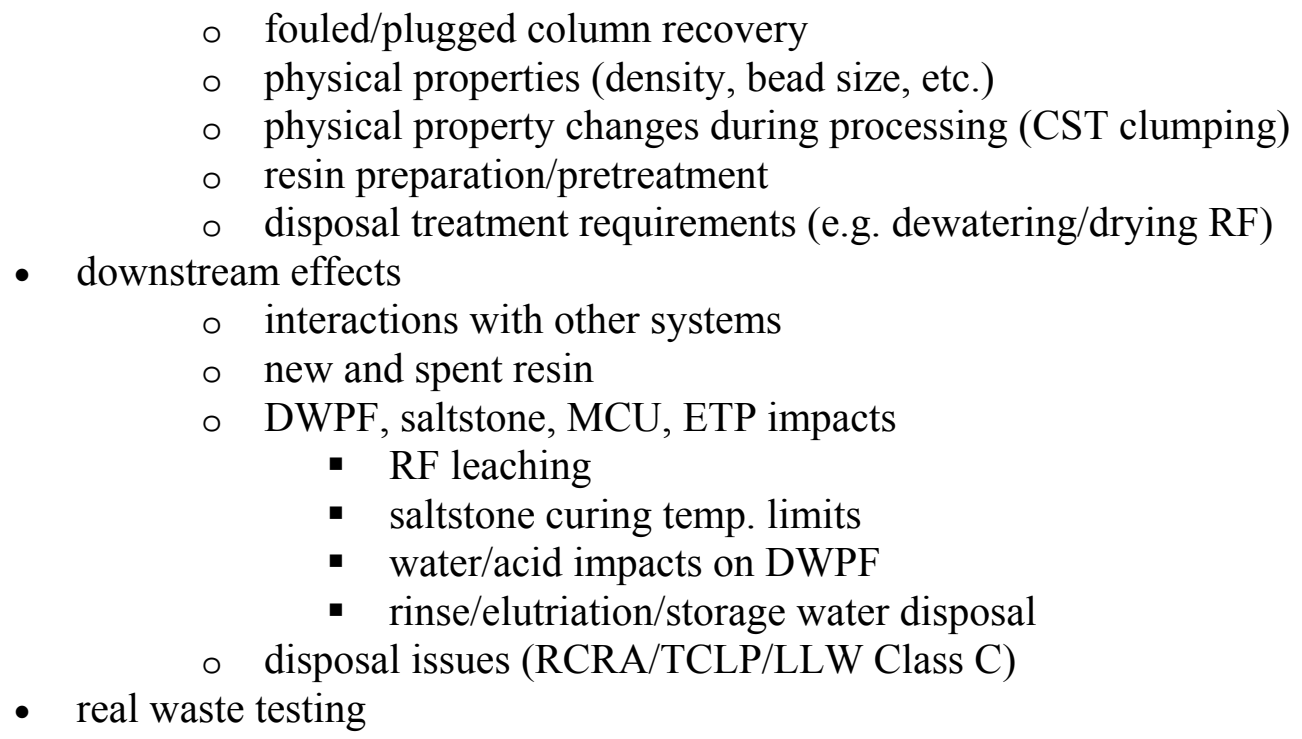

\subsection{Organization of Report}

Report organization is as follows. Section 2.0 includes a list of the primary references for each ion exchange media expected to be useful for technology selection. The location of key information in the various reports is also provided. Complete references, including reports not provided in Section 2.0, are provided in Section 8.0. Sections 3.0 and 4.0 include summaries of the technical information reported for RF and CST, respectively. Section 5.0 includes a comparison of the two technologies with regard to their potential application for SRS SCIX. A listing of gaps in the available technical information for each ion exchange media and recommendations for additional study are provided in Section 6.0. Conclusions are provided in Section 7.0 and complete references in Section 8.0.

\subsection{Summary of Primary References for IX Technology Selection and SCIX Design}

Pertinent information for the application of RF and CST in the SCIX unit is included in numerous references published over the past decade. A summary of the most pertinent MSP references for both technologies is provided in Table 2-1 with locations and descriptions of particularly useful information in each report. Spherical RF resin was only recently developed and evaluated for application towards the treatment of radioactive waste. Most reports describing spherical RF properties and cesium removal performance have been published since 2000. In addition, recent modeling evaluations (for both RF and CST) and laboratory tests have been conducted specifically to support the MSP program and the reports on these subjects are included in this review. 
Table 2-1. Primary MSP References for RF and CST Ion Exchange Media.

\begin{tabular}{|c|c|c|c|}
\hline Author & Year & Pages & Information \\
\hline \multicolumn{4}{|c|}{ Teneral RF References } \\
\hline \multirow[t]{6}{*}{ Thorson } & 2006 & general & $\begin{array}{l}\text { The basis for the recommendation of spherical RF as the approved } \\
\text { equivalent to SL644 for Cs removal in the Hanford WTP is provided. } \\
\text { A summary of spherical RF test results as of November } 2006 \text { is } \\
\text { provided. }\end{array}$ \\
\hline & & $8-9$ & $\begin{array}{l}\text { RF test results and performance verses WTP design requirements are } \\
\text { summarized in Tables } 1 \text { and } 2 \text {. The basic WTP cesium removal } \\
\text { process and a summary of throughput requirements are provided in } \\
\text { Figure } 1 .\end{array}$ \\
\hline & & 15 & $\begin{array}{l}\text { The refined spherical RF processes for use in the WTP are provided } \\
\text { in Tables } 4 \text { and } 5 \text { for two different flow rates. The information } \\
\text { includes flow rates, processing times, and expected resin volumes for } \\
\text { each step. }\end{array}$ \\
\hline & & 24 & $\begin{array}{l}\text { An overview of WTP cesium loading requirements and conditions is } \\
\text { provided in Figure } 6 .\end{array}$ \\
\hline & & 25 & $\begin{array}{l}\text { The average number of load/elute cycles predicted for RF resin during } \\
\text { processing of Hanford waste in the WTP during 5-year intervals (over } \\
\text { a } 25 \text { year period) is provided in Table } 6 \text { along with the average } \\
\text { supernate composition during each period. }\end{array}$ \\
\hline & & 32 & A schematic of the RF synthesis process is provided in Figure 7. \\
\hline \multirow[t]{5}{*}{ Fiskum } & $2006 \mathrm{a}$ & general & $\begin{array}{l}\text { This report describes results of spherical RF column testing with } \\
\text { simulated and actual waste from Hanford Tank 241-AP-101. }\end{array}$ \\
\hline & & xiv & $\begin{array}{l}\text { Load and elution summaries for the actual AP-101 waste are provided } \\
\text { in Table S.4. }\end{array}$ \\
\hline & & 3.10 & $\begin{array}{l}\text { The concentrations of multiple constituents in the column effluent } \\
\text { solution and their ratios to the feed concentrations are provided in } \\
\text { Table 3.3. }\end{array}$ \\
\hline & & 3.14 & $\begin{array}{l}\text { The concentrations of multiple constituents in the composite nitric } \\
\text { acid eluate solution and their ratios to the feed concentrations are } \\
\text { provided in Table 3.4. }\end{array}$ \\
\hline & & 3.15 & $\begin{array}{l}\text { The concentrations of radionuclides in the composite nitric acid eluate } \\
\text { solution and their ratios to the feed concentrations are provided in } \\
\text { Table 3.5. }\end{array}$ \\
\hline \multirow[t]{4}{*}{ Fiskum } & $2006 b$ & general & $\begin{array}{l}\text { This report describes results of spherical RF column testing with } \\
\text { actual waste from Hanford Tank 241-AN-102. }\end{array}$ \\
\hline & & 3.6 & $\begin{array}{l}\text { The concentrations of multiple constituents in the column effluent } \\
\text { solution and their ratios to the feed concentrations are provided in } \\
\text { Table 3.3. }\end{array}$ \\
\hline & & 3.10 & $\begin{array}{l}\text { The concentrations of multiple constituents in the composite nitric } \\
\text { acid eluate solutions for each column (lead/lag) and their ratios to the } \\
\text { feed concentrations are provided in Table 3.4. }\end{array}$ \\
\hline & & 3.12 & $\begin{array}{l}\text { The concentrations of radionuclides in the composite nitric acid eluate } \\
\text { solution and their ratios to the feed concentrations are provided in } \\
\text { Table 3.5. }\end{array}$ \\
\hline \multirow[t]{2}{*}{ Fiskum } & $2006 c$ & general & $\begin{array}{l}\text { This report describes spent resin analysis results for the two actual } \\
\text { waste column tests with spherical RF. }\end{array}$ \\
\hline & & $\mathrm{x}$ & A summary of analyte concentrations in spent RF resins after actual \\
\hline
\end{tabular}




\begin{tabular}{|c|c|c|c|}
\hline & & & waste testing is provided in Table S.2. \\
\hline & & 2.2 & $\begin{array}{l}\text { The history of the resin samples analyzed including total cesium } \\
\text { loading and breakthrough during simulant and actual waste testing is } \\
\text { provided in Table } 2.1 \text {. }\end{array}$ \\
\hline & & 3.1 & $\begin{array}{l}\text { Metals analysis results for spent RF resin after real waste testing are } \\
\text { provided in Table 3.1. }\end{array}$ \\
\hline & & 3.5 & $\begin{array}{l}\text { Radionuclide analysis results for spent RF resin after real waste } \\
\text { testing are provided in Table 3.3. }\end{array}$ \\
\hline & & 3.7 & $\begin{array}{l}\text { Total analyte quantities recovered from spent resin are provided in } \\
\text { Table 3.4. }\end{array}$ \\
\hline \multirow[t]{16}{*}{ Fiskum } & $2006 \mathrm{~d}$ & general & $\begin{array}{l}\text { This report includes comparative column testing results and general } \\
\text { evaluations of nearly } 30 \mathrm{RF} \text { resin batches during the refinement of the } \\
\text { RF synthetic recipe and scale-up production. This is a highly useful } \\
\text { report for a general understanding of spherical RF resin characteristics } \\
\text { and performance. }\end{array}$ \\
\hline & & $\mathrm{xxxV}$ & $\begin{array}{l}\text { A comparison plot of cesium removal performance during column } \\
\text { testing with multiple scale-up production RF batches is provided in } \\
\text { Figure S.2. }\end{array}$ \\
\hline & & 3.2 & $\begin{array}{l}\text { A listing of all of the spherical RF resin batches produced and tested } \\
\text { is provided in Table 3.1. }\end{array}$ \\
\hline & & 5.23 & $\begin{array}{l}\text { This is the only reported measurement of formaldehyde } \\
\text { concentrations in the RF shipment cover liquid and subsequent wash } \\
\text { solutions. Results are summarized in Figure 5.16. }\end{array}$ \\
\hline & & 6.1 & $\begin{array}{l}\text { Evaluations of worst-case oxygen exposure impacts on RF } \\
\text { performance are presented in report Section 6.0. }\end{array}$ \\
\hline & & 6.8 & $\begin{array}{l}\text { A schematic of the proposed chemical reactions associated with RF } \\
\text { oxidation is provided in Figure 6.6. }\end{array}$ \\
\hline & & 11.10 & $\begin{array}{l}\text { Column elution performance comparisons as a function of nitric acid } \\
\text { concentration are provided in Table } 11.9 \text { and cesium elution profiles } \\
\text { are provided in Figures } 11.9 \text { and } 11.10 \text {. }\end{array}$ \\
\hline & & 11.14 & $\begin{array}{l}\text { Packed bed volumes for scale-up production RF batches in the } \\
\text { various column processing solutions are provided in Table 11.12. }\end{array}$ \\
\hline & & 11.16 & $\begin{array}{l}\text { Composite eluate analysis results for scale-up production batches after } \\
\text { cesium loading tests with AP-101 simulant are provided in Table } \\
11.13 \text {. }\end{array}$ \\
\hline & & 13.11 & $\begin{array}{l}\text { Packed bed volumes for scale-up production RF batches in the } \\
\text { various column processing solutions are provided in Table 13.10. }\end{array}$ \\
\hline & & 14.9 & $\begin{array}{l}\text { Photographs of RF resin beads and micrographs of bead core structure } \\
\text { from scale-up production batches are provided. }\end{array}$ \\
\hline & & $\begin{array}{l}14.15- \\
14.16\end{array}$ & $\begin{array}{l}\text { Photographs of resin color changes and conversion wave fronts } \\
\text { observed during column processing of scale-up production batches } \\
\text { are provided. }\end{array}$ \\
\hline & & 14.27 & $\begin{array}{l}\text { Packed bed volumes for scale-up production RF batches in the } \\
\text { various column processing solutions are provided in Table 14.18. }\end{array}$ \\
\hline & & 16.2 & $\begin{array}{l}\text { A summary of selected physical properties for all resin batches is } \\
\text { provided in Table } 16.1 \text {. }\end{array}$ \\
\hline & & 16.8 & $\begin{array}{l}\text { Post-elution cesium leakage is discussed in Section } 16.3 \text { and } \\
\text { compared for various resins in Table 16.3. }\end{array}$ \\
\hline & & 16.4 & $\begin{array}{l}\text { Suggestions regarding resin purchase specifications are provided in } \\
\text { Table 16.4. }\end{array}$ \\
\hline
\end{tabular}




\begin{tabular}{|c|c|c|c|}
\hline & & 17.1 & $\begin{array}{l}\text { The summary and conclusions provided in Section } 17.0 \text { are useful for } \\
\text { those interested in utilization of spherical RF for large-scale cesium } \\
\text { removal. }\end{array}$ \\
\hline \multirow[t]{9}{*}{ Olson } & 2002 & general & $\begin{array}{l}\text { This report describes the Hanford WTP system description for the } \\
\text { cesium process using ion exchange. This system description was } \\
\text { developed for SuperLig } 644 \text { resin with some intentional flexibility to } \\
\text { accommodate an alternative ion exchange technology. }\end{array}$ \\
\hline & & 3 & $\begin{array}{l}\text { Cesium ion exchange process safety requirements are provided in } \\
\text { Section } 4.2 \text {. }\end{array}$ \\
\hline & & 9 & $\begin{array}{l}\text { The expected process parameter monitoring requirements are } \\
\text { provided in Section 4.3.3.1. }\end{array}$ \\
\hline & & 14 & $\begin{array}{l}\text { The cesium removal process expectations and description are } \\
\text { provided in Section 6.2.1. }\end{array}$ \\
\hline & & 17 & $\begin{array}{l}\text { A description of the hydrogen off-gas dilution and removal approach } \\
\text { is provided in Section 6.2.4. }\end{array}$ \\
\hline & & 18 & $\begin{array}{l}\text { Emergency cooling systems and requirements are discussed in Section } \\
\text { 6.2.6. }\end{array}$ \\
\hline & & 20 & Operations details are provided in Section 7. \\
\hline & & $22-23$ & $\begin{array}{l}\text { Reagents, flowrates, and durations for the various processing steps are } \\
\text { provided in Tables } 1 \text { and } 2 .\end{array}$ \\
\hline & & $27-28$ & $\begin{array}{l}\text { Resin removal and addition requirements are provided in Sections } \\
\text { 7.1.10 and 7.1.11. }\end{array}$ \\
\hline \multirow[t]{5}{*}{ Fondeur } & 2006 & general & $\begin{array}{l}\text { This report summarizes the reactivity of spherical RF resin with nitric } \\
\text { acid and other WTP process solutions. Conditions required to } \\
\text { promote resin nitration are provided. Off-gassing associated with } \\
\text { bulk resin oxidation occurring at higher temperatures is evaluated } \\
\text { with regard to vessel pressurization rates. }\end{array}$ \\
\hline & & 15 & Off-gassing rates are provided for various conditions in Table 1-2. \\
\hline & & 16 & $\begin{array}{l}\text { Onset temperatures promoting reaction between nitric acid and } \\
\text { spherical RF resin are provided. }\end{array}$ \\
\hline & & 17 & $\begin{array}{l}\text { An optical micrograph is provided in Figure } 1-1 \text { with examples of the } \\
\text { RF particle changes associated with progressively harsher conditions. }\end{array}$ \\
\hline & & $29-30$ & $\begin{array}{l}\text { Expected chemical structures for RF polymer and various possible } \\
\text { nitration and oxidation products are provided in Figures 2-1 through } \\
2-4 \text {. }\end{array}$ \\
\hline \multirow[t]{7}{*}{ Duffey } & 2006 & general & $\begin{array}{l}\text { This report describes the impacts of radiolytic and thermal treatments } \\
\text { on spherical RF cesium removal performance, head pressure profiles, } \\
\text { and off-gas composition. }\end{array}$ \\
\hline & & $38-40$ & A summary of treatment conditions is provided in Table 4-1. \\
\hline & & $41-45$ & Gas generation rates and G-values are provided in Table 4-2. \\
\hline & & 46 & $\begin{array}{l}\text { Total gas generation rates and hydrogen generation rates for various } \\
\text { conditions are provided in Tables } 4-4 \text { and } 4-5 \text {. }\end{array}$ \\
\hline & & $57-59$ & $\begin{array}{l}\text { Pressure profiles for various conditions are provided in Figures 4-1 } \\
\text { through 4-5. }\end{array}$ \\
\hline & & 60 & $\begin{array}{l}\text { An optical micrograph showing physical property changes associated } \\
\text { with } 100 \text { Mrad dose is provided in Figure 4-7. }\end{array}$ \\
\hline & & 63 & $\begin{array}{l}\text { The impacts of various conditions on cesium loading are summarized } \\
\text { in Figure } 4-11 .\end{array}$ \\
\hline Nash & 2006 & general & $\begin{array}{l}\text { This report summarizes spherical RF cesium removal test results used } \\
\text { as primary input data for model development. The impacts of various }\end{array}$ \\
\hline
\end{tabular}




\begin{tabular}{|c|c|c|c|}
\hline & & & $\begin{array}{l}\text { waste components on cesium loading were evaluated. Cesium } \\
\text { loading kinetics tests were conducted. Eluate and spent resin analysis } \\
\text { was conducted. }\end{array}$ \\
\hline & & 37 & $\begin{array}{l}\text { Cesium loading kinetics data indicating that chemical degradation } \\
\text { begins to negatively impact cesium loading is provided in Figures } 19 \\
\text { and } 20 .\end{array}$ \\
\hline & & 45 & $\begin{array}{l}\text { Results of metals analysis for spent resin after simulant column } \\
\text { testing are provided in Table } 19 .\end{array}$ \\
\hline & & $46-48$ & $\begin{array}{l}\text { Eluate concentration profiles for various metals are provided in } \\
\text { Figures } 26-28 \text {. }\end{array}$ \\
\hline & & 50 & $\begin{array}{l}\text { Fractions of metals loaded onto RF during column processing are } \\
\text { provided in Table } 22 \text {. }\end{array}$ \\
\hline \multirow[t]{4}{*}{ Nash } & 2007 & general & $\begin{array}{l}\text { TCLP analysis results for spent RF resin after column testing using } \\
\text { simulants containing RCRA metals and regulated organics are } \\
\text { provided in this report. }\end{array}$ \\
\hline & & 28 & TCLP metal analysis results are provided in Table 14. \\
\hline & & 29 & TCLP organics analysis results are provided in Table 16. \\
\hline & & 31 & Total organics solids analysis results are provided in Table 18. \\
\hline \multirow[t]{4}{*}{ Adamson } & 2006 & general & $\begin{array}{l}\text { Pilot-scale hydraulic results for spherical RF resin conducted in } \\
\text { support of the Hanford RPP-WTP test program are provided in this } \\
\text { report. }\end{array}$ \\
\hline & & 33 & $\begin{array}{l}\text { A photograph of the largest scale hydraulic test performed to date } \\
\text { with spherical RF resin is provided in Figure } 4 \text {. }\end{array}$ \\
\hline & & $43-44$ & $\begin{array}{l}\text { Test conditions for the } 16 \text { hydraulic test cycles performed with the } 24 \\
\text { inch spherical RF column are provided in Table } 8 \text {. }\end{array}$ \\
\hline & & $88-89$ & $\begin{array}{l}\text { Summaries of hydraulic test results for the } 24 \text { inch column with } \\
\text { simulant and eluate solutions are provided in Tables } 21 \text { and } 22 \text {, } \\
\text { respectively. }\end{array}$ \\
\hline \multirow[t]{6}{*}{ Aleman } & 2007 & general & $\begin{array}{l}\text { This report provides modeling results for spherical RF resin generated } \\
\text { in support of the Hanford WTP test program. }\end{array}$ \\
\hline & & 96 & $\begin{array}{l}\text { Expected cesium breakthrough profiles for the full-scale WTP column } \\
\text { with the Hot Commissioning feed are provided in Figures 10-1 and } \\
10-2 \text {. }\end{array}$ \\
\hline & & 35 & $\begin{array}{l}\text { Selectivity coefficients and heats of reaction for various ion exchange } \\
\text { reactions on spherical RF resin are provided in Table 4-3. }\end{array}$ \\
\hline & & 79 & $\begin{array}{l}\text { Predicted and observed cesium breakthrough profiles for actual } \\
\text { Hanford AP-101 supernate are provided in Figures 9-1 (linear scale) } \\
\text { and 9-2 (log scale). }\end{array}$ \\
\hline & & 83 & $\begin{array}{l}\text { Predicted and observed cesium breakthrough profiles for actual } \\
\text { Hanford AN-102 supernate are provided in Figures 9-9 (linear scale) } \\
\text { and 9-10 (log scale). }\end{array}$ \\
\hline & & $\begin{array}{l}126- \\
129\end{array}$ & $\begin{array}{l}\text { The impacts of varying numerous parameters }\left(\mathrm{K}^{+}, \mathrm{Na}^{+}, \mathrm{Cs}^{+}\right. \\
\text {concentrations, temperature, and flow rate) upon cesium breakthrough } \\
\text { with the WTP Hot Commissioning feed are shown in Figures 10-61 } \\
\text { through 10-67. }\end{array}$ \\
\hline \multicolumn{4}{|c|}{ General CST References } \\
\hline McCabe & 2005 & general & $\begin{array}{l}\text { The impacts of SCIX processing with the potential waste streams } \\
\text { identified at that time on the SRS High Level Waste System were } \\
\text { evaluated. }\end{array}$ \\
\hline
\end{tabular}




\begin{tabular}{|c|c|c|c|}
\hline \multirow[t]{6}{*}{ Hamm } & 2002 & general & $\begin{array}{l}\text { This report describes the column modeling methodology used for } \\
\text { CST with more basis and detail than is provided in the Smith (2007) } \\
\text { report. }\end{array}$ \\
\hline & & 18 & $\begin{array}{l}\text { The cesium loading performance of CST as a function of solution } \mathrm{pH} \\
\text { is provided in Figure } 2-2 \text {. }\end{array}$ \\
\hline & & $42-43$ & $\begin{array}{l}\text { Key CST ion exchange media properties (bulk density, particle } \\
\text { diameter, bed and particle porosity, particle density, and total bed } \\
\text { porosity estimates) are provided in Tables 5-1 through 5-3. }\end{array}$ \\
\hline & & 191 & $\begin{array}{l}\text { Selectivity coefficients for the cesium-CST system are provided in } \\
\text { Table B-20. }\end{array}$ \\
\hline & & 280 & $\begin{array}{l}\text { The conceptual surface sorption model for the ZAM isotherm model } \\
\text { is discussed and a cartoon drawing is provided. }\end{array}$ \\
\hline & & 290 & $\begin{array}{l}\text { The cationic species considered in the ZAM model are provided in } \\
\text { Table F- } 2 \text {. }\end{array}$ \\
\hline Beasley & 2001 & general & $\begin{array}{l}\text { Cesium equilibrium loading and kinetics test results with CST using } \\
\text { six actual Savannah River Site waste supernates are provided. }\end{array}$ \\
\hline \multirow[t]{2}{*}{ Cherry } & 2004 & general & $\begin{array}{l}\text { Results of detailed studies determining the structural basis for } \\
\text { improved selectivity of niobium-doped CST. }\end{array}$ \\
\hline & & 2080 & $\begin{array}{l}\text { The crystal structure of CST is shown in Figure } 1 \text { along the axis } \\
\text { containing the tunnel where cesium ion exchange is believed to occur. }\end{array}$ \\
\hline Walker & 1999 & general & $\begin{array}{l}\text { This report describes the results of real waste testing with actual SRS } \\
\text { waste. Column pluggage was observed during } \mathrm{NaOH} \text { pretreatment. }\end{array}$ \\
\hline Taylor & 2001 & general & $\begin{array}{l}\text { This report describes the thermal and chemical stability of baseline } \\
\text { and improved versions of IE- } 911 \text {. }\end{array}$ \\
\hline Taylor & 2003 & general & $\begin{array}{l}\text { This report describes the results of CST clumping tests conducted } \\
\text { with bounding SRS simulants. }\end{array}$ \\
\hline \multirow[t]{8}{*}{ Walker } & 1998 & general & $\begin{array}{l}\text { This is a very useful reference for the MSP project as far as CST is } \\
\text { concerned. This is the final report describing the large-scale real } \\
\text { waste demonstration for treatment of Melton Valley waste supernate } \\
\text { with CST. Resin conditioning, sluicing, hydraulics, drying, and } \\
\text { packaging for transport (cesium-loaded material) were demonstrated. } \\
\text { Column performance with real waste was demonstrated through } \\
\text { remote operations. Greater than } 30,000 \text { gallons of waste was } \\
\text { processed in } 12 \text { inch ID columns containing } 38 \text { L of CST ( } 4 \text { tests } \\
\text { with both single column and series operations). }\end{array}$ \\
\hline & & 30 & $\begin{array}{l}\text { Packed CST bed volume as a function of flow rate during upflow } \\
\text { backwashing of the } 30 \mathrm{~L} \text { bed is provided in Figure } 5 .\end{array}$ \\
\hline & & 32 & $\begin{array}{l}\text { Pressure drop versus flow rate data for the } 30 \mathrm{~L} \text { bed is provided in } \\
\text { Figure } 6 .\end{array}$ \\
\hline & & 34 & $\begin{array}{l}\text { Relative humidity of CST column air effluent as a function of } \\
\text { cumulative air volume passed is provided in Figure } 7 .\end{array}$ \\
\hline & & $67-68$ & $\begin{array}{l}\text { CST column breakthrough profiles for various metals are provided in } \\
\text { Figures } 21 \text { and } 22 \text { for Run } 2 \text {. }\end{array}$ \\
\hline & & $74-75$ & $\begin{array}{l}\text { CST column breakthrough profiles for various metals are provided in } \\
\text { Figures } 26 \text { and } 27 \text { for Run } 3 \text {. }\end{array}$ \\
\hline & & 89 & Radiation dose rates for loaded CST drums are provided in Table 10. \\
\hline & & 104 & $\begin{array}{l}\text { Radiation dose rates for the equipment after CST removal and } \\
\text { backwashing are provided in Table } 16 .\end{array}$ \\
\hline Wilmarth & 2004 & general & $\begin{array}{l}\text { This reports describes the reactivity and metal retention of the } \\
\text { improved versions of IE-911. Evaluations of ground, spent CST with }\end{array}$ \\
\hline
\end{tabular}




\begin{tabular}{|c|c|c|c|}
\hline & & & $\begin{array}{l}\text { regard to cesium leaching, CST degradation, and impacts on the } \\
\text { rheology of CST/sludge mixtures are reported. }\end{array}$ \\
\hline & & 12 & $\begin{array}{l}\text { RCRA metal TCLP leachate analysis results for spent CST are } \\
\text { provided in Table } 3 \text {. }\end{array}$ \\
\hline & & 13 & $\begin{array}{l}\text { Hazardous metal analysis results for spent CST are provided in Table } \\
4 .\end{array}$ \\
\hline Wilmarth & 2000 & general & $\begin{array}{l}\text { This report includes evaluations of residual synthesis reagent leaching } \\
\text { from IE-911 and the development of caustic wash procedures for } \\
\text { washing away the residual reagents. }\end{array}$ \\
\hline \multirow[t]{2}{*}{$\mathrm{Su}$} & 2001 & general & $\begin{array}{l}\text { Additional studies on the chemical and thermal stability of IE-911 are } \\
\text { described. }\end{array}$ \\
\hline & & $\begin{array}{l}31-34 \\
36-37\end{array}$ & $\begin{array}{l}\text { SEM images showing the aluminosilicate deposits that can form on } \\
\text { CST in caustic waste simulants are provided in Figures } 31-33 \text { and } 35- \\
36 \text {. }\end{array}$ \\
\hline \multicolumn{4}{|c|}{ MSP Reports } \\
\hline \multirow[t]{12}{*}{ Smith } & 2007 & general & $\begin{array}{l}\text { Results of ion exchange modeling to predict cesium loading } \\
\text { isotherms, column effluent bucket average breakthrough, cesium } \\
\text { concentration profiles within the columns, cycling times, volume } \\
\text { processed per cycle, and total processing times for the five MSP feeds } \\
\text { using RF and CST are provided in this report. }\end{array}$ \\
\hline & & 4 & $\begin{array}{l}\text { The required decontamination factors for each waste feed are } \\
\text { provided in Table 1-1. }\end{array}$ \\
\hline & & 6 & $\begin{array}{l}\text { Waste volumes processed per cycle (after steady-state) with each tank } \\
\text { composition under various conditions are provided for RF and CST in } \\
\text { Table 1-3. }\end{array}$ \\
\hline & & 7 & $\begin{array}{l}\text { The total ion exchange cycles required to process the volume of feeds } \\
\text { predicted for each tank using RF and CST are provided in Table 1-4. }\end{array}$ \\
\hline & & 30 & $\begin{array}{l}\text { Maximum Curie loadings for each tank composition using CST are } \\
\text { provided in Table 9-2. }\end{array}$ \\
\hline & & 34 & $\begin{array}{l}\text { The estimated metric tons of CST required to process each tank } \\
\text { volume are provided in Table 9-15. }\end{array}$ \\
\hline & & $39-41$ & $\begin{array}{l}\text { Cesium concentration profiles in the CST columns are provided for } \\
\text { each feed in Figures 9-6 through 9-10. }\end{array}$ \\
\hline & & 46 & $\begin{array}{l}\text { Maximum Curie loadings for each tank composition using the "new" } \\
\text { RF isotherm are provided in Table } 10-2 \text {. }\end{array}$ \\
\hline & & $55-57$ & $\begin{array}{l}\text { Cesium concentration profiles in the RF columns using the "new" } \\
\text { isotherm are provided for each feed in Figures 10-6 through 10-10. }\end{array}$ \\
\hline & & 62 & $\begin{array}{l}\text { Maximum Curie loadings for each tank composition using the "old" } \\
\text { RF isotherm are provided in Table 11-2. }\end{array}$ \\
\hline & & $71-73$ & $\begin{array}{l}\text { Cesium concentration profiles in the RF columns using the "old" } \\
\text { isotherm are provided for each feed in Figures 11-6 through 11-10. }\end{array}$ \\
\hline & & 79 & $\begin{array}{l}\text { Waste volume in thousands of gallons processed (after steady state) } \\
\text { for RF and CST are provided in Table 12-1. }\end{array}$ \\
\hline \multirow[t]{3}{*}{ Lee } & 2007 & general & $\begin{array}{l}\text { Thermal analysis results for fully loaded RF and CST columns under } \\
\text { bounding and nominal conditions are provided in this report. }\end{array}$ \\
\hline & & 17 & $\begin{array}{l}\text { The total heat wattage for CST and RF columns of various lengths is } \\
\text { provided in Table } 4 .\end{array}$ \\
\hline & & 26 & $\begin{array}{l}\text { The maximum and minimum bed temperatures for RF and CST } \\
\text { columns under no flow conditions with and without active cooling are } \\
\text { provided in Table } 5 \text {. }\end{array}$ \\
\hline
\end{tabular}




\begin{tabular}{|l|c|c|l|}
\hline & $33-34$ & $\begin{array}{l}\text { Maximum and minimum bed temperatures for RF and CST columns } \\
\text { versus time under no flow conditions without active cooling are } \\
\text { provided in Figure 17 and Table 6. }\end{array}$ \\
\hline & 40 & $\begin{array}{l}\text { Temperature increases expected during salt solution transport down } \\
\text { packed RF and CST columns of different lengths are provided in } \\
\text { Table 12. }\end{array}$ \\
\hline Duignan & 2007 & general & $\begin{array}{l}\text { Comparisons of steady-state temperature profiles and maximum } \\
\text { temperatures for CST columns with various cooling system } \\
\text { configurations are provided in Figure 24 and Table 14. }\end{array}$ \\
\hline & & $\begin{array}{l}\text { Spherical RF hydraulic testing results using the current SCIX annular } \\
\text { column design and the RF column processing procedure are provided } \\
\text { in this report. }\end{array}$ \\
\hline & 19 & $\begin{array}{l}\text { An explanation of each column processing step is provided in Table } \\
6 .\end{array}$ \\
\hline & 26 & $\begin{array}{l}\text { Bed volume changes occurring during hydraulic testing with the } \\
\text { annular 3 inch ID column are provided in Table 10. }\end{array}$ \\
\hline & 27 & $\begin{array}{l}\text { Photographs of the resin plug formed during regeneration testing are } \\
\text { provided in Figure 9. }\end{array}$ \\
\hline & 30 & $\begin{array}{l}\text { Photographs showing the physical changes occurring during elution } \\
\text { are provided in Figure 11. }\end{array}$ \\
\hline
\end{tabular}

\subsection{Spherical Resorcinol-Formaldehyde Resin}

Two SRNL patents have been issued regarding the preparation of RF and derivatized RF resins and their application for cesium removal from solutions containing high sodium ion concentrations (Ebra, et al., 1983; Bibler, et al., 1995). These syntheses involved the preparation of polymer monoliths, which were subsequently ground and sieved prior to testing. A separate (non-SRNL) patent issued in 1997 (Berge, et al.) described the preparation of highly monomodal, spherical beads of various polymers including resorcinolformaldehyde using preformed polystyrene seed particles with light divinyl benzene crosslinking which contained an active ionic group. Thorson (2006) described a similar synthesis for spherical RF resin. The MSDS (2005) for the spherical RF resin, which was prepared by Microbeads AS, describes the material as a 1,3-benzenediol formaldehyde polymer. As such, the composition of the material is expected to include carbon, hydrogen, and oxygen with minor amounts of material associated with the polystyrene seed. Elemental analysis results for spherical RF resin reported by Fondeur (2006) confirm this elemental composition.

\subsection{Spherical RF Manufacturability - Production scale and Reproducibility}

Synthesis conditions for spherical RF resin have been optimized and successfully scaled up with testing conducted on 26 resin batches (Fiskum, 2006d). Six 100-gallon (Na-form volume) scale-up production lots of spherical resorcinol-formaldehyde resin were produced at two commercial facilities. This production scale approaches full-scale synthesis for SCIX applications since a 15 foot column with the current annular design (effective column inside diameter: 26.56") would contain approximately 432 gallons of sodium-form spherical RF 
resin. Comparison testing conducted on the scale-up batches confirmed high synthetic reproducibility as indicated by consistent physical properties and cesium removal performance. Selected characterization data for the six RF scale-up production batches is provided in Table 3-1. Discussion of the impacts of the various particle properties upon performance will be provided in subsequent sections. Clearly, spherical RF resin can be prepared with high reproducibility as indicated by the percent relative standard deviation values calculated for the measured properties.

\subsection{Spherical RF Physical Properties}

\subsubsection{Initial Physical Properties}

Spherical RF resin synthesis conditions were optimized as part of the RPP test program to provide resin beads with acceptable and reproducible physical and chemical properties. RF resin beads produced in the six scale-up production batches were highly spherical with few deformations and fines and a solid bead core structure. The resin physical properties were thoroughly characterized by Fiskum (2006d) and results are summarized in Table 3-1. Physical property variations between the six scale-up production batches were minimal as indicated by the relative standard deviations of $<8 \%$ for particle size distribution, skeletal density, and packed bed density. The level of consistency is impressive given the scale of the synthesis and the fact that the batches were produced at two different locations. The resin beads were fairly monomodal in size distribution as indicated by the close agreement between mean particle diameters calculated on volume, number, and area bases and the fact that for Na-form resin the $5^{\text {th }}-90^{\text {th }}$ percentiles for the distributions typically cover a diameter range of only $200 \mu \mathrm{m}(300-500 \mu \mathrm{m})$. Control over the spherical RF bead size was also demonstrated. As summarized in Table 16-1 of the Fiskum (2006d) report, synthesis conditions were varied to tune particle size to the optimal value. Average particle diameters (mean volume basis) for the various batches tested ranged from 439 to $777 \mu \mathrm{m}$ for sodiumform resin. This range was not the result of synthetic variability. Instead these were targeted average particle diameters for evaluation. Once the optimal diameter was identified ( $\sim 50 \mu \mathrm{m}$ mean volume basis) small variability in particle diameter was observed between batches produced under the same conditions, as discussed above.

\subsubsection{Physical Property Changes Associated with Chemical Cycling and Radiolysis}

Spherical RF resin is typically provided as hydrogen-form beads in water. After one chemical processing cycle in an unconstrained geometry the scale-up resin samples increase in volume by $\sim 30 \%$ (pretreated $\mathrm{H}$-form resin versus as-received $\mathrm{H}$-form resin, Fiskum, 2006d). This initial swelling is irreversible and presumably associated with relaxation of the polymer structure following synthesis. Overall unconstrained volume expansions from as-received $\mathrm{H}$-form resin to pretreated Na-form resin ranged from 55-60\%. Furthermore, the pretreated resins decreased in volume by $20-25 \%$ when converted from Na-form to Hform during column processing. This volume change is reversible with the resin swelling back to the initial sodium-form volume in each successive cycle during regeneration. Such large volume changes have been known to lead to resin compaction, packed bed void reduction, bead attrition, and excursive pressure drops and wall forces during column 
processing of these types of materials (Fowley, 2004). However, a column processing sequence was developed as part of the RPP-WTP research and technology program which greatly minimizes these concerns. The critical processing step is upflow regeneration which involves at least partial fluidization of the resin bed during conversion from hydrogen form to sodium form such that resin swelling does not occur in a confined geometry. Estimates of relative resin volumes in various process solutions can be deduced from Tables 4 and 5 of the Thorson report (2006).

In general, no significant attrition or degradation in the RF bead physical properties was observed after chemical cycling and radiolysis. RF bead physical properties are not greatly effected by repeated resin volume changes, upflow fluidization, or osmotic shock effects during multiple chemical cycles following the WTP waste processing protocol. Particle size analysis results and optical micrographs of resin beads exposed to 16 chemical cycles using air-saturated simulant indicated no significant change in particle morphology and essentially no change in particle diameter (Fiskum, 2006d). Oxygen exposure during cycling did result in a darkening of some resin beads due to polymer oxidation. The resin beads show no tendency to adhere to one another after multiple cycles and no fissures were observed in packed RF beds (Adamson, 2006) as had been observed for SuperLig ${ }^{\circledR} 644$ (another elutable, organic resin) during WTP testing (Fowley, 2004). RF radiolysis to $100 \mathrm{Mrad}$ exposure results in darkening of the resin beads as was observed with oxygen exposure, but there was no indication of particle attrition or significant change in particle size by optical microscopy (Duffey, 2006). No hydraulic testing was conducted on beads exposed to high radiation. Small scale column tests were conducted on actual Hanford radioactive waste supernates with no hydraulic performance issues and no indication of particle degradation (Fiskum, 2006a and 2006b), but resin radiolytic exposure in these tests was small. No indication of mass loss was observed for resin samples exposed to one in-column pretreatment cycle and one cesium loading and elution cycle with simulated waste supernate (Nash, 2006) or for resin samples exposed to a total of five chemical cycles (three cesium loading cycles) in actual waste column testing (Fiskum, 2006a-c).

\subsubsection{Physical Property Changes Associated with Chemical Reactivity}

Spherical RF resin reacts with dissolved oxygen in the various WTP processing solutions. Column testing conducted using large volumes (300-600 bed volumes) of oxygen-saturated $0.5 \mathrm{M} \mathrm{NaOH}$ solution $(26 \mu \mathrm{g} \mathrm{O} / \mathrm{mL})$ revealed that reaction with oxygen results in the formation of a dark band of oxidized RF at the top of the column (Fiskum, 2006d). Furthermore, 10\% resin bed expansion was observed under these bounding conditions. During 16 chemical cycles using air-saturated simulant in a 24 inch diameter column, only a $3 \%$ resin bed height increase was observed (Adamson, 2006). It is believed that the airsaturated simulant contained significantly less soluble oxygen than the oxygen-saturated 0.5 $\mathrm{M} \mathrm{NaOH}$ solution. As discussed in section 3.2.2, no changes were observed in the average particle diameter and there was no indication of particle attrition at the conclusion of the 16cycle testing. As will be discussed in Section 3.4.3 resin hydraulic performance also was not impacted significantly by chemical cycling and mild resin oxidation. As a result, spherical RF physical property degradation during the expected resin lifetime resulting from oxygen reactivity is believed to be minimal. 
RF exposure to high nitric acid concentrations leads to resin color changes and bead physical property degradation (for extreme conditions) and could likely be utilized for complete (or nearly complete) resin digestion under controlled conditions (Fondeur, 2007). Reaction with nitric acid at lower temperatures initially results in a gradual and seemingly symmetrical decrease in the average particle diameter (based on optical microscopy). However, more extreme conditions, such as very high acid concentration $(8 \mathrm{M})$ or high temperature $\left(55^{\circ} \mathrm{C}\right)$, result in loss of the spherical bead structure and the formation of what appears to be hollow beads (likely the remains of the initial polystyrene seed). The physical properties of RF resin and residues remaining after reaction with nitric acid were not studied extensively, since this was considered to be an accident scenario and design limits were implemented to avoid these conditions. Minimal reaction with nitric acid is expected during normal operations and little impact on the resin physical properties is anticipated from exposure to $0.5 \mathrm{M} \mathrm{HNO}_{3}$.

\subsubsection{Handling (Fluidization, Slurry Transport, and Settling Behavior)}

RF beads have a narrow size distribution and are highly spherical (99.5\% sphericity). These properties contribute to good fluidization, relatively easy slurry transport, and rapid settling as summarized by Thorson (2006). Good fluidization is achieved with $40 \%(0.5 \mathrm{M} \mathrm{NaOH})$ to $60 \%$ ( $5 \mathrm{M} \mathrm{Na}^{+}$simulant) bed volume expansion in upflow. Slurry transfers have been designed to contain 50 volume percent beads or 80 volume percent packed bed. Over $99 \%$ resin bed removal has been achieved with less than 2.5 resin bed volumes of fluid. In addition, there is no indication of significant degradation in the resin handling and transport properties with use. Through 16 chemical cycles during hydraulic testing there was no indication of bead attrition and no change in bed permeability, despite the fact that the resin had been exposed to air-saturated feed (Adamson, 2006). No rheology tests have been conducted on spherical RF slurries. Spherical RF beads settle quickly in the various WTP wash and regeneration solutions. Resin settling rates have been measured for hydrogenform resin in water $(75.2 \mathrm{~cm} / \mathrm{min})$, sodium-form resin in $0.5 \mathrm{M} \mathrm{NaOH}(101.8 \mathrm{~cm} / \mathrm{min})$, and sodium-form resin in $5 \mathrm{M} \mathrm{Na}^{+}$simulant with a viscosity of $3.2 \mathrm{cP}(27.4 \mathrm{~cm} / \mathrm{min}$; Thorson, 2006). Spherical RF column hydraulic performance will be discussed in Section 3.4.3.

\subsection{Spherical RF Chemical Properties}

\subsubsection{Sorption/Desorption Behavior}

Sorption of monovalent ions on resorcinol-formaldehyde polymer involves the exchange of ions at two acidic phenyl hydroxy functionalities (basic RF structure provided in Fondeur, 2006) in each repeating unit within the chemical structure. Activation of these molecular sites toward ion exchange requires deprotonation which occurs in the $\mathrm{pH}$ range 9-12 (Aleman, 2007). Cesium loading on RF resin is primarily impacted by the concentrations of the Group 1 cations known to exist in tank waste supernates, with affinities for RF sorption sites following the order $\mathrm{H}^{+}>\mathrm{Cs}^{+}>\mathrm{Rb}^{+}>\mathrm{K}^{+}>\mathrm{Na}^{+}$. During cesium loading operations $\mathrm{Na}^{+}$ ion is the primary species on the resin due to the high sodium concentration in waste supernates. $\mathrm{K}^{+}$is a primary competitor for RF sorption sites in Hanford waste supernates, but the potassium concentration in SRS SCIX supernates is quite low and potassium is 
expected to have less impact on cesium loading. In the presence of moderate hydrogen ion concentrations $\left(0.5 \mathrm{M} \mathrm{H}^{+}\right)$all of the other Group 1 cations are rapidly desorbed from RF resin back into the liquid phase. This characteristic is the basis for cesium elution from RF resin using nitric acid in the RPP-WTP process.

No other primary competitors for RF ion exchange sorption sites besides the Group 1 metals have been identified in caustic, tank waste supernates, although several other metals are extracted by RF from Hanford waste solutions. Nash reported that calcium, strontium, cadmium, and lead were observed in RF column eluate solutions ( $\%$ recoveries ranged from 8-70\%) following loading tests with Hanford waste simulants (2006). Resin loadings for these metals decreased to near zero after processing $20 \mathrm{BV}$ of $0.5 \mathrm{M}$ nitric acid eluate. Chromium and iron were also observed in the eluate solutions, but significant amounts of these metals remained on the resin after elution. Fiskum also reported $10 \%$ Ba removal with AP-101 simulant (2006a). Based on these results spherical RF resin has some tendency to sorb the Group 2 metals (as indicated by Ebra for granular RF, 1983) and some tendency to sorb selected transition metals. Removal of chromium and iron may involve oxidation/reduction reactions since sorption of these metals is less reversible. Retention of these metals on the resin is not fully understood. Actinide sorption by RF has been evaluated in two reports involving treatment of actual Hanford waste supernates using spherical resin beads. No significant actinide removal was observed during column loading experiments with Hanford AP-101 and AN-102 tank wastes. However, plutonium was observed in column eluates at low recovery rates (8\% for AP-101 and $0.9 \%$ for AN-102) indicating that a small fraction of the total $\mathrm{Pu}$ was retained on the resin during loading. Concerns over actinides in column eluates for the Hanford WTP are largely associated with the possibility of criticality events resulting from the concentration of eluate solutions in evaporators. The impact of minor metal sorption on RF is believed to have little impact on cesium removal performance.

Cesium equilibrium loading (isotherm) models were developed at SRNL for spherical RF resin (Aleman, 2007). The isotherm models consider only the Group 1 cations listed above (excluding $\mathrm{Li}^{+}$and $\mathrm{Fr}^{+}$), with no other species being considered as competitors for resin sorption sites. The models also include the impact of hydroxide upon the total available sites for exchange. Due to inconsistencies between historical RF performance data, two isotherm models exist which give significantly different predictions in some cases with regard to cesium loading on RF resin (Smith, 2007). The TMIXP RF isotherm model (based on older data) gives more conservative (lower) cesium loading predictions than the CERMOD model (based on more recent data) with the MSP feed streams, though it is not known whether the TMIXP model can be considered as a bounding conservative model. The total cesium capacity was determined to be $0.7 \mathrm{mmol} \mathrm{Cs} / \mathrm{g} \mathrm{H}$-form resin (Aleman, 2007). The RF cesium capacity and selectivity are in the generally acceptable range for cesium removal applications with tank waste supernates. At $25{ }^{\circ} \mathrm{C}$, cesium equilibrium loading predictions for the five MSP feeds (SRS Tanks 1-3, 37, and 41) generated using the TMIXP isotherm model are $42 \%$ lower on average (standard deviation 14\%) than the corresponding predictions with the CERMOD isotherm. 
Higher temperatures result in lower equilibrium cesium loadings on RF resin. Smith (2007) predicted maximum cesium loadings for each of the five MSP feed solutions as a function of temperature using both RF isotherms. Increasing the temperature from $25-45{ }^{\circ} \mathrm{C}$ results in cesium loading decreases of 40-60\% for the CERMOD model and 30-50\% for the TMIXP model. Exposure of RF resin to high temperatures may also result in mild resin degradation, as indicated by lower cesium loading. Nash, et al. (2006) reported a 5-15\% decrease in RF cesium capacity over a 3 day contact period with simulated wastes at high flow rates during cesium sorption kinetics tests at $45^{\circ} \mathrm{C}$. (Note the estimate of $15 \%$ capacity decrease may be high due to temperature control problems during testing.) Duffey, et al. (2006) reported that heating $\mathrm{RF}$ resin to $65^{\circ} \mathrm{C}$ in water for 10 days results in a decrease in cesium capacity of $<10 \%$. In contrast, 10 day contact with $0.5 \mathrm{M} \mathrm{HNO}_{3}$ at $65^{\circ} \mathrm{C}$ results in a slight increase $(<5 \%)$ in cesium capacity. Contact with caustic waste simulant at $65{ }^{\circ} \mathrm{C}$ resulted in a $15 \%$ decrease in cesium capacity. These results are consistent with the idea that hydrogen form $\mathrm{RF}$ resin is more stable to oxidation and degradation. However, $0.5 \mathrm{M}$ nitric acid exposure at $65{ }^{\circ} \mathrm{C}$ does result in mild off-gassing (see Section 3.5.3) and high temperatures should be avoided when possible.

The data indicates that the MSP upper temperature limit for RF resin should be near $65^{\circ} \mathrm{C}$, although exposure to this temperature does not lead to dramatic degradation in cesium removal performance on a short timescale. For the highest expected MSP Cs loading at the lowest MSP flow rate (5 gpm), the predicted solution temperature increase resulting from radiolysis during transport through a 25 foot column (largest expected column height) using the current baseline design configuration but without active cooling is only $1.4{ }^{\circ} \mathrm{C}$ (Lee, 2007). In stagnant salt solution, but with design basis cooling, the maximum steady-state temperature expected in a fully-loaded RF column is only $40.7{ }^{\circ} \mathrm{C}$. These results indicate that maintaining temperature control below $45^{\circ} \mathrm{C}$ should be possible even under these offnormal conditions. In the bounding accident scenario involving no liquid flow, no active cooling, and a fully loaded column, the temperature can exceed $65^{\circ} \mathrm{C}$ as discussed in Section 3.5.3.

Besides the known ion exchange of $\mathrm{Na}^{+}$ions on $\mathrm{RF}$ resin, significant amounts of neutral sodium species (such as $\mathrm{NaOH}$ ) are apparently absorbed to the resin surface in high ionic strength solution (Fiskum, 2006d). This is believed to have little impact upon RF resin performance. The total sodium capacity (including both neutral species and sodium ions) of $\mathrm{RF}$ resin was estimated to be near $6 \mathrm{mmol} \mathrm{Na}^{+} / \mathrm{g} \mathrm{H}$-form resin, which is nearly an order of magnitude higher than the total cesium capacity. It should also be noted that the current baseline MSP feed is $6 \mathrm{M} \mathrm{Na}^{+}$, whereas the nominal sodium concentration for the Hanford WTP is $5 \mathrm{M} \mathrm{Na}^{+}$(Thorson, 2006). This difference may lead to greater sorption of neutral sodium species in the MSP feeds. It is expected that the primary consequence of higher sodium concentrations for MSP will be higher solution viscosities and slower cesium loading kinetics.

\subsubsection{Chemical Reactivity and Impacts on Cesium Removal Performance}

The chemical reactions of spherical RF resin under waste processing conditions have been extensively studied. For the purposes of this discussion the term chemical reactions refers 
to essentially irreversible reactions and therefore does not include the simple reversible ion exchange reactions discussed in Section 3.3.1. Impacts of radiolysis on performance will be discussed in Section 3.3.3. Concerns regarding chemical reactivity are associated with potential impacts upon: 1) cesium removal performance, 2) resin physical properties (particularly with regard to column hydraulics and bed fluidization), 3) operations safety, and 4) resin disposal. In this section specific reactions involving $R F$ resin and the conditions involved will be presented. The impacts of these reactions will be further discussed in other sections. Known RF chemical reactions include:

- air oxidation

- $\quad$ oxidation with metals and deposition of metal species

- nitration with nitric acid

- bulk polymer oxidation and digestion with nitric acid resulting in off-gassing.

RF resin reacts with dissolved oxygen in the various column processing solutions (both acidic and basic), though oxidation is more facile under caustic conditions. Spectroscopic examination of RF beads after air exposure in caustic waste simulant confirmed the formation of various new oxidized carbon functionalities within the resin (Adamson, 2006). $80 \%$ oxygen consumption was observed with spherical RF columns using oxygen-saturated Hanford AP-101 simulant (Fiskum, 2006d). RF reaction with oxygen is associated with darkening of resin beads at the top of packed columns, loss of resin ion exchange capacity, mild bed expansion, and yellow coloration of column effluents (indicative of partial polymer cleavage and dissolution). Direct reaction of dry RF resin with air is also expected over time. For these reasons RF resin is generally stored in hydrogen form under water in a sealed container with an inerted headspace.

Several species are known to react with RF resulting in the deposition of metal species on the resin. RF reacts with chromium and iron in caustic waste supernate solutions (Nash, 2007), to give spent resin containing as much as $2 \mathrm{mg} \mathrm{Cr}$ and $0.1 \mathrm{mg} \mathrm{Fe} / \mathrm{g} \mathrm{H}$-form resin after elution. The chromium is not highly leachable from the resin as indicated by low chromium levels in $0.5 \mathrm{M}$ nitric acid eluate solutions, even though elution in this case was conducted at $45^{\circ} \mathrm{C}$. Though only a small fraction $(<5 \%)$ of the chromium was removed from solution, 48 to $85 \%$ (depending on the feed composition) of the loaded chromium remained on the resin after elution. Chromium was also observed in spent resin samples exposed to two Hanford actual waste supernates during small column testing (Fiskum, 2006c). Spent resin in this case contained $0.3 \mathrm{mg} \mathrm{Cr} / \mathrm{g} \mathrm{H}$-form resin after a total of three load and elute cycles, a final elution treatment with $30 \mathrm{BV}$ of $0.5 \mathrm{M} \mathrm{HNO}_{3}$, and water storage for 81 days. Treatment of selected waste types in the Hanford WTP process involves the addition of $1 \mathrm{M}$ sodium permanganate $\left(\mathrm{NaMnO}_{4}\right)$ solutions to promote precipitation of manganese oxides and the sorption of transuranic species from the waste prior to ion exchange processing. Due to the possibility of inadvertent contact between RF resin and permanganate solution, tests were conducted to evaluate RF reactivity with $1 \mathrm{M}$ sodium permanganate (Fonduer, 2007). RF resin reacts with permanganate solution resulting in the formation of a manganese oxide film on the beads. Interestingly, even in the presence of large excesses of permanganate the 
reaction appears to be limited to the resin surface with minimal off-gassing and heat generation. Uranium was also observed in spent resin samples after real waste testing at concentrations ranging from 0.1-0.2 $\mathrm{mg} \mathrm{U} / \mathrm{g} \mathrm{H}$-form resin. Uranium and chromium were recovered from spent resins after real waste testing at higher levels than all other metals analyzed $(0.7 \%$ and $0.2 \%$ recovery, respectively, relative to the total concentrations in processed waste solutions; Fiskum, 2006c).

Two distinct reactions have been identified between RF resin and nitric acid solutions. Resin contact with $3 \mathrm{M}$ nitric acid at $25{ }^{\circ} \mathrm{C}$ under stagnant flow conditions results in resin nitration and (presumably) in the subsequent thermal degradation of the nitrated material to give organonitrate and oxidized carbon functionalities in the resin (Fondeur, 2007). Contact with $3 \mathrm{M}$ nitric acid under stagnant flow conditions at higher temperatures (approaching 50 ${ }^{\circ} \mathrm{C}$ ) leads to bulk resin oxidation and dissolution and rapid off-gassing of primarily $\mathrm{CO}_{2}$, $\mathrm{NO}_{2}$, and $\mathrm{N}_{2} \mathrm{O}$. As the acid concentration is decreased, higher temperatures are required to promote reaction. Contact with $0.5 \mathrm{M} \mathrm{HNO}_{3}$, the current baseline cesium eluate solution for the RPP-WTP, results in relatively mild off-gassing even at temperatures approaching 90 ${ }^{\circ} \mathrm{C}$. As a result of the known reactivity of RF resin with nitric acid, controls on the acid concentration and temperature are necessary for safe utilization of RF with nitric acid eluent.

Of the various chemical reactions involving RF resin, only those expected to occur during normal waste processing operations have been evaluated with regard to impacts upon cesium removal performance. After $16 \mathrm{RF}$ processing cycles (load/elute) with air-saturated waste simulant $\leq 10 \%$ reduction in cesium removal performance was observed (Fiskum, 2006d) which corresponds to $\sim 0.63 \%$ cesium capacity reduction per cycle. Impacts from $\mathrm{RF}$ reaction with chromium species (or with other metals) did not lead to unacceptable cesium removal performance, though no direct quantitative measure of specific metal impacts (other than Group 1) were conducted. Impacts on cesium removal performance resulting from RF reactions with nitric acid and permanganate solutions were not studied since these events are considered to be accident scenarios and engineering protections are planned to avoid their occurrence.

\subsubsection{Radiolytic Effects on Cesium Removal Performance}

Radiolytic effects upon cesium removal performance were studied by Duffey, et al. (2006). Besides the potential for direct radiolytic damage to RF resin under these conditions, radiolysis increases the oxidative chemical environment. A parametric study was conducted varying $R F$ radiolytic exposure $(0,35,100 \mathrm{Mrad})$, temperature $\left(25\right.$ and $\left.65^{\circ} \mathrm{C}\right)$, and contact liquid (water, $0.5 \mathrm{M} \mathrm{HNO}_{3}$, and caustic simulant). All tests involved 10 day contacts followed by cesium removal performance evaluations by batch contact with waste simulant. Cesium loading was observed to decrease in the order: $\mathrm{H}_{2} \mathrm{O}$, acid, simulant (initial contact solutions during radiolysis). $100 \mathrm{Mrad}$ exposure in simulant at $65{ }^{\circ} \mathrm{C}$ resulted in a $25 \%$ decrease in cesium loading while less than a $10 \%$ decrease was observed with water. Lower degradation levels were observed at $25{ }^{\circ} \mathrm{C}$ where a $14 \%$ decrease in cesium loading was observed after a $100 \mathrm{Mrad}$ dose. $90 \%$ of the resin dose is expected during waste supernate processing with the remainder in the elution and restoration steps. The bottom of the 
columns will receive the lowest total dose in a given cesium loading cycle, but partial bed fluidization may result in some mixing and redistribution of the beads during regeneration. These results indicate that RF resin degradation resulting from radiation exposure is $\sim 0.14 \%$ reduced cesium capacity per $1 \mathrm{Mrad}$ exposure. Expected maximum resin radiation dosage for the SCIX spherical RF columns are provided in Section 3.4.5.

Similar radiolytic studies were conducted with granular RF resin in earlier testing by Crawford (1994). Minimal impact on cesium removal performance was observed with radiation doses less than $10 \mathrm{Mrad}$. At $25 \mathrm{Mrad}$ exposure for a contact period of 96 hours in caustic simulant, decreased cesium uptake and significant liquid coloration were observed. Resin dissolution and decreased cesium uptake were also observed for control samples exposed to no radiation over this time period. For a radiation dose of $120 \mathrm{Mrad}$ applied over a contact time of 451 hours the cesium $\mathrm{K}_{\mathrm{d}}$ values decreased from $1400 \mathrm{~mL} / \mathrm{g}$ to 80 $\mathrm{mL} / \mathrm{g}$, which corresponds to a cesium loading decrease near $50 \%$. Examination of the $\mathrm{K}_{\mathrm{d}}$ values obtained for the control samples in caustic simulant indicates $5-10 \%$ degradation in cesium removal performance from chemical exposure in the absence of radiation. Similar chemical degradation was observed with spherical RF in caustic solution. Results observed by Duffey for spherical RF are qualitatively consistent with those reported by Crawford, though larger decreases in cesium loading were observed for the granular material at 67 Mrad exposure $(\sim 35 \%)$ than were observed for spherical RF at $100 \mathrm{MRad}$ exposure.

\subsection{Spherical RF Performance under Dynamic Flow Conditions in Column Configuration}

\subsubsection{Hanford RPP-WTP Resin Pretreatment, Column Loading, and Column Processing Summary}

Resin pretreatment, column loading, and column processing steps for spherical RF resin have been developed as part of the WTP Research and Technology test program. Resin pretreatment and column loading steps were prescribed for all laboratory testing in an SRNL protocol (Nash, 2004) and are summarized below. The standard pretreatment process involved one complete chemical treatment outside of the column and a second chemical treatment inside the column. The initial chemical cycle performed outside of the column promotes irreversible expansion of the resin by $\sim 30 \%$ (as-received hydrogen form to pretreated hydrogen-form) as discussed in Section 3.2.2. It is expected that this pretreatment step could be performed by the resin vendor. It is also possible to perform the pretreatment steps in column configuration, as long as all hydrogen- to sodium-form conversions are conducted in upflow. The term "equivalent volume" refers to the volume of the resin bed in a non-packed state such as in a beaker or tank.

Initial Resin Pretreatment Protocol (typically performed in an unconstrained geometry)

- remove excess fluid from as-received hydrogen-form resin and soak resin in five equivalent volumes $(\mathrm{EV})$ of deionized water for 30 minutes with mild agitation every 10 minutes 
- remove excess water from resin and soak overnight in $5 \mathrm{EV}$ of $1 \mathrm{M} \mathrm{NaOH}$ under an inerted atmosphere to minimize air oxidation (confirm $\mathrm{pH}>13$ after 30 minutes of contact)

- remove excess fluid and wash three successive times with $3 \mathrm{EV}$ portions of deionized water with agitation at 10-minute intervals and 30-minute total contact times per wash (final $\mathrm{pH}$ typically $12.5-13.0$ )

- remove excess fluid from resin and soak in $10 \mathrm{EV}$ of $0.5 \mathrm{M} \mathrm{HNO}_{3}$ solution for 2 hours with agitation every 10 minutes (confirm $\mathrm{pH}<1$ after 30 minutes of contact)

- remove excess fluid from resin and wash three times with $3 \mathrm{EV}$ portions of deionized water

Based on the above processing assumptions the following pretreatment solution volumes would be generated assuming a 15 foot column height (sodium-form volume basis). Pretreatment is required once for each resin bed. Presumably this pretreatment would be conducted outside of the column in a tank (possibly by the resin vendor) and would not involve contaminated equipment.

Pretreatment solution volumes for 15 foot tall (431.8 gallon sodium-form basis) column

- 9,931 gallons of water

- 2,159 gallons of $1.0 \mathrm{M} \mathrm{NaOH}$

- 4,318 gallons of $0.5 \mathrm{M} \mathrm{HNO}_{3}$

Equivalent molar amounts of nitric acid and sodium hydroxide are used such that the caustic and acidic solutions could be carefully mixed for neutralization prior to disposal. The end result of this treatment and mixing of all solutions is approximately 16,408 gallons of 0.132 $\mathrm{M} \mathrm{NaNO} 3$ solution. These solutions should not be radioactive unless these steps are performed in the SCIX column. It should be noted that as-prepared resin has been observed to leach formaldehyde during initial washes. Fiskum (2006d) characterized formaldehyde leachate concentrations for several non-scale-up production spherical RF resin batches. Formaldehyde concentrations in the water cover solutions for four as-received resins ranged from 1000-3000 mg/L. Formaldehyde concentrations in three successive 1 bed volume water rinses ( 2 hour contact times) decreased from 500 to $<200 \mathrm{mg} / \mathrm{L}$. Soaking in $1 \mathrm{BV}$ of water overnight resulted in an increase to $500 \mathrm{mg}$ formaldehyde/L. Subsequent washes with four $10 \mathrm{BV}$ portions of $1 \mathrm{M} \mathrm{NaOH}$ and water resulted in a concentration decrease to below the detection limit of $5 \mathrm{mg} / \mathrm{L}$.

Column loading procedures are listed below. Conversion of the resin to sodium form should be conducted just prior to loading the column and should not be performed at an offsite location by the resin vendor.

Column Loading (downflow unless otherwise indicated)

- remove excess fluid from pretreated hydrogen-form resin and soak in $5 \mathrm{EV}$ of $1 \mathrm{M}$ $\mathrm{NaOH}$ for 30 minutes with mild agitation every 10 minutes

- transfer the resin/ $\mathrm{NaOH}$ slurry into the column and remove excess fluid to the desired liquid level

- cycle (elute/regenerate) the resin one time in the column prior to use as described below beginning with the pre-elution rinse step (\#3) 
- Note: For large scale applications it may be possible to load the resin in hydrogen form and regenerate the resin in upflow beginning with step \#7 below prior to waste introduction. The MSP project may also consider operations without preliminary chemical cycling in the column.

The column processing sequence developed and suggested for spherical RF resin in WTP operations (Thorson, 2006) differs somewhat from the process outlined in the WTP cesium removal system description (Olson, 2002). Presumably the proposed RF processing scheme developed by Thorson or some variation will eventually replace the process outlined in the system description since spherical RF has now been selected as the baseline WTP cesium removal technology. The basic RF column processing steps are provided in Tables 4 and 5 of the Thorson reference. The current best estimate column processing sequence for spherical RF is also summarized below (primarily based on Table 4 of the Thorson reference). The term "bed volume" (abbreviated as BV) refers to the sodium-form resin bed volume in $0.5 \mathrm{M} \mathrm{NaOH}$ regenerate solution within the packed column geometry.

Column Processing Sequence (downflow unless otherwise indicated)

1. The following steps assume that the column has been properly packed with sodium-form RF resin and that the resin bed is immersed in 0.25 or $1.0 \mathrm{M} \mathrm{NaOH}$ at the start of step 2 .

2. process waste supernate through the columns at a flow rate of 1.5 to $2.2 \mathrm{BV} / \mathrm{hr}$ (equates to 15-22 gpm for the WTP column design using a 600 gallon sodium-form RF bed)

3. transfer 3.0 BV of $0.1 \mathrm{M} \mathrm{NaOH}$ solution through the column at $2.2 \mathrm{BV} / \mathrm{hr}$ (feed displacement)

4. transfer 2.2 BV of deionized water through the column at 2.2 BV/hr (pre-elution rinse)

5. transfer $15.3 \mathrm{BV}$ of $0.45 \mathrm{M} \mathrm{HNO}_{3}$ through the column at $1.0 \mathrm{BV} / \mathrm{hr}$ (elution) Note: Longer elution times will likely be used in WTP operations when loading times are sufficiently long to allow for increased elution (Thorson, 2006).

6. transfer 2.5 BV of deionized water through the column at $2.2 \mathrm{BV} / \mathrm{hr}$ (post-elution rinse)

7. transfer $2.9 \mathrm{BV}$ of $0.5 \mathrm{M} \mathrm{NaOH}$ solution through the column in upflow at $4.7 \mathrm{BV} / \mathrm{hr}$ (regeneration step 1)

8. allow the bed to soak and settle in $0.5 \mathrm{M} \mathrm{NaOH}$ solution for 0.1 hours (settling)

9. transfer $0.32 \mathrm{BV}$ of $0.5 \mathrm{M} \mathrm{NaOH}$ solution through the column in upflow at $0.74 \mathrm{BV} / \mathrm{hr}$ (regeneration step 2)

10. transfer 1.8 BV of decontaminated salt solution (or solution of comparable sodium molarity) through the columns in upflow at $0.94 \mathrm{BV} / \mathrm{hr}$

11. transfer $0.25 \mathrm{BV}$ of decontaminated salt solution (or solution of comparable sodium molarity) through the columns in upflow at $1.5 \mathrm{BV} / \mathrm{hr}$

12. allow the bed to settle for 0.5 hours

Hydraulic testing results at SRNL indicate that steps 10 and 11 may not be necessary for the annular SCIX design (Duignan, 2007). The estimated time for column elution and regeneration (steps 2-11) based on these flow rates and using estimated switching times (which for WTP involves removal of columns from the processing carousel) was 22.9-24.3 hours depending on whether the system description or RF recommended flow rates and concentrations were used. Note that these times are particularly important for the WTP since they intend to operate with continuous waste supernate processing and off-line elution 
and regeneration. The total time for elution and regeneration must not exceed cesium loading times (step 2 above) in order to support continuous operations.

\subsubsection{Cesium Loading/Elution Performance}

Numerous small column tests have been conducted with spherical RF resin batches using simulated Hanford waste supernates as described by Fiskum (2006d). Column performance has generally been as expected based on the measured RF batch contact cesium equilibrium loading in each feed. There has been little indication of channeling effects resulting from non-ideal bed packing, other than non-uniform color changes during transitions between resin forms in some cases (Fiskum, 2006d). There are no reports of resin fouling and pluggage resulting from precipitation. Low levels of (presumably) aluminum-based precipitates were visually observed in column effluent solutions in a few cases during sodium hydroxide displacement following column loading (Fiskum, 2006d). Duignan also reported the observation of small amounts of white precipitates after storage of hydrogen form RF resin in water overnight (2007). However, there were no reported negative consequences from precipitation in either case. Resin fouling effects are minimized by the high permeabilities of packed RF beds and the fact that the acid eluate likely dissolves many solids that might form on the resin. It does not appear that any tests have been conducted where packed RF beds were intentionally exposed to conditions that might cause fouling and no recovery schemes have been developed besides the standard $0.5 \mathrm{M} \mathrm{HNO}_{3}$ elution.

Spherical RF resin synthesis conditions were optimized as part of the RPP test program to provide resin beads with acceptable and reproducible physical and chemical properties. Very consistent performance with regard to cesium removal was observed for the six scaleup production batches during column testing with Hanford AP-101 (high $\mathrm{K}^{+}$) simulant as reported by Fiskum (2006d) and summarized in Table 3.1. The average early cesium breakthrough (represented by the WTP contract limit), 50\% breakthrough, and cesium loading at $50 \%$ breakthrough were quite consistent for the six production scale resins as indicated by the percent relative standard deviations of $\leq 11 \%$.

Models have been developed to predict cesium breakthrough during WTP column operations (Aleman, 2007). The WTP models were also recently used to predict performance with the five MSP feeds for the current SCIX annular design (Smith, 2007; effective column inside diameter: 26.56"). A limited parametric study was conducted varying feed flow rate $(5,10$, and $15 \mathrm{gpm})$, temperature $\left(25,35\right.$, and $\left.45^{\circ} \mathrm{C}\right)$, and column length $(10,15$, and 25 feet). For the baseline case, it was assumed that two columns containing equal resin heights were used in sequence (lead/lag configuration). The bucket average cesium concentration in the lag column effluent was calculated and $45 \mathrm{nCi} / \mathrm{gram}$ was the composite breakthrough limit used to determine the waste loading time in each cycle. Column performance predictions were generated for both of the cesium loading isotherms (CERMOD and TMIXP) discussed in Section 3.3.2. Results for the various conditions were compared after completion of the second load/elute cycle where nearly steady-state performance was observed. Results reported as waste volume processed per cycle in thousands of gallons revealed significantly different results for the two isotherms (as expected based on the previous discussion in Section 3.2.2). The new isotherm resulted 
in larger volumes processed since this isotherm was developed to account for seemingly enhanced cesium removal performance at low cesium concentrations for some waste feeds. This feature in the isotherm model tends to suppress the early portion of the cesium breakthrough profile and allow more waste volume to be processed prior to reaching the effluent activity limit. For a 15 foot column at $10 \mathrm{gpm}$ flow and $25{ }^{\circ} \mathrm{C}$ an average of $93 \%$ more waste volume can be processed with MSP feeds using the newer CERMOD model than the older TMIXP model.

Cesium breakthrough profiles with RF resin are quite sharp as a result of excellent sorption kinetics (high cesium pore diffusivities) in $6 \mathrm{M} \mathrm{Na}^{+}$feeds. Changing the volumetric flow rate by a factor of four from 5 to $20 \mathrm{gpm}$ only results in a $6 \%$ decrease (average for all MSP feeds using both isotherms with a $15 \mathrm{ft}$. column at $25^{\circ} \mathrm{C}$ ) in waste volume processed. This result indicates that even faster flow rates could be considered if other process components (such as the pre-column filters) could support this throughput. Besides greater throughput, higher flow rate also reduces loading time and resin radiation exposure. Another potential advantage of sharp breakthrough profiles is the possibility of using a single column rather than two columns in sequence. If the cesium loading profile is contained within one column length there may be little advantage to using two columns. A single column design would be simpler and cheaper and should result in less resin exposure to radiation in a given cycle since loading times would be shorter.

Smith (2007) provided cesium distribution profiles on the columns for spherical RF resin for each of the MSP feeds using both isotherms. For both RF isotherms the liquid phase cesium concentration increases from the bucket average breakthrough limit $(45 \mathrm{nCi} / \mathrm{gram})$ to essentially $100 \%$ of the feed value across less than one column length ( 15 foot column, 10 gpm, $25^{\circ} \mathrm{C}$ ). Sharper breakthough profiles are observed with the newer CERMOD isotherm because of the aforementioned compression of the early portion of the profile. For all five MSP feeds using the new isotherm the profile is contained within $\sim 70 \%$ of the column length. For selected feeds ( 2 and 41 ) using the old TMIXP isotherm the profile is distributed across $\sim 95 \%$ of the column length. Changing the flow rate would impact the widths of the profiles, though not greatly as discussed above. Perhaps for marginal cases with single column operations, lower flow rates could be used to better utilize the resin capacity. In all two column cases considered with series (lead/lag) processing for RF (old and new isotherm) the lead column is saturated well before the loading limit is reached and the resin in the lead column is exposed to radiation during the loading of the second column. This observation indicates that operation with two columns in sequence with a $45 \mathrm{nCi} / \mathrm{g}$ bucket average lag column breakthrough limit may not be the best processing option due to excessive radiation exposure of the lead column. Other processing options exist which could serve to reduce radiation damage to the lead column, such as lead column elution immediately after saturation or changing the breakthrough criteria to the lead column effluent. The desire to minimize radiation damage must be balanced against such things as efficient utilization of resin capacity, minimization of wash and regenerate solution volumes, and maximization of waste processing durations.

RF column performance is significantly impacted by temperature but is not greatly impacted by resin height. Lower temperatures result in significantly improved performance, as would 
be expected based on the temperature sensitivity of the loading isotherms. Increasing the temperature from 25 to $45{ }^{\circ} \mathrm{C}$ results in a $44 \%$ decrease in waste volume processed per cycle (average for all MSP feeds using both isotherms). Increasing the column height and L/D does not result in large differences in performance at a given flow rate. The primary result of taller columns is that increased resin volume results in proportionally greater column capacity for cesium. For example, increasing the column height from 10 to 25 feet (10 gpm flow and $25^{\circ} \mathrm{C}$ ) corresponds to a $150 \%$ increase in bed volume, while the average predicted increase in waste volume processed was 161\% (average for all MSP feeds using both isotherms). The largest increase in volume processed was 172\% with Tank 41 feed using the new isotherm. It therefore appears that $\mathrm{L} / \mathrm{D}$ effects on cesium removal performance are small under these conditions and the optimal amount of resin for use in the SCIX will be determined by other factors.

Column performance modeling was also conducted by Smith using a single column with cycling after reaching a $45 \mathrm{nCi} / \mathrm{g}$ bucket average breakthrough. Single column processing appears feasible based on the volumes of supernate processed per cycle. The lowest volume processed under single column operations was 43,000 gallons using a10 foot tall column (10 gpm flow and $25^{\circ} \mathrm{C}$ ) with Tank 3 feed. Lower process volumes would be expected at higher temperatures, but higher temperatures were not evaluated for single column operations. Comparison of modeling results for single and two-column operations using the old isotherm reveals that on average single column operation leads to a $21 \%$ reduction (standard deviation 8\%) in waste volume processed per cycle versus two-column operations with lead/lag carouseling. Greater differences in volumes processed are observed with faster flow rates and shorter columns where the mass transfer zone is more difficult to contain within a single column. Of course, single column operation will involve more frequent elution and greater total eluent volume than two-column operations.

The baseline elution process for RF columns in the Hanford WTP is $15 \mathrm{BV}$ of $0.5 \mathrm{M} \mathrm{HNO}_{3}$ at a flow rate of $1.0 \mathrm{BV} / \mathrm{hr}$ (Thorson, 2006). Residual cesium levels on RF columns after elution are typically quite low and are relatively consistent between resin batches and column tests. The cesium concentration dropped below $4.2 \mu \mathrm{g}$ Cs-137 per g H-form resin (the assumed WTP design limit for RF, Thorson, 2006) after processing of 8 BV of eluate for actual Hanford AN-102 and AP-101 testing. With Hanford AZ-102 simulant feed, which contains high levels of cesium (possibly worst case) and chromium, the presumed design limit is reached after processing $15 \mathrm{BV}$ of eluate. Longer elution is known to result in lower residual cesium and might be used prior to spent resin disposal. Lower nitric acid concentrations have been considered for elution to provide greater margin for avoiding $\mathrm{RF} /$ nitric acid reaction. After column loading with Hanford AP-101 simulant, elution with 0.4 and $0.25 \mathrm{M}$ nitric acid increases the volume required to reach the design limit by approximately $20 \%$ and $40 \%$, respectively, relative to performance with $0.5 \mathrm{M}$ acid (eluate volumes required: $0.5 \mathrm{M}-9 \mathrm{BV}, 0.4 \mathrm{M}-10-11 \mathrm{BV}, 0.25 \mathrm{M}-12-13 \mathrm{BV}) .0 .45 \mathrm{M}$ nitric acid eluate has been proposed as an alternative eluate concentration (Fiskum, 2006d). Various other metals have been observed to elute from RF columns after loading of actual and simulated Hanford waste supernates as discussed on Section 3.3.1. 
Certain processing differences between the designed Hanford WTP and the conceptual MSP process exist which could favor the consideration and development of alternative elution conditions or different acid eluates. The WTP design includes a nitric acid evaporation and recovery step (Olson, 2002) which minimizes the nitrate contribution to the high level waste glass. Nitric acid recovery is not currently planned for MSP. Furthermore, WTP operations are designed for continuous waste processing with off-line column elution and regeneration, while MSP may or may not involve continuous loading. For the WTP, elution and regeneration time cannot exceed loading time. The above described results indicate that if sufficient time were available cesium elution can be more efficiently accomplished with lower acid concentrations at a flow rate of $1 \mathrm{BV} / \mathrm{hr}$. Decreasing the acid concentration by $50 \%$ to $0.25 \mathrm{M}$ only resulted in a $40 \%$ increase in eluate volume required (rather than the $100 \%$ increase needed to provide an equimolar amount of acid). Other elution optimization methods could also be evaluated if the total nitric acid utilized is the factor of greatest importance rather than elution time. For example, higher temperature elution could be considered, particularly if lower acid concentrations are used. (Note: RF reacts rapidly with significant off-gassing in $0.625 \mathrm{M}$ acid at $66^{\circ} \mathrm{C}$, see Sections 3.3.3 and 3.5.3.) Other possible methods to minimize nitric acid utilization include soaking the bed in acid rather than using continuous flow, and using sequentially lower acid concentrations once resin neutralization is complete. This option may be particularly useful after the bulk of the cesium has been removed in the first 8-10 BV of eluent.

\subsubsection{Column Hydraulic Performance}

Extensive hydraulic testing was conducted with spherical RF columns as part of the WTP Research and Technology program. Small-scale tests were conducted with 3 inch ID columns at PNNL (Arm, 2006) and larger scale tests were conducted at SRNL using 12 and 24 inch ID columns (Adamson, 2006). Multi-cycle testing using air-saturated feed indicated no change in permeability over 16 load/elute cycles. The RF beds were observed to be nearly incompressible at typical operating pressures. At a flow rate of $22 \mathrm{gpm}$ the pressure drop across a 600 gallon bed $(\mathrm{L} / \mathrm{D}=1)$ was predicted to be only 3.8 psid (Thorson, 2006). Since the SCIX design involved column dimensions with significantly higher L/D and included an annular design with a center cooling pipe, it was necessary to conduct hydraulic tests to evaluate utilization of spherical RF. Historical testing at SRNL with SuperLig ${ }^{\circledR} 644$ resin (an elutable, organic resin which also underwent volume changes during processing) revealed that substantial pressure drops can be observed when using resins of this type in large-scale applications with downflow fluid processing only. For this reason an alternative processing scheme was developed which involved upflow regeneration of the resin after acid elution. This processing scheme allows for expansion of the resin from the low-volume acid form to the high-volume sodium form in an unconstrained, partially fluidized state. As

a result, it was hoped that it would now be possible to utilize RF in higher L/D applications such as SCIX.

Spherical RF resin hydraulic tests were conducted with a 3 inch ID column using a scaled approach whereby the annular design and the resin bed heights were scaled relative to the full scale SCIX dimensions (Duignan, 2007). Three different resin bed heights (12.6, 18.8, and 31.4 inches, representative of 10, 15, and 25 foot SCIX columns, respectively) were 
tested using three different feed superficial velocities $(2.6,16.1$, and $27.4 \mathrm{~cm} / \mathrm{min})$. These column heights correspond to $\mathrm{L} / \mathrm{D}$ ratios of 5.8, 8.7, and 14.5 for the full-scale column. The superficial velocities were the same as the expected operating fluid velocities in the fullscale SCIX design. Tests were conducted following the WTP protocol using a simplified, nominal $6 \mathrm{M} \mathrm{Na}^{+}$feed with a viscosity equal to or greater than the anticipated MSP feeds. In every test case a linear pressure drop response was observed as a function of the fluid superficial velocity, indicating that neither bed compression nor other changes lead to excursive pressure drops across the flow range of interest. The highest observed pressure drops occurred during simulant loading. It is believed that the pressure drop response per foot of bed height is constant at each given flow rate and is independent of the total bed height. A simple formula for the calculation of RF resin bed pressure drop for the annular design during column loading was reported and is shown in equation 3-1. The formula is believed to give conservative results since a relatively high viscosity feed was used for testing. The formula indicates that maximum bed pressure drops of 16, 47, and 80 inches of water per foot of bed height would be expected during processing of MSP feeds at 5.6, 16.1, and $27.4 \mathrm{~cm} / \mathrm{min}$, respectively. These superficial velocities correspond to volumetric flow rates of 5.2, 15.1, and $25.6 \mathrm{gpm}$ in the full scale column with an annular flow area of 3.81 $\mathrm{ft}^{2}$. The results indicate that the maximum pressure drop across a 25 foot SCIX column at 25.6 gpm would be 2000 inches of water or 72.3 psi.

$\mathrm{dP}\left(\right.$ in. $\left.\mathrm{H}_{2} \mathrm{O}\right) /(\mathrm{ft}$ of bed height $)=2.912 \times$ (fluid superficial velocity in $\mathrm{cm} / \mathrm{min}$ )

Other observations during hydraulic testing follow. In this testing upflow processing of decontaminated salt solution was not used (steps 10-11 of the Column Processing Sequence in Section 3.4.1) since it was anticipated that this was unnecessary for SCIX applications. Test results indicated no issues with disturbance of the top of the resin bed during downflow introduction of waste simulant into the columns and it was suggested that the introduction of decontaminated salt solution (intended to eliminate fluid motions in the column headspace associated with liquid density differences) be removed from the protocol for SCIX. A resin plug was observed to form during upflow regeneration with the tallest column tested. Approximately 10 volume percent of the bed raised to the upper screen and remained at that location until flow was interrupted. However, no increase in pressure drop was observed during upflow and there were no significant consequences of plug formation. Air bubbles observed under the resin plug may have contributed to plug formation. Plug formation should be less likely in the full-scale SCIX application since bridging of resin particles across the larger column annular distance is not expected. $80 \%$ and $50 \%$ bed volume increases were observed during regeneration relative to the hydrogen and sodium form volumes, respectively. The observation of no pressure drop increase during plug formation at the upper screen during upflow suggests that minimization of the column freeboard of the RF beds may be possible. Further studies on this topic would be necessary should it become advantageous to increase the RF column height. 


\subsubsection{Column Testing using Actual Hanford Tank Supernates}

Two small column tests have been conducted using actual Hanford tank waste supernates. Results of these tests are described in three reports by Fiskum (2006a-c). Tests were conducted using one set of columns in a lead/lag configuration with each column containing approximately $11 \mathrm{~mL}$ of sodium-form spherical RF resin. Three waste loading tests were conducted using the same columns and resin with cesium loading using Hanford tank AP101 simulant, AP-101 actual waste, and AN-102 actual waste (previously treated for $\mathrm{Sr}$ /TRU removal) in sequential tests. All three feed solutions were diluted to near $5 \mathrm{M}$ sodium, the typical feed concentration used for most WTP RF column testing. Cesium breakthrough and elution profiles were characterized, nitric acid eluate solutions were analyzed, and the resin samples were digested and analyzed to quantify residual metals. Hanford AP-101 supernate is high in potassium $(\sim 0.7 \mathrm{M})$ and is considered to be one of the more challenging feeds for cesium removal. Hanford AN-102 supernate contains many metals and it was expected that this material might provide a bounding evaluation of the tendency of RF resin to react with and retain hazardous metals.

As expected, due to the high potassium levels, early cesium breakthrough (within $\leq 4 \mathrm{BV}$ ) was observed with actual AP-101 supernate and 50\% cesium breakthrough was observed after processing $92 \mathrm{BV}$ of solution (Fiskum, 2006a). There was some indication of bed channeling for the lead column in the AP-101 tests and this was listed as a possible reason for the early cesium breakthrough. Bed channeling is more likely with small columns such as those used in these tests (1.5 cm ID), though it was not expected from a theoretical perspective. However, subsequent modeling of the tests results with actual AP-101 waste revealed that such early breakthrough was expected primarily due to the high potassium concentration (Aleman, 2007). Excellent agreement was observed between the actual and predicted cesium breakthrough profiles with this real waste supernate sample. It is not expected that such high potassium feeds will be processed as part of the MSP process and generally better performance is expected than was observed with AP-101. Cesium breakthrough performance with AN-102 waste was much better (10\% lead column cesium breakthrough after processing $202 \mathrm{BV}$ of solution) even though the lead column still contained significant cesium (near 50\% of the resin capacity) from previous testing with AP-101 (Fiskum, 2006b). The better loading performance in this case is the result of both lower potassium and lower cesium concentrations in the feed solution. The concentrations of virtually all species (except Cs) in the cesium-decontaminated effluent solutions were the same as those of the feed, which speaks to the high selectivity of the resin for cesium. Acceptable and expected performance was observed during column loading with the actual Hanford waste supernates.

Characterization of the composite $0.5 \mathrm{M}$ nitric acid eluate solutions following column loading with actual Hanford waste was also provided in the Fiskum reports. Nearly quantitative $(>99 \%)$ cesium elution was observed within processing of $10 \mathrm{BV}$ of eluate for both actual waste tests. Eluate recoveries from the lead column following AP-101 loading included $31 \% \mathrm{Zn}, 2.5 \% \mathrm{U}, 9 \% \mathrm{Pu}(239 / 240$ isotopes), $11 \% \mathrm{Cm}$, and $2 \% \mathrm{Am}$ (relative to feed levels). Eluate recoveries from the two columns (lead/lag) following AN-102 loading included $9 \% \mathrm{~Pb}, 12 \% \mathrm{Cu}, 37 \% \mathrm{Zn}, 3 \% \mathrm{U}$. Differences in the metals recovered in the two 
tests are likely impacted by the presence of complexing organics in the AN-102 supernate which may decrease the likelihood that some metals will sorb to the resin during column loading. No tests have been conducted with Savannah River Site actual or simulated waste supernates using spherical RF resin.

Discussion of analysis results for the spent RF resin samples following the actual waste testing is provided in Section 3.7.

\subsubsection{Anticipated RF Radiation Exposure and Resin Lifetime in the SCIX Packed Column Geometry}

Rigorous RF dose calculations have not been conducted. However, general dose estimates are provided in Tables 3-2 and 3-3. The estimates were calculated for the highest expected RF cesium loading (Tank 37) of the five MSP feeds and for a nominal cesium loading case (Tank 3) using both the old and new isotherms. Based on the equilibrium cesium loadings predicted by Smith (2007), RF radiation dose rates for the Tank 37 and 3 feeds at $25^{\circ} \mathrm{C}$ were calculated to be 4.37 and $2.47 \mathrm{Mrad} /$ day, respectively, using the new isotherm. Analagous calculations conducted using Curie loadings based on the old isotherm gave dose rates of 3.27 and $1.20 \mathrm{Mrad} /$ day for Tanks 37 and 3, respectively. The density of the packed RF column immersed in salt solution reported by Lee (2007) was used for all calculations (1306.4 g/L). Most performance modeling calculations were conducted using the old RF isotherm, which is not the most conservative isotherm as far as radiation dosage is concerned. The old isotherm is the most conservative with regard to cesium loading and, as a result, single column calculations were only reported for the old isotherm by Smith (2007). Directly comparable cases using the old and new isotherms were calculated for the lead/lag column configuration and are provided in Tables 3-2 and 3-3, along with single column results based on the old isotherm alone.

Calculations were conducted using the old and new RF isotherms and Tank 37 and 3 feeds for the cases listed below. RF resin lifetimes were estimated assuming a radiation dose limit of $100 \mathrm{Mrad}$ (corresponds to $\sim 14 \%$ Cs loading reduction, Duffey, 2006). Estimates of the total supernate volume processed, loading duration, and number of cycles corresponding to a dose of $\sim 100 \mathrm{Mrad}$ are provided in the tables. Only integral numbers of processing cycles were considered so the total dosages varied as indicated in the tables. It was assumed that all of the radiation dose was absorbed, although a fraction (perhaps $25 \%$ ) will likely escape from the column. All calculations were based on the total predicted waste volumes processed per cycle by Smith for each feed under the appropriate conditions. For cases involving lead/lag column configurations where the number of cycles prior to resin replacement exceeded the total number modeled by Smith, the volume reported for the last modeled cycle was used for all subsequent cycles (i.e. steady state performance was assumed). Performance impacts during processing resulting from radiolytic and chemical exposure were not accounted for in the calculations. Full resin capacity was assumed until the $100 \mathrm{Mrad}$ dose limit was reached, at which point the resin was considered spent. For cases where many $(>30)$ load/elute cycles appear possible from a radiolytic perspective, it should be remembered that chemical degradation may be the limiting factor with regard to 
resin lifetime. The expected cesium loading decrease per cycle resulting from chemical degradation is $\sim 0.6 \%$ (Fiskum, 2006d).

\section{Cases Considered for RF Dose Calculations}

1) two-columns operated in series with a lag column $45 \mathrm{nCi} / \mathrm{g}$ bucket average processing limit (old and new isotherm) and carousel sequencing (rotation of lead and lag positions between cycles)

2) two columns operated in series with a lead column $50 \%$ instantaneous cesium breakthrough processing limit (old isotherm only) and lead/lag carousel sequencing (involves lower processing volumes and less dose per cycle than Case 1)

3) one column operation with a $45 \mathrm{nCi} / \mathrm{g}$ bucket average processing limit (old isotherm only, involves lower processing volumes and less dose per cycle than Case 2)

Fractional cesium loadings in each cycle and the effects of gradual and (assumed) linear loading were accounted for by adjustments to the total dose rates as shown in Table 3-4. When the lead column was not processed beyond saturation (Cases 2 and 3) a rough fractional time-averaged correction factor of 0.5 was applied to the dose rate to account for the fact that approximately linear cesium loading occurs during waste processing. For Case 1 , a correction of 0.75 was applied for the lead column since column processing was continued approximately twice as long as was needed for saturation of the lead column $(0.5$ for first half of processing, and 1.0 for second half). A correction of 0.25 was applied for the lag column (Case 1) maximum dose since this column received no dose during the first half of processing and a time-averaged dose of 0.5 during the remainder of processing in a given cycle. For Case 2, lag column loading was assumed to be minimal and was neglected as indicated by the time-averaged correction of zero. Fractional cesium loading corrections were also applied for the lag column in Case 1, the lead column in Case 2, and the single column in Case 3, since these columns were only partially loaded with cesium. It was assumed that fractional loading during two-column operations based on a $45 \mathrm{nCi} / \mathrm{g}$ bucket average process limit (Case 1) were the same as single column fractional loadings based on the same process limit (Case 3). The lead column for Case 1 was assumed to be loaded to saturation based on the results reported by Smith (2007). With the old isotherm, for Cases 1 and 3, the fractional loadings were calculated directly from the modeling results. For the new isotherm, fractional loadings were visually estimated from the column loading profiles provided by Smith, since the calculated values were not available. For Case 2, the volume processed to reach 50\% instantaneous cesium breakthrough and percent loading were estimated by visual extrapolation of the single column breakthrough profiles (provided by Smith). Volumes processed to reach $50 \%$ instantaneous breakthrough were estimated to be 155,000 and 95,000 gallons for Tanks 37 and 3, respectively.

Cases 1 and 3 are considered to represent extreme processing options with Case 1 representing the largest lead column resin dose per cycle and Case 3 the least. The large resin dose associated with Case 1 is due to the fact that in this operating mode the loading phase continues well beyond saturation (see Smith, 2007) for the lead column resulting in significant additional (and seemingly unnecessary) dose as the cesium mass transfer zone 
migrates entirely into the lag column. For Case 3 the mass transfer zone is contained within a single column and processing is stopped with minimal cesium breakthrough $(\sim 1 \%)$ and only partial cesium loading (50-81\% cesium saturation). Case 2 is considered intermediate with regard to resin dose per cycle since the process limit is based on a lead column cesium breakthrough of $50 \%$. In this case, lead column loading is expected to be $\geq 95 \%$ of saturation. The total volumes processed and number of cycles for cases involving a lead/lag configuration (Cases 1 and 2) are impacted by the fact that the total radiation dose is distributed between two RF columns. The process operation is considered to involve lead/lag carousel (or switching between cycles). This means that resin lifetime, in this case, generally corresponds to replacement of both columns.

Careful inspection of Tables 3-2 and 3-3 reveals that predictions of resin lifetime vary considerably. Higher cesium loadings, slower flow rates, and larger columns all result in less waste volume processed before resin replacement. It should be noted that normalizing the volumes processed and cycles before replacement to the total resin volume would result in 50\% reductions in the values reported in the table for Cases 1 and 2 relative to those reported for the single column cases (Case 3), since the radiation dose is distributed between two columns for lead/lag operations. For both feeds, using the old isotherm versus the new results in significant increases in volume processed and total cycles before replacement due to significantly lower cesium loadings using the old isotherm. For Tank 37, calculations using the new isotherm indicate that only one cycle can be processed before resin replacement under nominal conditions (10 gpm, $15 \mathrm{ft}$. column). Longer resin lifetimes and greater volumes processed are observed in all cases for Tank 3 relative to Tank 37 . Operating at $10 \mathrm{gpm}$ vs $20 \mathrm{gpm}$ results in approximately a two-fold increase in processed volume due to the fact that faster flow rates decrease process time and resin radiation exposure. Given the minimal impact of faster flow rates on cesium removal performance, it seems that faster flow rates would be preferred. Comparison of single column versus lead/lag carousel operations reveals that the volumes processed are comparable, with single column operation resulting in slightly larger volumes. As mentioned earlier, however, normalizing these volumes to the amount of resin consumed reveals that single column operation allows for much more efficient use of the resin. Single column operation does require more cycles than does two-column operation as would be expected. Selection of the preferred processing option will likely involve balancing between eluent volume minimization and efficient resin utilization, although many other factors will be considered as well. The total maximum supernate volumes requiring treatment are 1 million gallons for Tank 37 and 2.1 million gallons for Tank 3 (Smith, 2007). For both tanks it appears that for many of the processing cases considered in Tables 3-2 and 3-3 the entire tank supernate volume can be processed with one single column or one lead/lag pair of columns.

\subsection{Process Safety and Risk}

\subsubsection{General}

There are no significant hazards or acute health risks listed for general use of resorcinolformaldehyde polymer (MSDS, 2002). RF is combustible after evaporation of water and expected to produce acid smoke and irritating fumes upon thermal degradation with carbon 
monoxide and carbon dioxide being generated as primary gaseous decomposition products. As-received spherical RF resin has been observed to leach formaldehyde, presumably present as residual starting reagent from the resin synthesis (Fiskum, 2006d). Initial formaldehyde concentrations in resin cover solutions were as high as $3000 \mathrm{mg} / \mathrm{L}$. Water and caustic rinses resulted in a rapid decrease in the formaldehyde concentration.

\subsubsection{Risks Associated with Hydraulic Performance and Column Pluggage}

There have been no observations of column hydraulic pluggage during testing with spherical RF resin. Small amounts of solids have been observed during processing of solutions following the standard protocols. Solid formation typically occurs during transitions between acidic and caustic conditions or during storage conditions with no flow. No negative consequences of solids formation have been reported. In all cases the solids have disappeared with subsequent processing. Risks associated with column pluggage are considered low and recovery is not expected to be problematic since most solids are expected to dissolve during subsequent processing. Even in the case of significant precipitation within the bed it is expected that acid elution could be conducted since the resin volume decreases in acid and bed permeability during this stage is expected to be high. Removal of fouled resin from the columns is not expected to be problematic from a hydraulic perspective. There have been no reports of resin bead clumping or agglomeration resulting from fouling and precipitate formation.

It is possible to observe excursive pressure drops during RF processing by inadvertently performing the regeneration step in downflow or by skipping the column regeneration step prior to feed introduction. This could result in bed expansion in a semi-confined geometry which could lead to loss of bed permeability, deformation/attrition of resin beads, generation of large forces on the column walls, and excursive hydraulic pressure drops. Such an event could damage equipment and resin, result in compaction of the resin bed in the column (making removal difficult), and lead to safety concerns associated with vessel pressurization. For this reason it is recommended that column pressures be monitored and/or that procedural measures be put in place to avoid downflow regeneration of RF columns.

\subsubsection{Hazards Associated with Heat Sources}

Potential heat sources associated with the utilization of spherical RF resin for cesium removal include:

- acid-base reactions associated with inadvertent contact between process solutions

- exothermic chemical reactions resulting from inadvertent contact of RF resin with concentrated nitric acid

- resin radiolysis under off-normal conditions where inadequate column cooling is available. 
The first two cases above involve inadvertent contact of acidic and basic process solutions or resin and inadvertent contact of higher than normal acid solutions with resin. The most concentrated acid/base streams expected during RF processing are $0.5 \mathrm{M} \mathrm{HNO}_{3}$ and $1.0 \mathrm{M}$ $\mathrm{NaOH}$. Inadvertent contact between these solutions will generate heat from neutralization. Inadvertent contact between acid and waste supernate will involve $\mathrm{NO}_{\mathrm{x}}$ and $\mathrm{CO}_{2}$ offgassing, heat of neutralization, and the formation of aluminum precipitates. Inadvertent contact between acid form resin and tank waste supernate would have a similar effect, but bubble formation and precipitation in this case would occur within the ion exchange bed. Inadvertent contact of concentrated nitric acid with RF resin leads to off-gassing, resin dissolution, and temperature increases (Fondeur, 2007). Reaction with $3 \mathrm{M} \mathrm{HNO}_{3}$ at $25^{\circ} \mathrm{C}$ results in a mild exotherm with temperatures increasing to $>35^{\circ} \mathrm{C}$ within about 45 minutes. A second exotherm is observed in $3 \mathrm{M}$ nitric acid at an onset temperature near $46{ }^{\circ} \mathrm{C}$ which leads to runaway reactive conditions with rapid off-gassing and a temperature increase under pseudoadiabatic conditions to $120-180{ }^{\circ} \mathrm{C}$. No reaction is observed at $25{ }^{\circ} \mathrm{C}$ between $\mathrm{RF}$ resin and $\leq 1 \mathrm{M}$ acid. Resin contact with concentrated nitric acid in the SCIX is not likely since current plans are to purchase $0.5 \mathrm{M} \mathrm{HNO}_{3}$ reagent. In contrast, WTP operations included an acid recovery step and more concentrated acids were possible within the facility.

Thermal excursions associated with resin radiolysis involve loss of feed flow through the columns and loss of column coolant flow at a time when the columns are highly loaded with cesium. Lee has conducted heat transfer analysis calculations for cesium-saturated RF columns in the current annular SCIX design (2007). Heat transfer from spherical RF resin beds under MSP operating conditions is quite good and the total heat wattage from radiolysis is relatively low. As a result, the maximum column temperature expected under worst-case bounding conditions is not high. The most bounding case analyzed is described below.

Bounding Thermal Analysis Condition Evaluated by Lee (2007)

- cesium-saturated RF beads (based on more conservative, new RF isotherm) immersed in stagnant salt solution with convective heat transfer mechanisms within the packed bed frozen (i.e. no fluid motion contributions to heat transfer, conductive heat transfer only)

- no coolant flow, jackets and center tube filled with water without temperature control

- columns immersed in stagnant air at $35^{\circ} \mathrm{C}$ rather than salt solution (which would dramatically increase heat transfer from the column) with no forced convective heat transfer at the column boundary (forced air circulation is expected in the tank headspace) and natural convection heat transfer into the tank headspace

These conditions are thought to be highly conservative for several reasons. The cesiumsaturated state only occurs near the end of a loading cycle and the column may not be run to saturation depending on the design selected. Only one of the five feeds will load the resin to the maximum saturated level with three of the five feeds loading to $<60 \%$ of the maximum level. Convective heat transfer mechanisms would certainly be operative in a stagnant column. This bounding condition is an unlikely accident scenario involving simultaneous 
maximum loading, no liquid flow, no cooling, no tank air headspace flow, and with none of the column immersed in salt solution. Under these bounding conditions the maximum temperatures within an RF column with an initial temperature of $35^{\circ} \mathrm{C}$ are predicted to be $41,47,56$, and $78{ }^{\circ} \mathrm{C}$ after $10,24,48$, and 144 hours, respectively (Lee, 2007). The maximum and minimum steady state temperatures were predicted to be 88 and $62{ }^{\circ} \mathrm{C}$. Therefore, the fully loaded RF column will never reach boiling under these bounding conditions, though the maximum temperature is sufficiently high to degrade the resin.

The WTP system description (Olson, 2002) includes a requirement for emergency column cooling in the event of a power outage. Emergency elution is also listed in the Safety Requirements but no details are provided.

\subsubsection{Vessel Pressurization and Explosion Hazards Associated with Off-gassing from Chemical Reactions and Radiolysis}

Inadvertent RF resin exposure to concentrated nitric acid leads to rapid off-gassing at slightly elevated temperatures. Dangerously high off-gassing rates $(47 \mathrm{mmol}$ gas $/ \mathrm{g}$ $\mathrm{resin} / \mathrm{min}$ ) have been observed in some cases (Fondeur, 2007). For this reason, it is recommended that all vendor supplied nitric acid eluate $(0.45$ or $0.5 \mathrm{M})$ be verified prior to use in the facility and that appropriate pressure relief systems be put in place to deal with this unlikely, but dangerous, condition.

McCabe (2004b) conducted hydrogen gas production rate calculations for the SCIX design for cesium loaded IE-911. The same methodology and assumptions reported by McCabe have been used to calculate hydrogen gas generation rates for a 15 foot tall column of RF. The maximum expected RF loading for the MSP feeds of $133.49 \mathrm{Ci}{ }^{137} \mathrm{Cs} / \mathrm{L}$ (Tank 37 at 25 ${ }^{\circ} \mathrm{C}$, Smith, 2007) was assumed. Hydrogen G-values of $0.038,0.11$, and 0.45 molecules $\mathrm{H}_{2}$ per $100 \mathrm{eV}$ were assumed for waste supernate, $0.5 \mathrm{M}$ nitric acid, and water, respectively, at $25^{\circ} \mathrm{C}$ based on data reported by Duffey (2007). The calculated hydrogen gas generation rates for cesium-saturated RF resin in supernate, acid, and water were $0.33,0.86$, and $3.72 \mathrm{~L}$ $\mathrm{H}_{2}$ /hour, respectively. The hydrogen production rate in supernates could vary significantly from the predicted value generated in this calculation.

\subsection{Downstream Impacts/Secondary Waste Streams}

Secondary waste streams from RF processing include caustic feed displacement and regenerate solutions and water wash solutions (both acidic and basic). These solutions may be disposed of by simple transfer to the MSP feed tank.

Minimal dissolution and leaching of soluble organics from RF resin is typically observed under normal conditions, though reaction with oxygen and radiolytic exposure are known to promote resin dissolution. Exposure of RF resin to a $100 \mathrm{Mrad}$ dose in waste simulant lead to moderate resin degradation as indicated by an $\sim 25 \%$ decrease in cesium loading (Duffey, 2007). No semi-volatile organic compounds were present in the liquid phase and few NMR-active organic species were observed. Unfortunately, neither total organic carbon analysis of the liquid phase or resin mass loss testing were conducted to quantify organic 
leaching levels after radiolytic exposure. Crawford reported deep coloration of simulant solutions containing granular RF resin after irradiation to $\geq 25 \mathrm{Mrad}$ (2007). No total organic carbon (TOC) analysis was conducted for the contact solutions used for irradiation. However, TOC analysis of water rinse solutions $(60 \mathrm{~mL}$ water/1.2 $\mathrm{g}$ resin) revealed that carbon levels approached $1200 \mathrm{mg} / \mathrm{L}$ after a radiation dose of $120 \mathrm{Mrad}$. The carbon contribution to the liquid phase from RF leaching during operations is expected to be small given the large volumes of solution processed per cycle. An estimate of the maximum carbon contribution to the effluent resulting from resin leaching has been calculated. If it is assumed that $25 \%$ resin dissolution into the effluent occurs in a single processing cycle (not considered likely) using a 15 foot tall column at $25^{\circ} \mathrm{C}$ with the lowest effluent volume predicted by Smith (93,000 gallons for Tank 3, old RF isotherm) the effluent should contain $210 \mathrm{mg} \mathrm{C} / \mathrm{L}$, which corresponds to $0.017 \mathrm{M}$ carbon. Based on this calculation, the carbon contribution to the decontaminated effluent does not seem significant as long as the material is diluted into the total effluent volume. Leaching of formaldehyde has also been observed in as-received RF samples (Fiskum, 2006d), but the effluent formaldehyde concentration decreased rapidly with washes and this feature is expected to have minimal impact on effluent TOC. Measures to eliminate formaldehyde from fresh resin may be needed.

Off-gasses resulting from radiolysis will also generate a secondary waste stream. At $25^{\circ} \mathrm{C}$ the total gas production during a $100 \mathrm{Mrad}$ dose for RF slurries was 9.5 and $180 \mathrm{mmol}$ gas $/ \mathrm{kg}$ resin in waste simulant and $0.5 \mathrm{M} \mathrm{HNO}_{3}$, respectively. Hydrogen and oxygen from radiolysis are the primary gaseous products at $25^{\circ} \mathrm{C}$ with small amounts of $\mathrm{CO}_{2}, \mathrm{CO}, \mathrm{CH}_{4}$, and $\mathrm{N}_{2} \mathrm{O}$ being produced as well. These gases would be produced over the resin lifetime, which varies depending on the processing conditions. Off-gassing resulting from inadvertent resin exposure to high acid concentrations (which is not likely for SCIX) would lead primarily to the production of $\mathrm{CO}_{2}, \mathrm{~N}_{2} \mathrm{O}$, and $\mathrm{NO}_{2}$ (Fonduer, 2007)

\subsection{Resin Disposal}

RF resin disposal requirements depend on the concentrations of regulated metals and organics in leachate solutions, the concentrations of trace regulated organics in spent resin, and on the level of radionuclide decontamination in spent resin. TCLP analysis has been conducted with spherical RF resin samples exposed to 16 chemical cycles during hydraulic testing using air-saturated Hanford waste simulant (Nash, 2007). Two sub-samples of the multi-cycle resin were exposed to three sequential column tests using two different levels of metal concentrations. The simulant solutions were also spiked with a cocktail containing 29 regulated organic species. The RF columns used during testing were eluted with $30 \mathrm{BV}$ of $0.5 \mathrm{M} \mathrm{HNO}_{3}$ and washed with $3 \mathrm{BV}$ of water following the conclusion of the last loading test and prior to analysis. TCLP leachate analysis tests were conducted for RCRA metals and regulated organics. Organic solids analysis was also conducted to determine the concentrations of regulated organics in the solid phase.

The spent spherical RF resin passed TCLP analysis for RCRA metals. The Hanford waste simulant used for this testing initially contained high levels of many metals. However, exposure of this simulant to a precipitation treatment prescribed for this waste type in the Hanford WTP reduced the concentrations of many of the metals to varying degrees. 
Mercury was reduced to below detectable levels. Barium was reduced to below detectable levels in one simulant and to only $9 \mathrm{mg} / \mathrm{L}$ in the other. Other metals $(\mathrm{Ag}, \mathrm{Ba}, \mathrm{Cd}, \mathrm{Cr}, \mathrm{Ni}$, $\mathrm{Pb}$, and $\mathrm{Zn}$ ) were present at moderate to high concentrations (ranging from $21 \mathrm{mg} / \mathrm{L}$ for $\mathrm{Zn}$ to $4340 \mathrm{mg} / \mathrm{L}$ for $\mathrm{Cr}$ ). Since $\mathrm{RF}$ resin is eluted with $0.5 \mathrm{M} \mathrm{HNO}_{3}$, one would expect the majority of elutable (or leachable) metals to have been removed from the resin during elution to sufficient levels to pass TCLP analysis, which involves leachate tests with dilute acetic acid solution. As indicated by eluate analysis conducted by Nash (2006), though many of these metals sorb to RF resin during loading they are removed from the resin relatively quickly during elution (typically within the first $10 \mathrm{BV}$ of eluate). Chromium, however, only slowly leaches from the resin during elution with significant amounts of chromium remaining on the resin. As a result, chromium was expected to be the greatest threat to the successful passage of spent RF resin during RCRA metal TCLP tests. Not surprisingly, chromium is the only metal present in TCLP leachates at detectable levels, but the maximum chromium leachate concentration observed of $0.233 \mathrm{mg} / \mathrm{L}$ is $<5 \%$ of the RCRA limit (5 mg/L).

Spent RF resin is also suitable for disposal with regard to leachable organics and residual solid organics. Out of a total of 29 regulated organic species spiked into the simulant solutions only methanol (which is naturally present in the environment) was observed at detectable levels (as high as $0.871 \mathrm{mg} / \mathrm{L}$ ). Organic solids analysis test results conducted on spent RF resin confirmed that most of the organic species analyzed were not present above detectable levels. Toluene, 2-butanone, and nitrobenzene were present at maximum levels of $1.040,0.2692$, and $0.456 \mathrm{mg} / \mathrm{kg}$ dry resin, respectively. 2,4,5 trichlorophenol and tetrachloroethylene were also present at detectable levels but could not be quantified. The spent RF resin passed both organic TCLP and organic solids analysis.

Spent resin from small column tests (lead/lag configuration) conducted with actual Hanford waste supernates contained measurable amounts of $\mathrm{Cs}, \mathrm{Cr}, \mathrm{Ni}, \mathrm{Tc}, \mathrm{U}, \mathrm{Cu}, \mathrm{Mo}, \mathrm{Sn}$, and $\mathrm{W}$ (three load elute cycles - 1 simulant and 2 actual, final elution with $30 \mathrm{BV}$ of $0.5 \mathrm{M} \mathrm{HNO}_{3}$, water soak for 81 days). RCRA metals $\mathrm{Ag}, \mathrm{As}, \mathrm{Ba}, \mathrm{Cd}, \mathrm{Pb}$, and $\mathrm{Se}$ concentrations were all $\leq 10 \mu \mathrm{g} / \mathrm{g} \mathrm{H}$-form resin (Fiskum, 2006a and 2006b). Mercury was not analyzed in the spent resin samples. $\mathrm{Cr}$ and $\mathrm{U}$ were present at concentrations greater than $0.1 \mathrm{mg} / \mathrm{g} \mathrm{H}$-form resin. ${ }^{137} \mathrm{Cs}$ concentrations in the spent resins were approximately 0.02 and $0.2 \mu \mathrm{g} / \mathrm{g} \mathrm{H}$-form resin for the two separate columns. It was observed that approximately $50 \%$ of the residual cesium was removed during the 81-day water soak period. The order of magnitude difference in the cesium concentrations for the two columns was attributed to cesium loading differences in the last treatment cycle. An alternative explanation not discussed in the Fiskum report is that the column containing higher residual cesium was left in a partially loaded state for 11 days between the completion of AP-101 testing and the start of AN-102 testing. Surface migration of cesium ions between sorption sites during this period may have resulted in greater penetration of cesium ions into the core of the resin polymer structure. These cesium ions would then be less accessible during elution and remain in the spent resin. Leaving RF columns in a loaded state during SCIX operations is not an anticipated event since this would increase the resin radiation dose. The spent resin samples also contained 1.0-2.4 $\mathrm{nCi} / \mathrm{g} \mathrm{H}$-form resin of transuranic species $(<3 \%$ of the threshold for 
TRU waste of $100 \mathrm{nCi} / \mathrm{g}$ ). Other radionuclides quantified on the resin samples included ${ }^{60} \mathrm{Co},{ }^{99} \mathrm{Tc},{ }^{126} \mathrm{Sn} / \mathrm{Sb},{ }^{241} \mathrm{Am},{ }^{238} \mathrm{Pu}$, and ${ }^{239 / 240} \mathrm{Pu}$.

Drying the resin prior to disposal would presumably involve initial filtration to remove freeflowing water and the passage of air or nitrogen through the resin bed to evaporate as much residual water as possible. Significant amounts (possibly near 50 weight percent) of water will likely remain in the resin at this point due to the high bead porosity. Further drying has typically been conducted under vacuum at $45-50{ }^{\circ} \mathrm{C}$ during laboratory testing. Drying the resin to constant weight under these conditions can take weeks. The fully dried material contains static energy which leads to significant handling problems associated with bead adhesion to container walls and creepage or migration of the beads up the sides of container walls. One liter resin samples were dried in preparation for resin TCLP and organics totals analysis as reported by Nash (2007). This is believed to be the largest scale of RF drying attempted during testing. 
Table 3-1. Physical Property and Performance Data for Six Production Scale Spherical RF Resin Batches ${ }^{\mathrm{a}}$

\begin{tabular}{|c|c|c|c|}
\hline Property & Mean & $\begin{array}{l}\text { Standard } \\
\text { Deviation }\end{array}$ & $\%$ RSD $^{b}$ \\
\hline \multicolumn{4}{|l|}{ Physical Properties } \\
\hline $\begin{array}{l}\text { volume-based mean particle diameter }{ }^{\mathrm{c}} \\
\qquad(\mu \mathrm{m})\end{array}$ & 454 & 18 & 4.0 \\
\hline $\begin{array}{l}\text { number-based mean particle diameter }{ }^{\mathrm{c}} \\
\qquad(\mu \mathrm{m})\end{array}$ & 401 & 5 & 1.2 \\
\hline area-based mean particle diameter ${ }^{\mathrm{c}}(\mu \mathrm{m})$ & 431 & 8 & 1.9 \\
\hline $\begin{array}{l}\text { H-form skeletal density }{ }^{\mathrm{d}} \text { ( } \mathrm{g} \mathrm{H} \text {-form } \\
\text { resin/mL H-form resin) }\end{array}$ & 1.475 & 0.006 & 0.4 \\
\hline $\begin{array}{l}\text { Na-form skeletal density }{ }^{\mathrm{d}} \text { (g Na-form } \\
\text { resin/mL Na-form resin) }\end{array}$ & 1.634 & 0.016 & 1.0 \\
\hline $\begin{array}{l}\text { H-form packed bed density }{ }^{\mathrm{e}}(\mathrm{g} \text { H-form } \\
\text { resin/mL H-form resin) }\end{array}$ & 0.381 & 0.028 & 7.2 \\
\hline $\begin{array}{l}\text { Na-form packed bed density }{ }^{\mathrm{e}}(\mathrm{g} \mathrm{H} \text {-form } \\
\text { resin } / \mathrm{mL} \mathrm{Na-form} \mathrm{resin)}\end{array}$ & 0.310 & 0.024 & 7.7 \\
\hline \multicolumn{4}{|l|}{ Chemical Performance Properties } \\
\hline contract limit Cs breakthrough $^{\mathrm{f}}(\mathrm{BV})$ & 59 & 5 & 8.4 \\
\hline $50 \%$ Cs breakthrough $^{\mathrm{f}}(\mathrm{BV})$ & 139 & 7 & 5.2 \\
\hline $\begin{array}{c}\text { Cs loading at } 50 \% \text { breakthrough }^{\mathrm{g}}(\mathrm{mg} \\
\text { Cs/g H-form resin) }\end{array}$ & 2.4 & 0.2 & 6.7 \\
\hline $\begin{array}{l}\text { post-elution residual } \mathrm{Cs}^{\mathrm{h}}(\mu \mathrm{g} \mathrm{Cs} / \mathrm{g} \mathrm{H}- \\
\text { form resin) }\end{array}$ & 0.350 & 0.035 & 10.1 \\
\hline
\end{tabular}

${ }^{\mathrm{a}}$ based on data provided in Tables 16.1 and 16.2 of Fiskum, 2006d.

${ }^{\mathrm{b}}$ percent relative standard deviation or coefficient of variation defined as the standard deviation divided by the mean and reported as percentage

${ }^{\mathrm{c}}$ particle size analysis results for $\mathrm{Na}$-form resin

${ }^{d}$ measured by pycnometer and representative of the RF material density excluding particle pore volume

${ }^{\mathrm{e}}$ measured in $2 \mathrm{~cm}$. ID columns

${ }^{\mathrm{f}}$ breakthrough observed from a single column with Hanford AP-101 (high $\mathrm{K}^{+}$) simulant, although the RPP contract limit is based on cesium breakthrough from the lag column

${ }^{\mathrm{g}}$ loading observed with Hanford AP-101 (high $\mathrm{K}^{+}$) simulant, expected to approach but be less than RF cesium loading saturation in this feed

${ }^{\mathrm{h}}$ measured after column elution with $\sim 15 \mathrm{BV}$ of $0.5 \mathrm{M} \mathrm{HNO}_{3}$ following loading experiments with Hanford AP-101 (high $\mathrm{K}^{+}$) simulant 
Table 3-2. Estimations of RF Resin Radiation Dose and Lifetime for Tank 37 Processing.

\begin{tabular}{|c|c|c|c|c|c|c|c|c|}
\hline $\begin{array}{l}\text { Isotherm } \\
\text { (Case) }\end{array}$ & $\begin{array}{c}\text { Column } \\
\text { Configuration }\end{array}$ & Process Limit & $\begin{array}{l}\text { Flow } \\
\text { Rate } \\
\text { (gpm) }\end{array}$ & $\begin{array}{c}\text { Column } \\
\text { Length } \\
\text { (ft) }\end{array}$ & $\begin{array}{c}\text { Cumulative } \\
\text { Dose A/B } \\
\text { (Mrad) }^{\text {b }}\end{array}$ & $\begin{array}{c}\text { Cumulative } \\
\text { Volume }^{c} \\
\text { (1000 gal.) }\end{array}$ & $\begin{array}{c}\text { Total } \\
\text { Loading } \\
\text { Duration } \\
\text { (Days) }\end{array}$ & $\begin{array}{l}\text { Cycles } \\
\text { before }^{\text {Spent }} \\
\text { Spent }^{c}\end{array}$ \\
\hline new (1) & lead/lag & $\begin{array}{c}\text { lag effluent } \\
\text { average } 45 \mathrm{nCi} / \mathrm{g}\end{array}$ & 5 & 15 & $232 / 78^{d}$ & 510 & 71 & 1 \\
\hline new (1) & lead/lag & $\begin{array}{c}\text { lag effluent } \\
\text { average } 45 \mathrm{nCi} / \mathrm{g}\end{array}$ & 10 & 15 & $135 / 96$ & 755 & 52 & 2 \\
\hline new (1) & lead/lag & $\begin{array}{c}\text { lag effluent } \\
\text { average } 45 \mathrm{nCi} / \mathrm{g}\end{array}$ & 20 & 15 & $135 / 99$ & 1506 & 52 & 5 \\
\hline old (1) & lead/lag & $\begin{array}{c}\text { lag effluent } \\
\text { average } 45 \mathrm{nCi} / \mathrm{g}\end{array}$ & 5 & 15 & $126 / 57$ & 486 & 67 & 2 \\
\hline old (1) & lead/lag & $\begin{array}{c}\text { lag effluent } \\
\text { average } 45 \mathrm{nCi} / \mathrm{g}\end{array}$ & 10 & 15 & $133 / 116$ & 1137 & 79 & 6 \\
\hline old (1) & lead/lag & $\begin{array}{c}\text { lag effluent } \\
\text { average } 45 \mathrm{nCi} / \mathrm{g}\end{array}$ & 20 & 15 & $118 / 111$ & 2094 & 73 & 12 \\
\hline old (1) & lead/lag & $\begin{array}{c}\text { lag effluent } \\
\text { average } 45 \mathrm{nCi} / \mathrm{g}\end{array}$ & 10 & 10 & $111 / 100$ & 966 & 67 & 8 \\
\hline old (1) & lead/lag & $\begin{array}{c}\text { lag effluent } \\
\text { average } 45 \mathrm{nCi} / \mathrm{g}\end{array}$ & 10 & 25 & $103 / 72$ & 802 & 56 & 2 \\
\hline old $(2)^{\mathrm{e}}$ & lead/lag & $\begin{array}{c}\text { lead effluent } \\
\text { instantaneous } \\
50 \% \mathrm{C} / \mathrm{C}_{\mathrm{o}}\end{array}$ & 10 & 15 & $103 / 103$ & 1860 & 129 & 12 \\
\hline old (3) & single & $\begin{array}{c}\text { effluent average } \\
45 \mathrm{nCi} / \mathrm{g}\end{array}$ & 5 & 15 & 102 & 590 & 82 & 4 \\
\hline old (3) & single & $\begin{array}{l}\text { effluent average } \\
45 \mathrm{nCi} / \mathrm{g}\end{array}$ & 10 & 15 & 105 & 1407 & 98 & 11 \\
\hline old (3) & single & $\begin{array}{l}\text { effluent average } \\
45 \mathrm{nCi} / \mathrm{g}\end{array}$ & 20 & 15 & 101 & 3431 & 119 & 34 \\
\hline old (3) & single & $\begin{array}{c}\text { effluent average } \\
45 \mathrm{nCi} / \mathrm{g}\end{array}$ & 10 & 10 & 103 & 1571 & 109 & 21 \\
\hline old (3) & single & $\begin{array}{l}\text { effluent average } \\
45 \mathrm{nCi} / \mathrm{g}\end{array}$ & 10 & 25 & 101 & 1198 & 83 & 5 \\
\hline
\end{tabular}

${ }^{a}$ Lead/lag configuration assumes carousel operation with column rotation between lead and lag positions in successive cycles.

$\mathrm{b} \mathrm{A}$ and $\mathrm{B}$ represent the columns in the lead and lag positions in cycle 1. One additional cycle was conducted with the lead column in the lag position after the 100 Mrad limit was reached for the lead column.

${ }^{\mathrm{c}}$ Note that Cases 1 and 2 will generally involve resin replacement in both the lead and lag columns once the $100 \mathrm{Mrad}$ limit is reached for the lead. Normalization of the cumulative liquid volume processed to the amount of resin (supernate volume/resin volume) decreases the effective volume treated for Cases 1 and 2 relative to Case 3 by a factor of 2 . In cases where lag column replacement is needed, one additional elution cycle must be added to the values in the table for lag column elution.

${ }^{\mathrm{d}}$ For this case the lead column dose rate was considered too high to conduct a second cycle with the lead column in the lag position.

e Lag column loading was assumed negligible in this operational mode and was not considered in the calculations. 
Table 3-3. Estimations of RF Resin Radiation Dose and Lifetime for Tank 3 Processing.

\begin{tabular}{|c|c|c|c|c|c|c|c|c|}
\hline $\begin{array}{l}\text { Isotherm } \\
\text { (Case) }\end{array}$ & $\begin{array}{c}\text { Column } \\
\text { Configuration }^{\mathrm{a}}\end{array}$ & Process Limit & $\begin{array}{l}\text { Flow } \\
\text { Rate } \\
\text { (gpm) }\end{array}$ & $\begin{array}{l}\text { Column } \\
\text { Length } \\
\text { (ft) }\end{array}$ & $\begin{array}{c}\text { Cumulative } \\
\text { Dose A/B } \\
\text { (Mrad) }^{\mathbf{b}}\end{array}$ & $\begin{array}{c}\text { Cumulative } \\
\text { Volume }^{c} \\
\text { (1000 gal.) }\end{array}$ & $\begin{array}{c}\text { Total } \\
\text { Loading } \\
\text { Duration } \\
\text { (Days) }\end{array}$ & $\begin{array}{l}\text { Cycles } \\
\text { before } \\
\text { Spent }^{c}\end{array}$ \\
\hline new (1) & lead/lag & $\begin{array}{c}\text { lag effluent } \\
\text { average } 45 \mathrm{nCi} / \mathrm{g}\end{array}$ & 5 & 15 & $123 / 53$ & 610 & 85 & 2 \\
\hline new (1) & lead/lag & $\begin{array}{c}\text { lag effluent } \\
\text { average } 45 \mathrm{nCi} / \mathrm{g}\end{array}$ & 10 & 15 & $132 / 116$ & 1425 & 99 & 6 \\
\hline new (1) & lead/lag & $\begin{array}{c}\text { lag effluent } \\
\text { average } 45 \mathrm{nCi} / \mathrm{g}\end{array}$ & 20 & 15 & $114 / 98$ & 2430 & 84 & 11 \\
\hline old (1) & lead/lag & $\begin{array}{c}\text { lag effluent } \\
\text { average } 45 \mathrm{nCi} / \mathrm{g}\end{array}$ & 5 & 15 & $111 / 104$ & 1284 & 178 & 12 \\
\hline old (1) & lead/lag & $\begin{array}{c}\text { lag effluent } \\
\text { average } 45 \mathrm{nCi} / \mathrm{g}\end{array}$ & 10 & 15 & $106 / 103$ & 2435 & 169 & 24 \\
\hline old (1) & lead/lag & $\begin{array}{c}\text { lag effluent } \\
\text { average } 45 \mathrm{nCi} / \mathrm{g}\end{array}$ & 20 & 15 & $103 / 102$ & 4625 & 161 & 48 \\
\hline old (1) & lead/lag & $\begin{array}{c}\text { lag effluent } \\
\text { average } 45 \mathrm{nCi} / \mathrm{g}\end{array}$ & 10 & 10 & $104 / 102$ & 2363 & 164 & 36 \\
\hline old (1) & lead/lag & $\begin{array}{c}\text { lag effluent } \\
\text { average } 45 \mathrm{nCi} / \mathrm{g}\end{array}$ & 10 & 25 & $107 / 101$ & 2460 & 171 & 14 \\
\hline old (2) ${ }^{\mathrm{d}}$ & lead/lag & $\begin{array}{c}\text { lead effluent } \\
\text { instantaneous } \\
50 \% \mathrm{C} / \mathrm{C}_{\mathrm{o}}\end{array}$ & 10 & 15 & $101 / 101$ & 5130 & 356 & 54 \\
\hline old (3) & single & $\begin{array}{c}\text { effluent average } \\
45 \mathrm{nCi} / \mathrm{g}\end{array}$ & 5 & 15 & 100 & 1485 & 206 & 18 \\
\hline old (3) & single & $\begin{array}{c}\text { effluent average } \\
45 \mathrm{nCi} / \mathrm{g}\end{array}$ & 10 & 15 & 100 & 3393 & 236 & 47 \\
\hline old (3) & single & $\begin{array}{l}\text { effluent average } \\
45 \mathrm{nCi} / \mathrm{g}\end{array}$ & 20 & 15 & 100 & 8380 & 291 & 143 \\
\hline old (3) & single & $\begin{array}{l}\text { effluent average } \\
45 \mathrm{nCi} / \mathrm{g}\end{array}$ & 10 & 10 & 101 & 3818 & 265 & 89 \\
\hline old (3) & single & $\begin{array}{l}\text { effluent average } \\
45 \mathrm{nCi} / \mathrm{g}\end{array}$ & 10 & 25 & 101 & 3080 & 214 & 23 \\
\hline
\end{tabular}

${ }^{a}$ Lead/lag configuration assumes carousel operation with column rotation between lead and lag positions in successive cycles.

${ }^{\mathrm{b}} \mathrm{A}$ and $\mathrm{B}$ represent the columns in the lead and lag positions in cycle 1 . One additional cycle was conducted with the lead column in the lag position after the 100 Mrad limit was reached for the lead column.

${ }^{\mathrm{c}}$ Note that Cases 1 and 2 will generally involve resin replacement in both the lead and lag columns once the $100 \mathrm{Mrad}$ limit is reached for the lead. Normalization of the cumulative liquid volume processed to the amount of resin (supernate volume/resin volume) decreases the effective volume treated for Cases 1 and 2 relative to Case 3 by a factor of 2 . In cases where lag column replacement is needed, one additional elution cycle must be added to the values in the table for lag column elution.

${ }^{\mathrm{d}}$ Lag column loading was assumed negligible in this operational mode and was not considered in the calculations. 
Table 3-4. Fractional loading and time-averaged dose corrections used for the dose calculations for Tanks 37 and 3.

\begin{tabular}{|c|c|c|c|c|c|c|}
\hline $\begin{array}{l}\text { Isotherm } \\
\text { (Case) }\end{array}$ & $\begin{array}{c}\text { Column } \\
\text { Configuration }\end{array}$ & Process Limit & $\begin{array}{l}\text { Flow } \\
\text { Rate } \\
\text { (gpm) }\end{array}$ & $\begin{array}{l}\text { Column } \\
\text { Length } \\
\text { (ft) }\end{array}$ & $\begin{array}{c}\text { Fractional } \\
\text { Loading } \\
\text { Correction }^{\mathrm{a}} \\
37 / 3(\%)\end{array}$ & $\begin{array}{c}\text { Time- } \\
\text { averaged } \\
\text { Correction } \\
\text { lead/lag (\%) }\end{array}$ \\
\hline new (1) & lead/lag & $\begin{array}{c}\text { lag effluent } \\
\text { average } 45 \mathrm{nCi} / \mathrm{g}\end{array}$ & 5 & 15 & $95 / 95$ & $75 / 25$ \\
\hline new (1) & lead/lag & $\begin{array}{c}\text { lag effluent } \\
\text { average } 45 \mathrm{nCi} / \mathrm{g}\end{array}$ & 10 & 15 & $90 / 85$ & $75 / 25$ \\
\hline new (1) & lead/lag & $\begin{array}{c}\text { lag effluent } \\
\text { average } 45 \mathrm{nCi} / \mathrm{g}\end{array}$ & 20 & 15 & $80 / 70$ & $75 / 25$ \\
\hline old (1) & lead/lag & $\begin{array}{c}\text { lag effluent } \\
\text { average } 45 \mathrm{nCi} / \mathrm{g}\end{array}$ & 5 & 15 & $75.83 / 81.07$ & $75 / 25$ \\
\hline old (1) & lead/lag & $\begin{array}{c}\text { lag effluent } \\
\text { average } 45 \mathrm{nCi} / \mathrm{g}\end{array}$ & 10 & 15 & $65.76 / 70.95$ & $75 / 25$ \\
\hline old (1) & lead/lag & $\begin{array}{c}\text { lag effluent } \\
\text { average } 45 \mathrm{nCi} / \mathrm{g}\end{array}$ & 20 & 15 & $51.88 / 57.59$ & $75 / 25$ \\
\hline old (1) & lead/lag & $\begin{array}{c}\text { lag effluent } \\
\text { average } 45 \mathrm{nCi} / \mathrm{g}\end{array}$ & 10 & 10 & $57.69 / 63.24$ & $75 / 25$ \\
\hline old (1) & lead/lag & $\begin{array}{c}\text { lag effluent } \\
\text { average } 45 \mathrm{nCi} / \mathrm{g}\end{array}$ & 10 & 25 & $73.91 / 78.95$ & $75 / 25$ \\
\hline old (2) & lead/lag & $\begin{array}{c}\text { lead effluent } \\
\text { instantaneous } \\
50 \% \mathrm{C} / \mathrm{C}_{\mathrm{o}}\end{array}$ & 10 & 15 & $97.5 / 95$ & $50 / 0$ \\
\hline old (3) & single & $\begin{array}{c}\text { effluent average } \\
45 \mathrm{nCi} / \mathrm{g}\end{array}$ & 5 & 15 & $75.83 / 81.07$ & 50/-- \\
\hline old (3) & single & $\begin{array}{c}\text { effluent average } \\
45 \mathrm{nCi} / \mathrm{g}\end{array}$ & 10 & 15 & $65.76 / 70.95$ & $50 /--$ \\
\hline old (3) & single & $\begin{array}{l}\text { effluent average } \\
45 \mathrm{nCi} / \mathrm{g}\end{array}$ & 20 & 15 & $51.88 / 57.59$ & $50 /--$ \\
\hline old (3) & single & $\begin{array}{l}\text { effluent average } \\
45 \mathrm{nCi} / \mathrm{g}\end{array}$ & 10 & 10 & $57.69 / 63.24$ & $50 /--$ \\
\hline old (3) & single & $\begin{array}{l}\text { effluent average } \\
45 \mathrm{nCi} / \mathrm{g}\end{array}$ & 10 & 25 & $73.91 / 78.95$ & 50/-- \\
\hline
\end{tabular}

${ }^{\text {a }}$ Fractional loading corrections determined from the column performance model (Smith, 2007) were applied to the maximum dose associated with cesium-saturated resin for partially loaded columns. Fractional loading corrections were applied to the lag column for Case 1 and the lead column for Cases 2 and 3. The lead column for Case 1 was assumed to be saturated and lag column loading for Case 2 was considered negligible.

${ }^{\mathrm{b}}$ Time-averaged corrections were applied to account for the fact that cesium gradually loads onto the resin during processing and the radiation field gradually builds. 


\subsection{IONSIV IE-911 Engineered Crystalline Silicotitanate}

Crystalline silicotitanates were originally developed at Sandia National Laboratories and Texas A\&M University and patents have been issued for their preparation, with niobiumdoped materials exhibiting particular utility for removal of cesium from radioactive waste solutions (Anthony, 2002). Engineered forms of these materials have been prepared, presumably in a manner similar to patented procedures (Sherman, 1999). IONSIV IE-911 is a granular form of CST commercially available through UOP LLC. According to the MSDS (2002) for this material it is composed of 70-90 wt. \% crystalline silicotitanate sorbent with the balance of the weight composed of an inorganic zirconium oxide binder and water. The MSDS indicates that the active CST ion exchange material is composed of sodium, silicon, titanium, and niobium oxides. The empirical formula of niobium-doped CST is reported as $\mathrm{HNa}_{2} \mathrm{Ti}_{3} \mathrm{NbSi}_{2} \mathrm{O}_{14} \cdot \mathrm{H}_{2} \mathrm{O}$ (Cherry, 2004).

\subsection{CST Manufacturability - Production scale and Reproducibility}

Little information is reported regarding IE-911 production scale. Approximately 70 gallons of material was utilized for the performance demonstration at ORNL, though the actual production lot size used to generate this material is unknown (Walker, 1998).

\subsection{CST Physical Properties}

Engineered crystalline silicotitanate is composed of granular white beads many of which are generally spherical in shape. The degree of sphericity is not high, especially as compared to RF resin beads.

\subsubsection{Initial Physical Properties}

IONSIV IE-911 is typically provided as dry beads previously sieved to give a mesh size range of 30-60 $(250-595 \mu \mathrm{m})$. The beads can be readily wetted by soaking in water. Particle size analysis results of IE-911 batches were discussed by Hamm (2000). Analysis of two samples of IE-911 by different methods (Lasentec chord length analysis and Microtrac laser technologies) indicated average particle diameters of 326 and $344 \mu \mathrm{m}$. These values are believed to be most representative of the engineered material. Only mesh size ranges were reported for the large-scale production batch (Walker, 1998). The asreceived material typically contains fines which can be removed by elutriation (upflow washing) with water. Fine particles (diameters $<70 \mu \mathrm{m}$ ) were observed in the chord length distribution reported by Hamm, but were excluded in the calculation of the average diameter. The fine particles are likely formed as a result of attrition of larger particles during movement and handling of the CST material. A small increase in fines was observed for IE-911 beads used for sluicing and hydraulic tests at ORNL with $30 \mathrm{~L}$ (7.9 gallons) columns. During sluicing operations with these columns a problem was encountered with a valve failure as a result of CST fines pluggage. Successful CST fines removal was achieved in the $30 \mathrm{~L}$ columns (12 in. ID) using $15.8 \mathrm{~L} / \mathrm{min}$ of water for backwashing $(32 \mathrm{BV} / \mathrm{hr}, 22$ $\mathrm{cm} / \mathrm{min}$ ). This flow rate lead to a $25 \%$ increase in bed volume during upflow with initial 
expansion observed at a flow of 2-3 L/min. The sorbent was backwashed for 6.5 hours with a total of $6,000 \mathrm{~L}(200 \mathrm{BV})$ of water. It should be pointed out that during real waste testing with SRS Tank 44F supernate low levels of CST fines in the column effluent were found to be the major contributor to the cesium dose, although the cesium levels in the samples were quite low even before filtration for fines removal (Walker, 1999).

Packed beds of IE-911 are not highly compressible and do not shrink and swell during processing due to the rigid nature of the inorganic sorbent and binder materials.

\subsubsection{Physical Property Changes Associated with Chemical Reactivity and Radiation}

IE-911 beads have been observed to clump after exposure to simple caustic solutions and simulants (Walker, 1999; Taylor, 1999a). It was believed that the clumping was associated to some degree with leaching of materials from the CST and the formation of aluminosilicate bridges between individual CST particles. Analysis of resin samples taken from various portions of packed columns during testing confirmed that the clumping was associated with the presence of aluminum in the media and that aluminum (indicative of cancrinite-like aluminosilicate) deposition occurred at the top of the column first (Taylor, 2001). Leaching tests with 0.5-3 M NaOH confirmed that $\mathrm{Ti}, \mathrm{Zr}$, and $\mathrm{Nb}$ leach from IE-911 during caustic washing (Wilmarth, 2000a; Su, 2001). $3 \mathrm{M} \mathrm{NaOH}$ was found to be most effective at removing these materials, though these elements were difficult to wash away completely. It was believed that the leaching components might promote precipitation, clumping, and column fouling. More recent evaluations using improved IE-911 with bounding simulants revealed that only weak clumping occurs over several weeks with minimal impacts expected for real waste processing (Taylor, 2003). For these reasons, it is recommended that if CST is selected for SCIX applications, the caustic-washed (cw) version of the material known as IONSIV IE-911-cw should be purchased.

Elevated temperature $\left(55-80^{\circ} \mathrm{C}\right)$ exposure of IE-911 to an average SRS simulant was also shown to lead to the growth of aluminosilicate solids on the bead surface with increasing amounts of deposition being observed as the temperature was increased (Wilmarth, 2000b; $\mathrm{Su}, 2001)$. A solid layer of aluminosilicate material was observed on the bead surface after $80{ }^{\circ} \mathrm{C}$ exposure. The simulant used for these tests was shown to be unstable to the formation of aluminosilicate solids at elevated temperature. However, IE-911 clearly shows a propensity toward aluminosilicate precipitation and surface fouling depending upon the feed composition. This tendency could impact cesium removal performance, column hydraulic performance, and spent resin removal and fluidization properties of CST columns, particularly when exposed to solutions which are unstable toward silicon precipitation.

A possible disposition pathway for spent (loaded) IE-911 is dumping the material into the SCIX feed tank after grinding. If clumping, agglomeration, and binding of ground CST particles on the waste tank floor occurs it may be difficult to remove this material from the tank. Further studies are needed to evaluate this possibility if this processing option is selected. Previous studies have examined the impact of transferring ground CST into a sludge tank where the ion exchange media is distributed into the sludge mass (Wilmarth, 2004). The ground CST/sludge mixtures had similar rheology to sludge alone and it is 
believed that this is a viable disposition path for this material, though thorough mixing of the slurries is likely necessary.

No significant impacts on CST physical properties resulting from radiolytic exposure have been reported. No physical property changes were observed for IE-911 samples loaded with cesium to as high as $7 \mathrm{Ci}{ }^{137} \mathrm{Cs} / \mathrm{L}$ during ORNL testing (Walker, 1998), although long-term effects were not evaluated. Evaluations of IE-911 stability and cesium removal performance in the presence of very high radiation fields (250-300 Mrad/day) were also conducted by Mattus (2001). No mention of significant physical property changes were reported.

\subsubsection{Handling (Fluidization, Slurry Transport, Settling, Abrasion, and Grinding)}

Sluicing of IE-911/water slurries has been studied on the 5-10 gallon scale during the ORNL performance demonstration and tall column testing (Welch, 2000; Walker, 1998). 50 volume percent IE-911 in water was successfully and easily transferred into the columns using 20 PSI head pressure in the sluicing vessel. IE-911/water slurries were sluiced out of the columns through 1.0-1.5 inch pipes using 20-40 psi head pressure. In each test three sluicing operations were required to remove all of the sorbent. Taylor (1999) reported that 24 wt \% slurries of IE-911 can be transported at a fluid velocity of $4.3 \mathrm{~cm} / \mathrm{sec}$ with no visible settling, while $5 \mathrm{wt} \%$ slurries will stay suspended at $3.8 \mathrm{ft} / \mathrm{sec}$. For cases where precipitation and reactivity result in fused columns or for those processing scenarios where CST might be left standing in caustic solution for extended time periods (in the bottom of the MSP feed tank, for instance) fluidization and transport of IE-911 beads may be more difficult. Centrifugal pumps were found to rapidly breakdown IE-911 particles to $<150 \mu \mathrm{m}$ with most particles below $1 \mu \mathrm{m}$. Progressive cavity (Moyno) pumps cause less particle attrition. IE-911 particles settle rapidly though no direct measurements of settling velocities are reported. IE-911/water slurries show low abrasivity towards 304L stainless steel and moderate abrasivity toward A106 mild steel. Mixing and distribution of IE-911 in sludge solids appears to alleviate these issues. IE-911/sludge mixtures show minimal tendencies to cake or form hard layers (Taylor, 1999b).

A process has been developed for grinding spent IE-911 particles in preparation for vitrification in the Defense Waste Processing Facility (Bickford, 2005). This operation is expected to occur in a grinder located in a tank top riser through remote operations with no contact maintenance due to the high radiation field resulting from the loaded sorbent. Grinding is needed to make the material more compatible with sludge processing. The grinding is expected to be performed in at least two batches ( 140 gallons each) depending upon the size of the columns. Grinder time per batch is expected to be less than 24 hours. The maximum IE-911 particle size must be reduced to $98 \%$ less than $177 \mu \mathrm{m}$, with a preference for most of the solids to be less than $37 \mu \mathrm{m}$. It is critical that the grinder does not plug during operations. The current design includes utilization of an oversized sand pump to fluidize and upwardly inject IE-911 solids into the grinder. This design avoids problems with pluggage experienced in downflow operations and allows utilization of $30-50 \mathrm{wt} \%$ slurries. Due to the CST bead porosities, $30 \mathrm{wt} \%$ slurries contain approximately $50 \%$ free flowing liquid, while $50 \mathrm{wt} \%$ slurries have sufficient water to just cover the settled solids. 
The grinder includes external and internal coolant loops and piping for material transfer. Grinding tests with zeolite (an inexpensive surrogate for CST) and IE-911 indicated that only modest wear of the grinder teeth occurs when using relatively soft $316 \mathrm{~L}$ head materials. The production grinder is expected to utilize hardened steel blades. The sand pump was found to be very effective at fluidizing wide ranges of solids loadings and low volumes. No pluggage was observed in any test using the current design with upflow feed into the grinder. Water flushing of the grinder head between cycles is expected to be necessary to avoid clogging the head.

Mixing requirements for $10 \mathrm{wt} \%$ water slurries of size-reduced IE-911 (ground to $<177 \mu \mathrm{m}$ maximum diameter) and ground material trimmed with $10 \mathrm{wt} \%$ of particles greater than $177 \mu \mathrm{m}$ were examined by Baich (2000). Mixing and 95\% homogenization of the sizereduced (untrimmed) material was accomplished with a 5 inch diameter top marine impellor at $\geq 500 \mathrm{rpm}$ and with an 8 inch diameter blade at $250 \mathrm{rpm}$. Resuspension of this material after 6 days was readily achievable. It was not possible, however, to attain 95\% homogenization for the material trimmed with larger particles even with the 8 inch blade at $700 \mathrm{rpm}$. Clearly, nearly complete size reduction to particles $<177 \mu \mathrm{m}$ results in improved slurry transport properties. The addition of size-reduced IE-911 to sludge simulants had little impact on sludge rheology even over 4 months of storage (Wilmarth, 2004). As mentioned above, the physical properties of size-reduced IE-911 particles during extended storage under caustic conditions without distribution and mixing with tank sludge solids are unknown.

\subsection{CST Chemical Properties}

\subsubsection{Sorption/Desorption Behavior}

CST is highly selective for the removal of cesium ions in the presence of relatively high sodium and potassium ion concentrations. The crystalline structure of the material is composed of $\mathrm{TiO}_{4}$ and $\mathrm{SiO}_{4}$ units arranged in such a way that $8 \AA$ tunnels exist along one crystallographic axis (Cherry, 2004). The structure includes both exchangeable and nonexchangeable sodium ions, with the exchangeable ions being located in the tunnels along with labile water molecules. The high selectivity for cesium ions over other cations arises from both the chemistry and geometry of the tunnels. Primary competitors with cesium ions for sorption sites on CST under typical tank waste processing conditions include $\mathrm{Na}^{+}, \mathrm{K}^{+}$, $\mathrm{Rb}^{+}$, and $\mathrm{SrOH}^{+}$. Besides these primary competitors, numerous other ions are known to compete for sorption sites on CST. Modeling conducted at SRNL for Hanford waste supernates using the ZAM isotherm model developed at Texas A\&M included 20 different competing cationic species for CST sorption sites (Hamm, 2002).

In contrast to RF resin, the cesium capacity of CST decreases with increasing $\mathrm{pH}$ (see Figure 2-2 of Hamm, 2002). Significantly higher cesium loading is observed under acidic conditions with the effective cesium capacity for CST decreasing by over an order of magnitude when the $\mathrm{pH}$ is increased from 7 to 10 . The $\mathrm{pH}$ effect and certain step changes observed in cesium loading isotherms with CST are consistent with a conceptual ion sorption model involving three interactive, neighboring surface sites (Hamm, 2002 and 
Zheng, 1996 and 1997). Steric interactions between the sites under high $\mathrm{pH}$ conditions where all sites are initially occupied by sodium ions effectively reduces the cesium capacity. At lower $\mathrm{pH}$ conditions, where one or more of the sites is occupied by hydrogen ions with a smaller radius of hydration, cesium ion exchange is sterically favored resulting in higher capacities. At very low $\mathrm{pH}(1-2)$ the cesium loading begins to decrease again due to the high solution hydrogen ion concentration. The cesium loading at $\mathrm{pH} 1$ is still higher than the equilibrium loading observed under basic conditions. These characteristics are consistent with the fact that cesium does not elute from CST during exposure to moderate acid concentrations.

CST is quite selective for cesium removal in the presence of high concentrations of sodium and potassium ions and lower concentrations of various other metals. Rubidium is a direct competitor with cesium because (it is believed) these two ions cannot coexist in the aforementioned surface "supersite" (Zheng, 1997). Alkaline earth (Group 2) metals compete strongly with cesium under groundwater conditions, but typically are not present at sufficient concentrations in caustic waste supernates to greatly impact cesium loading. The group 2 species $\mathrm{SrOH}^{+}$, which generally exists as a fractional component of the total strontium in caustic solution, can significantly impact cesium sorption in waste supernates with relatively high strontium concentrations in the absence of complexing anions. Although strontium sorption does not greatly impact cesium loading in caustic tank waste supernates, CST is still quite effective at removing strontium under these conditions (Anthony, 1994). CST has been shown to have some affinity for other divalent and some trivalent metals including cobalt, zirconium, manganese, americium, cerium, and iron (Marsh, 1994). During ORNL testing with actual Melton Valley Storage Tank supernate, IE-911 was observed to remove barium, lead, zinc, uranium, and plutonium (Walker, 1999). Spent CST samples analyzed after contact with simulated SRS waste solutions revealed that measurable levels of numerous metals are retained within the spent material including barium, chromium, mercury, lead, plutonium, and uranium (Wilmarth, 2004). Spent resin analysis will be discussed in greater detail in Section 4.7.

The total cesium capacity for CST is 0.57-0.58 mmol/g CST (Zheng, 1996; Hamm, 2002). At $25{ }^{\circ} \mathrm{C}$, cesium equilibrium loading predictions were calculated for the five MSP feeds (SRS Tanks 1-3, 37, and 41) using the ZAM isotherm model (Smith, 2007). Cesium

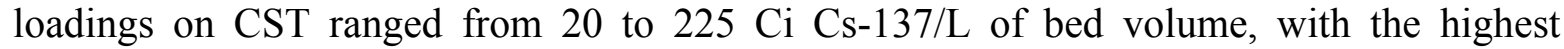
equilibrium loading being observed for Tank 37 supernate. Cesium equilibrium loading tests were conducted using six actual SRS waste supernates (4.4-5.6 $\mathrm{M} \mathrm{Na}^{+}$) and results were compared to ZAM model predictions (Beasley, 2001). The waste samples were collected from five SRS tanks including both the $\mathrm{F}$ and $\mathrm{H}$ tank farms. In general, ZAM adequately predicted cesium loading performance with actual results agreeing to within 33\% of the model predictions in all cases. Measured cesium loadings were lower than predictions for low initial cesium concentrations in some cases.

Higher temperatures result in lower equilibrium cesium loadings on CST. Predicted maximum cesium loadings for each of the five MSP feed solutions at 25 and $45^{\circ} \mathrm{C}$ revealed an average decrease in cesium loading of $26 \%$ at the higher temperature. Temperature increases resulting from process upset conditions such as loss of flow or cooling promote 
reversible cesium desorption. At temperatures as low as $50{ }^{\circ} \mathrm{C}$ irreversible cesium desorption has been observed in some cases. The data indicates that the MSP upper temperature limit for CST should be between 50 and $80{ }^{\circ} \mathrm{C}$. For the highest expected MSP cesium loading at the lowest MSP flow rate $(5 \mathrm{gpm})$ the predicted solution temperature increase resulting from radiolysis during transport through a 25 foot column (largest expected MSP column height) using the current baseline design configuration but without active cooling is only $2.75^{\circ} \mathrm{C}$ (Lee, 2007). In stagnant salt solution, but with design basis cooling, the maximum steady-state temperature expected in a fully-loaded RF column is $62.7^{\circ} \mathrm{C}$. These results indicate that maintaining the maximum temperature indefinitely below the temperature range where performance uncertainties exist $\left(50-80{ }^{\circ} \mathrm{C}\right)$ is not possible. In the bounding accident scenario involving no liquid flow, no active cooling, and a fully loaded column, the temperature is expected to reach $50{ }^{\circ} \mathrm{C}$ for the $\mathrm{CST} / \mathrm{salt}$ solution slurry within 18 hours, as discussed in Section 4.5.3.

Prior to disposal in a vitrified waste form IE-911 beads must be ground for size reduction. Minor desorption of cesium for ground IE-911 has been observed (Wilmarth, 2004). Ground and loaded CST equilibrated with water and cesium-free supernate leached cesium to concentrations of approximately 0.25 and $1.25 \mathrm{mg} / \mathrm{L}$, respectively. The presence of cesium in the cover liquid (a likely MSP processing scenario) would presumably have resulted in less cesium desorption from the ground material. A more likely cause for significant cesium desorption from ground material dumped into a waste tank would be from a temperature increase in the tank relative to the column loading temperature.

\subsubsection{Chemical Reactivity and Impacts on Cesium Removal Performance}

Aluminosilicate precipitation from waste supernate solutions leading to fouling of IE-911 is known. Some batches of IE-911 have also been shown to leach excess reagents ( $\mathrm{Si}, \mathrm{Ti}, \mathrm{Nb}$, Wilmarth, 2007, Taylor, 2001) from the media synthesis and this is believed to cause (or enhance) precipitation and fouling. Later improved batches showed lower propensities toward fouling and less tendency to leach excess starting reagents (Taylor, 2001 and 2003). The cesium capacity of IE-911 (improved recipe) beads taken from the top portions of packed beds after column testing at room temperature were $60 \%$ lower than was observed initially. Careful inspection of the data reveals that the simulant used for this testing was unstable toward aluminosilicate precipitation. Deposition of aluminum species on IE-911 during high temperature storage in waste simulant was also believed to correlate to a decrease in cesium capacity in some cases.

Irreversible cesium desorption from IE-911 has also been observed after media exposure to temperatures as low as $50{ }^{\circ} \mathrm{C}$ for 60 days and $55^{\circ} \mathrm{C}$ for 14 days in waste simulant (Taylor, 1999b; Su, 2001). Other studies indicated only minor decreases (1-2\%) in cesium loading resulting from $55^{\circ} \mathrm{C}$ exposure for 14 days (Wilmarth, 2000b). Initial studies conducted at $80{ }^{\circ} \mathrm{C}$ indicated that these conditions lead to as much as a $72 \%$ decrease in cesium capacity (Taylor, 1999b). Storage in waste simulant for 6 months at $80{ }^{\circ} \mathrm{C}$ lead to a $15 \%$ decrease in cesium capacity (after correction for aluminosilicate mass) in other studies. Inconsistent results have been observed for elevated temperature testing with completely reversible sorption and resorption being observed in one case even after 60 days of exposure to 55 and 
$80{ }^{\circ} \mathrm{C}$. Many of the tests involved simulant solutions which were shown to promote aluminosilicate formation on the bead surface, though it was believed that the pore size of the cancrinite solids formed was sufficiently large that cesium sorption should not be inhibited (Su, 2001). It is unclear whether the reduced cesium capacities observed after IE911 exposure to supernate at elevated temperatures are the results of resin fouling or if the reduction is associated with chemical or structural changes in the CST particles. Regardless, the data indicates that the MSP upper temperature limit for CST should be between 50 and $80^{\circ} \mathrm{C}$. We recommend a temperature limit for normal SCIX operations using IE-911 of $65{ }^{\circ} \mathrm{C}$ (the same limit recommended for spherical RF), until additional testing can be conducted to determine a more precise value.

\subsubsection{Radiolytic Effects on Cesium Removal Performance}

No chemical performance changes were reported for IE-911 columns loaded with cesium to as high as $7 \mathrm{Ci}{ }^{137} \mathrm{Cs} / \mathrm{L}$ during ORNL testing (Walker, 1998), although long-term effects were not evaluated. Evaluations of IE-911 stability and cesium removal performance in the presence of very high radiation fields were also conducted by Mattus (2001). No impact on cesium removal performance was observed for columns exposed to 250-300 Mrad/day radiation doses. Observed cesium breakthrough profiles were consistent with model predictions for both the real waste tests and the tests conducted in a high radiation field (Hamm, 2002). Bubbles of radiolytically produced gases $\left(\mathrm{H}_{2}, \mathrm{O}_{2}\right.$, and other species) can collect in stagnant columns, which could cause flow restrictions on restart. Earlier column designs also used gas de-entrainment equipment to remove gas bubbles generated in the lead column from passing to the lag column.

\subsection{CST Performance under Dynamic Flow Conditions in Column Configuration}

\subsubsection{Prototypical Column Packing and Processing Summary}

Two examples of relatively large scale column packing and fines elutriation exist (Walker, 1998 and Welch, 2000). In each case, the resin was sluiced into the columns in water ( 50:50 volume mixture) in three portions. In one case ( 3 inch ID column) the packed sorbent was backwashed to remove fines after the addition of each portion of IE-911, while in the other case (12 inch ID column) backwashing was not conducted until the column was fully loaded. Regardless, the effective removal of fines is a crucial step in the preparation of a suitable bed for waste processing. IE-911 columns are also typically treated with dilute caustic solution prior to waste feed processing. The presumed column loading and processing sequence for caustic-washed IE-911 beads (IONSIV IE-911-cw) would involve:

- $\quad$ wetting the IE-911 particles to give a 50 volume percent slurry

- removal of fines by backwashing

- transferring the slurry to the columns in such a manner that areas of low permeability are not created within the bed due to size segregation which could result in high bed pressure drops 
- media caustic adjustment with $0.1 \mathrm{M} \mathrm{NaOH}$

- processing radioactive waste supernate

- waste supernate displacement with $0.1 \mathrm{M} \mathrm{NaOH}$

- spent and loaded IE-911 media transfer to grinder

\subsubsection{Cesium Loading Performance}

Numerous small column tests have been conducted with IE-911 using simulated SRS tank waste supernates. Column performance has generally been as expected based on the measured batch contact cesium equilibrium loading in each feed. There has been only little indication of channeling effects resulting from non-ideal bed packing. Discoloration of portions of a tall IE-911 column during processing with a 16 foot, 3-inch ID column was suspected to have resulted from aluminum precipitation in areas of the column with low fluid contact and flow (Welch, 2000). There are numerous reports of resin fouling and hydraulic failure resulting from the deposition of aluminosilicate solids in packed beds of IE-911. For most of these tests questions existed regarding simulant stability and problems were generally observed when recirculating liquids through the column (rather than with once-through processing). In one column test where fouling and pluggage were observed, a small portion of IE-911 collected from the top of the column was shown to contain high amounts of aluminum and a reduced cesium capacity (Taylor, 2001). In nearly every case it was possible to break up the bridged beds (either by physical agitation of the top of the bed or by upflow fluidization) and continue processing with acceptable cesium removal performance. As will be discussed in Section 4.4.4, actual waste supernate samples from three different sites with varied compositions were successfully processed through IE-911 columns with minimal hydraulic problems during the loading phase and acceptable cesium removal performance.

A model was developed at SRNL to predict cesium breakthrough during CST column operations (Hamm, 2002). The model was recently used to predict performance with the five MSP feeds for the current SCIX annular column design (effective column inside diameter: 26.56"; Smith, 2007). A limited parametric study was conducted varying feed flow rate $(5,10$, and $15 \mathrm{gpm})$, temperature $\left(25,35\right.$, and $\left.45^{\circ} \mathrm{C}\right)$, and column length $(10,15$, and 25 feet). In the baseline case, it was assumed that two columns containing equal resin heights were used in sequence (lead/lag configuration). The bucket average cesium concentration in the lag column effluent was calculated and $45 \mathrm{nCi} / \mathrm{gram}$ was the composite breakthrough limit used to determine when the ion exchange media was spent and required removal from the column. Results for the various conditions were compared after completion of the second loading cycle where nearly steady-state performance was observed. Cesium breakthrough profiles with IE-911 are not as sharp as those observed with RF due to the fact that cesium loading kinetics is slower for CST (presumably a consequence of the location of the exchangeable sites for CST deep within the pores of the crystalline structure). Increasing the volumetric flow rate by a factor of four from 5 to 20 gpm results in a $20 \%$ decrease (average for all MSP feeds with a $15 \mathrm{ft}$. column at $25^{\circ} \mathrm{C}$ ) in 
waste volume processed, whereas the same flow rate increase led to only a $6 \%$ decrease in volume processed per cycle with RF. As shown by Smith for all five MSP feeds, the cesium mass transfer zone (wavefront) is not fully contained within a 15 foot tall column at the nominal flow rate of $10 \mathrm{gpm}$. These characteristics of the breakthrough profile hinder efficient use of the CST ion exchange capacity, although the capacity is so large that this fact may not be important for this material. The breadth of the breakthrough profiles may also favor lead/lag configuration rather than single column operation. For this material, slower flowrates can lead to significant improvements in cesium loading efficiency (at the cost of throughput) and increase the likelihood that the mass transfer zone can be contained within a single column length. Since radiation damage is not an issue with IE-911, processing at slower flow rates may be the preferred option.

Other processing options examined by Smith include temperature and bed height. Processing CST columns at higher temperatures may be preferred since cesium pore diffusivities and loading kinetics are more favorable under these conditions. This advantage must be balanced against lower cesium loading at elevated temperature. Increasing the temperature from 25 to $45^{\circ} \mathrm{C}$ results in a $26 \%$ decrease in waste volume processed per cycle (average for all MSP feeds) versus $44 \%$ for RF. Increasing the column height and L/D impacts performance to a larger degree than was observed for RF resin. Increasing the column height from 10 to 25 feet $\left(10\right.$ gpm flow and $25^{\circ} \mathrm{C}$ ) corresponds to a $150 \%$ increase in bed volume and the average increase in waste volume processed with IE-911 was $187 \%$ (average for all MSP feeds) versus $161 \%$ for RF.

Column performance modeling was also conducted by Smith using a single IE-911 column with a $45 \mathrm{nCi} / \mathrm{g}$ bucket average breakthrough limit. Single column processing appears feasible based on the volumes of supernate processed per cycle. The lowest volume processed under single column operations was 63,000 gallons using a 10 foot tall column ( 10 gpm flow and $25^{\circ} \mathrm{C}$ ) with Tank 1 feed. Even lower process volumes would be expected at higher temperatures, but higher temperatures were not evaluated by Smith for single column operations. A large increase in volume processed per cycle is observed for the single column case when increasing the column length due to better containment of the breakthrough profile within the column and more efficient resin loading (i.e. higher percent saturation). Increasing the column length from 10 to 25 feet results in an average increase in volume processed of $283 \%$ even though the resin height and volume increases are only $150 \%$ each. Clearly, taller columns should be considered for single column operation with IE-911. Comparison of modeling results for single and two-column operations reveals tha,t on average, single column operation leads to a $38 \%$ reduction (standard deviation 11\%) in waste volume processed per cycle versus two-column operations with lead/lag carouseling ( $21 \%$ reduction observed for RF). The larger average reduction in processed volume for IE911 versus $\mathrm{RF}$ is a consequence of the fact that the mass transfer zone is not contained in a single column. It is interesting to note that the percent decrease in processed volume for single column evaluations is substantially lower for those cases that favor sharpening and containment of the profile (higher temperature and slower flow rate) and higher for those cases that result in broadening of the profile. Single column processing at $5 \mathrm{gpm}$ and 20 gpm result in 25 and $51 \%$ reductions in volume processed, respectively (relative to the 2column case). Using single 10 and $25 \mathrm{ft}$ columns results in 28 and $46 \%$ volume reductions, 
respectively. The degree of sensitivity to processing conditions is not as great when using lead/lag columns since the mass transfer zone is contained within the total length of the two columns.

\subsubsection{Column Hydraulic Performance}

Clumping and bridging of IE-911 particles resulting from precipitation of aluminosilicate solids during processing of $\mathrm{NaOH}$ and caustic simulant solutions is known. In cases involving only $\mathrm{NaOH}$ solution this phenomenon is clearly indicative of involvement of leached sorbent components, though this likely would not have occurred were the caustic solution not being recycled through the column (Walker, 1999). Bridging and precipitation have lead to increased bed pressure drops during column processing. Backwashing and physical mixing were sometimes used to break up the clumped particles or partially fused mass of IE-911 beads within the packed beds in order to continue column processing. The degree of bridging and pressure buildup decreased when simulants were not recycled through the column (once-through operation) and were greater for the baseline IE-911 than for an improved material. IE-911 pretreatment with $3 \mathrm{M} \mathrm{NaOH}$ was found to remove much of the leached components and decrease the likelihood of precipitation (Wilmarth, 2000a). Few problems were experienced during column testing over several months with the improved, pretreated material using once through processing, though some clumping was observed at the conclusion of the test (Taylor, 2001). It is believed that the simulant used for this testing was unstable with regard to precipitation and that this contributed to clumping and bridging of the CST particles.

No hydraulic issues were reported during real waste column tests with tank waste supernates from three different Department of Energy (DOE) sites which had a range of chemical compositions (Walker, 1999, Hendrickson, 1997, Walker, 1998). However, with a 10 gallon column which had been allowed to stand in actual Melton Valley Storage Tank supernate for 146 days, backwashing attempts failed because of sorbent pluggage of the inlet line (Walker, 1998). It is not known whether this was the result of particle clumping and bridging. Recovery was accomplished in this case by simply increasing the liquid pressure on the backwash line. During three subsequent column tests in the same supernate using fresh IE-911 no problems with pluggage were encountered.

Hydraulic pressure drops were measured across $30 \mathrm{~L}$ packed beds of IE-911 as a function of flow rate in water and $\sim 5 \mathrm{M} \mathrm{Na}^{+}$simulant (Walker, 1998). The column ID and bed height were 30 and $42 \mathrm{~cm}$, respectively, which corresponds to an L/D of 1.4. Flow rates as fast as $1.35 \mathrm{gpm}$ were evaluated, which corresponds to a superficial velocity of $7.3 \mathrm{~cm} / \mathrm{min}$. Pressure drop increased linearly across the range of flow rates (as expected for a noncompressible material) with larger differential pressures being observed with simulant due to the higher viscosity. The largest measured pressure drop was near 2 psi at the maximum flow rate. Bed pressure drops across a $38 \mathrm{~L}$ bed $(30 \mathrm{~cm} \mathrm{ID,} 53 \mathrm{~cm}$ tall) measured in subsequent tests with actual $5 \mathrm{M} \mathrm{Na}^{+}$Melton Valley waste supernate (1.0-1.3 psi at $1 \mathrm{gpm}$ and 2.1-2.6 psi at $2 \mathrm{gpm}$ ) were generally consistent with simulant results. 
Hydraulic testing was also conducted for higher L/D columns needed for the processing of high level radioactive wastes as SRS (Welch, 2000). The columns were 3 inch ID and contained 16 feet of IE-911 ( 22 L of packed CST, L/D = 64). The nominal flow rate used for this testing was $5 \mathrm{~cm} / \mathrm{min}(\sim 225 \mathrm{~mL} / \mathrm{min}, 0.06 \mathrm{gpm})$ using the "average" $5.6 \mathrm{M} \mathrm{Na}^{+}$SRS simulant. Initial measured pressure drops ranged from $17-23$ psi with $60-70 \%$ of the pressure drop resulting from the top portion of the bed where fines, broken particles, and other solids had accumulated as a result of segregation during backwashing. The permeability of this upper portion of the bed was obviously much lower than the rest of the bed. After removal of some of these solids and upflow bed expansion to redistribute the beads, the hydraulic pressure drop decreased to near $7.4 \mathrm{psig}$, which is near the theoretical value expected for this system of $7.75 \mathrm{psig}$. These results indicate that relatively low theoretical pressure drops for this particle system can be achieved if fines are adequately removed. Furthermore, fines removal prior to column packing may be preferred to avoid segregation of small and irregular particles toward the top of the bed. Additional testing conducted by Welch evaluating the impact of gas generation from radiolysis upon hydraulic performance indicated that gas generation would increase the bed pressure drop by a factor of 2.0-2.5.

McCabe (2004) calculated pressure drops for the SCIX baseline design based on the data reported by Welch. For a feed viscosity near $5.6 \mathrm{M} \mathrm{Na}^{+}$, the pressure drop expected for a 13 foot tall column at a flow rate of $15 \mathrm{gpm}$ was determined to be $27 \mathrm{psi}$ at a feed viscosity of $3.4 \mathrm{cP}$ and $95 \mathrm{psi}$ at $12 \mathrm{cP}$. For the current nominal SCIX operating conditions (10 gpm, a $15 \mathrm{ft}$ column) with a 27.25 inch ID column, a 6.625 inch OD internal cooling tube, and a solution viscosity of $2.6 \mathrm{cP}$ (expected viscosity of $6 \mathrm{M} \mathrm{Na}^{+}$, Tank 37 feed at $25^{\circ} \mathrm{C}$; Smith, 2007) the predicted pressure drop is $15.7 \mathrm{psi}$. Note that this calculation does not take into account the impacts of the internal cooling tube on the hydraulic performance. In addition, gas generation from radiolysis is expected to increase the pressure drop by a factor of 2-2.5.

\subsubsection{Column Testing using Actual SRS or Other Tank Waste Supernates}

Approximately $75 \mathrm{~L}$ (265 BV) of waste supernate from SRS Tank 44F were treated with IE911 in column configuration (packed bed parameters: $1.5 \mathrm{~cm} \mathrm{ID,} 160 \mathrm{~cm}$ tall, $107 \mathrm{~L} / \mathrm{D}, 283$ $\mathrm{mL}$ ) resulting in $99.999 \%$ cesium removal (Walker, 1999). The Tank 44F waste sample was a high hydroxide supernate with the following measured concentrations for selected species: $5.6 \mathrm{M} \mathrm{Na}^{+}, 0.030 \mathrm{M} \mathrm{K}^{+}, 0.27 \mathrm{M} \mathrm{Al}$, and $3.05 \mathrm{M} \mathrm{OH}^{-}$. Modeling of cesium breakthrough performance indicated good agreement for actual samples collected at 10 and $85 \mathrm{~cm}$ down the column length (Hamm, 2002). Less than 1\% cesium breakthrough was observed for the first $85 \mathrm{~cm}$ portion of the bed after processing $470 \mathrm{BV}$ (BV based on volume of first $85 \mathrm{~cm}$ bed portion) of solution. Consistency between the modeling and experimental breakthrough profiles provided validation of the ability to predict cesium removal performance with actual SRS tank waste. Observations regarding hydrogen generation, bed pluggage during pretreatment, and hydraulic pressure drop during this testing are discussed in other sections of this report.

Perhaps the most significant real waste tests conducted with IE-911 are the large-scale demonstrations conducted at Oak Ridge National Laboratory using Melton Valley Storage 
Tank supernate (Walker, 1998). Approximately 30,000 gallons of radioactive waste were processed through a total of 70 gallons of IE-911 with minimal problems. The waste supernate was relatively low in hydroxide with the following measured concentrations for selected species: $5.1 \mathrm{M} \mathrm{Na}^{+}, 0.26 \mathrm{M} \mathrm{K}^{+}, 3.1 \mathrm{E}-5 \mathrm{M} \mathrm{Al}$, and $0.071 \mathrm{M} \mathrm{OH}^{-}$. Four test runs were conducted with $38 \mathrm{~L}$ columns using both single and lead/lag series operations (packed bed parameters: $30 \mathrm{~cm} \mathrm{ID,} 53.7 \mathrm{~cm}$ tall, $1.8 \mathrm{~L} / \mathrm{D}$ ). Consistent results were observed between tests with excellent cesium removal performance ( 1 and $50 \%$ Cs breakthrough was typically observed after processing $\geq 75$ and $\geq 475 \mathrm{BV}$, respectively). Reasonably accurate cesium performance predictions were generated for the various real waste demonstrations (Hamm, 2002). These results confirmed that models developed based on bench scale data can be utilized to predict large scale performance and that the available models can accurately predict performance for actual waste samples. Observations and other testing regarding bed pluggage during storage, hydraulic pressure drop, column loading and unloading, particle fluidization, and spent resin drying during this testing are discussed in other sections of this report.

Finally, column testing was also performed with IE-911 using Hanford AW-101 tank supernate (Hendrickson, 1997; bed parameters: $1 \mathrm{~cm} \mathrm{ID,} 10 \mathrm{~cm}$ tall, $\mathrm{L} / \mathrm{D}=10,7.9 \mathrm{~mL}$ ). The waste supernate was relatively low in hydroxide with the following measured concentrations for selected species: $5.6 \mathrm{M} \mathrm{Na}^{+}, 0.5 \mathrm{M} \mathrm{K}^{+}, 0.57 \mathrm{M} \mathrm{Al}$, and $2.54 \mathrm{M} \mathrm{OH}^{-}$. $50 \%$ cesium breakthrough was observed after processing approximately $700 \mathrm{BV}$ of supernate. Modeling predictions for the Hanford supernate samples were less accurate, although there was some uncertainty in the actual waste composition.

Column tests were performed with IE-911 using tank waste supernate from three different DOE sites (SRS, Melton Valley, and Hanford) with wide compositional ranges. Although, minor problems with column pluggage and CST media fouling of valves were observed during testing, the $50 \%$ cesium breakthrough point exceeded $450 \mathrm{BV}$ for all three waste types.

\subsubsection{Anticipated CST Radiation Exposure}

Radiation dose rates for cesium-loaded IE-911 columns were calculated from the maximum Curie loadings for the various MSP feeds as reported by Smith (2007). The Curie loadings at $25{ }^{\circ} \mathrm{C}$ ranged from $23 \mathrm{Ci}^{137} \mathrm{Cs} / \mathrm{L}$ for Tank 41 to $257 \mathrm{Ci}{ }^{137} \mathrm{Cs} / \mathrm{L}$ for Tank 37 (based on the maximum IE-911 density of $1.15 \mathrm{~g} / \mathrm{mL}$ ). These cesium loadings correspond to radiation dose rates of 0.62 and $6.93 \mathrm{Mrad} /$ day, respectively (based on a CST salt solution density of $1587.8 \mathrm{~g} / \mathrm{L}$ as reported by Lee, 2007). The dose rates would be expected to increase by more than $35 \%$ once the loaded columns were washed and dried. For comparison, the maximum Curie loading obtained with MVST supernate during ORNL testing was $7 \mathrm{Ci}$

${ }^{137} \mathrm{Cs} / \mathrm{L}$ for a column processed to near $75 \%$ breakthrough (Walker, 1998). Evaluations of IE-911 stability and cesium removal performance in the presence of very high radiation fields were also conducted by Mattus (2001). No impact on cesium removal performance was observed for columns exposed to 250-300 Mrad/day radiation doses. The dose rate impacts the shielding requirements for the column design, the hydrogen generation rate, and the hydraulic pressure drop (due to the formation of bubbles within the bed). 


\subsection{CST Column Process Safety and Risk}

\subsubsection{General}

IE-911 is listed as a slight health hazard (HIMS Health Rating 1) presumably due to inhalation and static discharge risks associated with handling the dry powder. The spent material is, of course, extremely hazardous due to the high radiation field associated with the loaded cesium. As long as the spent material is wet, hydrogen gas generation will occur due to water radiolysis.

\subsubsection{Risks Associated with Hydraulic Performance and Column Pluggage}

As is the case with any ion exchange column operation, headspace pressurization resulting from media pluggage is a process and safety risk. There are numerous examples of clumping and bridging of IE-911 particles to form a solid mass within packed columns, although many of these issues were believed to be associated with an unstable simulant composition. Nonetheless, the project should consider mitigating strategies to deal with such an event. Another potential risk is high pressure drops resulting from localized areas of low permeability within the bed which are associated with vertical particle size stratification resulting from backwashing. This issue may be best avoided by removing fines prior to column loading.

\subsubsection{Hazards Associated with Heat Sources}

The only heat source associated with IE-911 processing is from radiolysis. For the highest expected MSP cesium loading at the lowest MSP flow rate (5 gpm), the predicted solution temperature increase resulting from radiolysis during transport through a 25 foot column (largest expected column height) using the current baseline design configuration but without active cooling is only $2.75{ }^{\circ} \mathrm{C}$ (Lee, 2007). This indicates that as long as salt solution flow continues through the column, temperature increases from radiolysis are minimal. In stagnant salt solution, but with design basis cooling, the maximum steady-state temperature expected in a fully-loaded CST column is $62.7^{\circ} \mathrm{C}$. In the bounding accident scenario (see discussion in Section 3.5.3) involving no liquid flow, no active cooling, and a fully loaded column the temperature of a column containing CST and salt solution is expected to reach $65{ }^{\circ} \mathrm{C}$ (assumed temperature limit for IE-911) within $\sim 32$ hours and $130{ }^{\circ} \mathrm{C}$ (the slurry boiling point) within 6.4 days. In order to avoid clumping and binding of the CST beads resulting from precipitation, which is enhanced at elevated temperatures, the project might consider adding a mechanism for emergency feed displacement from the column (though this will result in increased $\mathrm{H}_{2}$ generation from radiolysis).

\subsubsection{Vessel Pressurization and Explosion Hazards Associated with Off-gassing from Chemical Reactions and Radiolysis}

The effect and fate of gases produced from radiolysis in a loaded CST column were evaluated in the tall column test conducted at ORNL by spiking waste simulants with peroxide (Welch, 2000). CST promotes catalytic destruction of the peroxide resulting in the 
generation of an oxygen gas wavefront down the column in a manner similar to what would be observed as a result of radiolysis with the cesium loading wavefront. At nominal liquid flow rates the gas bubbles were essentially swept out of the column with the effluent stream. When the flow was stopped the gases were observed as bubbles streaming up from the top of the bed into the liquid headspace above the column. Consistent with these observations, Walker (1999) observed gas bubbles forming above a loaded IE-911 bed during column testing with actual SRS waste only when flow was stopped. Presumably during waste processing the gases were swept out of the column with the effluent. Evaluations of IE-911 cesium removal performance in the presence of very high radiation fields were conducted by Mattus (2001). These tests involved high radiolytic gas production rates. No impact on cesium removal performance was observed as a result of radiolytic gas production during column processing. Gas de-entrainment equipment was included in the SCIX design to remove bubbles from the lead column effluent and prevent accumulation of flammable gas mixtures in the lag column headspace.

McCabe (2004b) conducted hydrogen gas production rate calculations for the SCIX design. It was noted that experimental studies indicated that the relative amounts of hydrogen and oxygen produced by radiolysis varied significantly depending upon the salt solution composition. Furthermore, CST appears to enhance radiolytic gas production relative to the values expected for salt solution alone. Using the same methodology and assumptions reported by McCabe for the current nominal MSP column (15 ft column, 27.25 inch ID column with 6.625 inch OD internal cooling tube) and assuming the maximum expected MSP loading of $223.67 \mathrm{Ci}{ }^{137} \mathrm{Cs} / \mathrm{L}$ (Tank 37 at $25{ }^{\circ} \mathrm{C}$, Smith, 2007), the predicted hydrogen gas generation rate in simulant is $1.42 \mathrm{~L} / \mathrm{h}$. As mentioned previously the actual hydrogen Gvalue in this supernate could vary significantly from the measured value used for this calculation. Other gases besides hydrogen (including oxygen) are also produced from radiolysis. The predicted hydrogen generation rate in water for a CST column previously saturated in Tank 37 feed is $4.57 \mathrm{~L} / \mathrm{h}$.

\subsection{Downstream Impacts/Secondary Waste Streams}

As discussed in other sections, leaching of materials from IE-911 may result in precipitation of aluminosilicate (or other) materials in the column effluent solutions. Other downstream effects are associated with the disposition of spent, ground CST within waste tanks and uncertainties with regard to the physical and chemical properties (clumping and cesium release due to high temperature desorption) under these conditions.

\subsection{Media Disposal}

Silver, arsenic and cadmium were reported at $\leq 25 \mu \mathrm{g} / \mathrm{g}$ CST, while barium, chromium, mercury, and lead were present at $>200 \mu \mathrm{g} / \mathrm{g}$ CST in spent resin. Lead was present at the highest concentration $(5940 \mu \mathrm{g} / \mathrm{g}$ CST). Spent CST samples were not analyzed for selenium. Although the affinity of CST for plutonium and uranium is low $\left(\mathrm{K}_{\mathrm{d}}\right.$ values typically $\leq 200 \mathrm{~mL} / \mathrm{g}$ ) both metals are retained on spent media samples. It is not anticipated that the presence of hazardous metals is an issue as far as disposal is concerned since the final waste form is likely a high level waste glass. 


\subsection{Comparisons of Spherical RF and Engineered CST Ion Exchange Media for SCIX Applications}

The properties of spherical RF and engineered CST media are directly compared in Tables

5-1. Evaluations of the technical maturity and acceptability with regard to numerous properties are provided in Table 5-2. 
Table 5-1. Comparison of Selected Properties for Spherical RF and IONSIV IE-911 (CST).

\begin{tabular}{|c|c|c|}
\hline Property & Spherical RF & CST \\
\hline mean particle diameter $(\mu \mathrm{m})$ & 454 & 344 \\
\hline sphericity $(\%)$ & $>99$ & $<90$ (granular) \\
\hline bed density (g media/mL packed bed) & 0.3 (Na-form) & $1.0-1.15$ \\
\hline total bed porosity $(\%)$ & 80 & 66 \\
\hline total cesium capacity $(\mathrm{mmol} \mathrm{Cs} / \mathrm{g})$ & 0.57 (Na-form) & $0.57-0.58$ \\
\hline pore diffusivity ( $\%$ of free cesium diffusivity) & 33 & 20 \\
\hline $\begin{array}{c}\text { cesium selectivity } \\
\mathrm{K}_{\mathrm{Cs} / \mathrm{Na}} \\
\mathrm{K}_{\mathrm{Cs} / \mathrm{K}} \\
\end{array}$ & $\begin{array}{l}4.2 \mathrm{E} 4^{\mathrm{a}} \\
3.1 \mathrm{E} 2^{\mathrm{a}} \\
\end{array}$ & $\begin{array}{l}2.6 \mathrm{E} 4 \\
1.4 \mathrm{E} 3 \\
\end{array}$ \\
\hline Tank 37 cesium loading at $25^{\circ} \mathrm{C}\left(\mathrm{Ci}{ }^{137} \mathrm{Cs} / \mathrm{L}\right.$ bed $)$ & $133 / 100^{b}$ & 224 \\
\hline Tank 3 cesium loading at $25^{\circ} \mathrm{C}\left(\mathrm{Ci}{ }^{137} \mathrm{Cs} / \mathrm{L}\right.$ bed $)$ & $75 / 37$ & 88 \\
\hline $\begin{array}{c}\text { temperature impacts on Cs loading (average \% } \\
\text { decrease in Cs loading from } 25 \text { to } 45^{\circ} \mathrm{C} \text { ) }\end{array}$ & 45 & 26 \\
\hline $\begin{array}{l}\text { temperature impacts on Cs loading (average } \% \\
\text { decrease in volume processed from } 25 \text { to } 45^{\circ} \mathrm{C} \text { at } \\
10 \mathrm{gpm})\end{array}$ & 44 & 26 \\
\hline assumed process temperature limit $\left({ }^{\circ} \mathrm{C}\right)$ & 65 & 65 \\
\hline fluidization & relatively easy fluidization observed & $\begin{array}{l}4.3 \mathrm{ft} / \mathrm{sec} \text { for } 24 \mathrm{wt} \% \text { slurry } \\
3.7 \mathrm{ft} / \mathrm{sec} \text { for } 5 \mathrm{wt} \% \text { slurry }\end{array}$ \\
\hline settling rate $(\mathrm{cm} / \mathrm{min})$ & $\begin{array}{c}\left.27 \text { (Na-form in } 5 \mathrm{M} \mathrm{Na}^{+} \text {supernate }\right) \\
75(\mathrm{H} \text {-form in water }) \\
102(\mathrm{Na} \text {-form in } 0.5 \mathrm{M} \mathrm{NaOH})\end{array}$ & $\begin{array}{l}\text { not available, though rapid settling } \\
\text { expected, except for fines }\end{array}$ \\
\hline $\begin{array}{c}\text { pressure drop (predicted } \Delta \mathrm{P} \text { for } 25 \mathrm{ft} \text { SCIX } \\
\text { column) }\end{array}$ & $\begin{array}{l}15 \mathrm{psi} \text { at } 5.6 \mathrm{~cm} / \mathrm{min}(5.2 \mathrm{gpm}) \\
72 \mathrm{psi} \text { at } 27 \mathrm{~cm} / \mathrm{min}(25.6 \mathrm{gpm})\end{array}$ & $\begin{array}{c}12 \mathrm{psi} \text { at } 5 \mathrm{~cm} / \mathrm{min}(4.6 \mathrm{gpm}) \\
34 \mathrm{psi} \text { at } 10.7 \mathrm{~cm} / \min (9.9 \mathrm{gpm})\end{array}$ \\
\hline $\begin{array}{c}\text { maximum hydrogen gas generation } \\
\left(\mathrm{L} \mathrm{H}_{2} / \mathrm{h} \text { for } 15 \mathrm{ft} \mathrm{SCIX} \text { column at } 25^{\circ} \mathrm{C}\right)\end{array}$ & $\begin{array}{c}0.33 \text { (supernate) } \\
0.86(0.5 \mathrm{M} \text { acid }) \\
3.72 \text { (water })\end{array}$ & $\begin{array}{l}1.42 \text { (supernate) } \\
4.57 \text { (water) }\end{array}$ \\
\hline swelling & $\begin{array}{c}\text { initial irreversible } 30 \% \text { increase, } \\
\text { reversible } 20-25 \% \text { decrease (Na- to } \\
\text { H-form) during cycling }\end{array}$ & none \\
\hline leaching & $\begin{array}{c}\text { low levels of soluble organics from } \\
\text { chemical/radiolytic degradation }\end{array}$ & $\begin{array}{c}\mathrm{Zr}, \mathrm{Nb}, \mathrm{Si} \text { at least with initial washes or } \\
\text { effluent }\end{array}$ \\
\hline chemical reactivity & mild polymer oxidation & $\begin{array}{c}\text { aluminosilicate deposition from } \\
\text { unstable feeds }\end{array}$ \\
\hline physical degradation & mild expansion with $\mathrm{O}_{2}$ exposure & $\begin{array}{l}\text { attrition during handling } \\
\text { clumping/chemical deposition in } \\
\text { unstable feeds }\end{array}$ \\
\hline TCLP & passed with Hanford simulants & $\begin{array}{l}\text { passed with SRS simulants and actual } \\
\text { MVST supernate }\end{array}$ \\
\hline dissolution conditions & $\geq 8 \mathrm{M} \mathrm{HNO}_{3}$ at elevated temp. & acid, peroxide \\
\hline safety risks & $\begin{array}{l}\text { inadvertent gas pressurization from } \\
\text { high acid contact } \\
\text { handling acidic cesium eluate }\end{array}$ & handling loaded CST \\
\hline process risk & $\begin{array}{l}\text { constrained swelling, hydraulic } \\
\text { failure, resin compaction }\end{array}$ & $\begin{array}{l}\text { in-column clumping, hydraulic failure, } \\
\text { ground media resuspension/transport }\end{array}$ \\
\hline
\end{tabular}

${ }^{a}$ based on new RF isotherm ${ }^{b}$ predicted loading values based on new/old isotherms, respectively ${ }^{\mathrm{c}}$ assuming constant pressure drop per foot at a given superficial velocity (feed: $\mathrm{RF}-3.2 \mathrm{cP}, \mathrm{CST}-2.6 \mathrm{cP}$ ) 
Table 5-2. Evaluations of Spherical RF and IONSIV IE-911 (CST) Technical Maturity.

\begin{tabular}{|c|c|c|c|}
\hline Test & $\begin{array}{l}\text { Spherica } \\
\text { I RF }\end{array}$ & IE-911 & Comments \\
\hline acceptable engineered form available & $\mathrm{Y}$ & $\mathrm{Y}$ & $\begin{array}{l}\text { - RF - highly spherical beads with narrow size } \\
\text { distribution } \\
\text { - IE-911 - granular or spheroidal beads }\end{array}$ \\
\hline adequate scale-up production demonstrated & $\mathrm{Y}$ & $\mathrm{Y}$ & $\begin{array}{l}\text { - RF - six 100-gallon, Na-form batches } \\
\text { - IE-911 - one } ~ 70 \text { gallon production, batch } \\
\text { size unknown, large batches believed } \\
\text { prepared but not formally documented }\end{array}$ \\
\hline adequate scale-up batch reproducibility & $\mathrm{Y}$ & $\underline{\mathbf{U}}$ & $\begin{array}{l}\text { - RF - very low variability } \\
\text { - IE-911 - some ion exchange capacity } \\
\text { variability observed with small-scale batches, } \\
\text { unknown on large scale }\end{array}$ \\
\hline $\begin{array}{l}\text { acceptable predictive isotherm models } \\
\text { developed for cesium equilibrium loading }\end{array}$ & $\underline{\mathbf{N}}$ & $\mathrm{Y}$ & $\begin{array}{l}\text { - RF - two alternative models exist due to } \\
\text { experimental inconsistencies or inadequate } \\
\text { conceptual understanding } \\
\text { - IE-911 - comprehensive isotherm model } \\
\text { developed from extensive binary testing, } \\
\text { conceptual understanding of cesium ion } \\
\text { exchange well understood }\end{array}$ \\
\hline $\begin{array}{l}\text { adequate column performance models } \\
\text { developed }\end{array}$ & Y & Y & $\begin{array}{l}\text { VERSE column performance models developed } \\
\text { for both materials, though predictive abilities } \\
\text { limited by isotherm accuracy for RF }\end{array}$ \\
\hline $\begin{array}{l}\text { acceptable performance with SRS simulants } \\
\text { confirmed }\end{array}$ & $\underline{\mathbf{N}}$ & $\mathrm{Y}$ & $\begin{array}{l}\text { - RF - extensive testing conducted with } \\
\text { Hanford simulants and modified simulants } \\
\text { with concentrations of primary chemical } \\
\text { species varied } \\
\text { - IE-911 - extensive small column testing } \\
\text { conducted with SRS simulants }\end{array}$ \\
\hline $\begin{array}{c}\text { acceptable performance with SRS actual } \\
\text { waste confirmed }\end{array}$ & $\underline{\mathbf{N}}$ & $\mathrm{Y}$ & $\begin{array}{l}\text { IE-911 } \\
\text { - } \quad \text { equilibrium batch contact tests conducted } \\
\text { for } 6 \text { actual SRS supernates } \\
\text { - } \quad 1.5 \mathrm{~cm} \mathrm{ID,} 283 \mathrm{~mL} \text { column, } 75 \mathrm{~L} \text { SRS } \\
\text { Tank } 44 \text { supernate processed }\end{array}$ \\
\hline $\begin{array}{c}\text { acceptable performance with other tank waste } \\
\text { samples confirmed }\end{array}$ & $\mathrm{Y}$ & $\mathrm{Y}$ & $\begin{array}{l}\text { - } \mathrm{RF} \text { - } 1.5 \mathrm{~cm} \mathrm{ID,} 11 \mathrm{~mL} \text {, Na-form columns } \\
\text { (lead/lag) } \\
\text { O } 1.5 \mathrm{~L} \text { Hanford tank AP-101 supernate } \\
\text { o } 2.3 \mathrm{~L} \text { Hanford tank AN-102 supernate } \\
\text { - } \mathrm{IE}-911 \\
\text { o } 1.0 \mathrm{~cm} \mathrm{ID,} 7.9 \mathrm{~mL} \text { column, } 6.3 \mathrm{~L} \text { Hanford } \\
\text { AW-101 supernate } \\
\text { o } 12 \text { in ID, } 38 \text { L columns (lead/lag), } 4 \\
\text { campaigns treated }>30,000 \mathrm{gallons} \\
\text { Melton Valley W-27 supernate }\end{array}$ \\
\hline $\begin{array}{l}\text { adequate scale-up column hydraulic } \\
\text { performance confirmed }\end{array}$ & $\mathrm{Y}$ & $\mathrm{Y}$ & 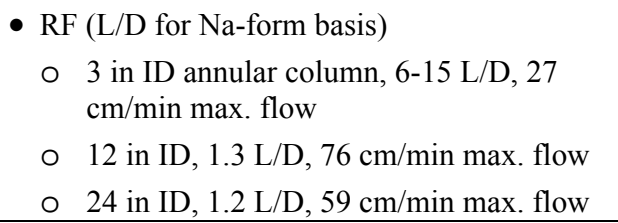 \\
\hline
\end{tabular}




\begin{tabular}{|c|c|c|c|}
\hline & & & $\begin{array}{l}\text { - IE-911 } \\
\begin{array}{l}\text { o } 3 \text { in ID, } 64 \mathrm{~L} / \mathrm{D}, 5 \mathrm{~cm} / \mathrm{min} \max \text {. flow } \\
\text { o } 12 \text { in ID, } 1.8 \mathrm{~L} / \mathrm{D}, 11 \mathrm{~cm} / \mathrm{min} \text { max. flow }\end{array}\end{array}$ \\
\hline $\begin{array}{l}\text { adequate scale-up fluidization and handling } \\
\text { performance confirmed }\end{array}$ & Y & $\mathrm{Y}$ & $\begin{array}{l}\text { RF - relatively easy slurry fluidization, bead } \\
\text { settling rates range from } 27-102 \mathrm{~cm} / \mathrm{min} \\
\text { depending on conditions, handling dry } \\
\text { materials less well characterized, possibly } \\
\text { more challenging } \\
\text { - IE-911 - fines removal and management } \\
\text { biggest challenge, no particle settling rates } \\
\text { reported but rapid settling observed, settling } \\
\text { rates for ground material may be needed, } \\
\text { drying methods developed but probably not } \\
\text { needed }\end{array}$ \\
\hline acceptable chemical stability confirmed & $\mathrm{Y}$ & $\mathrm{Y}$ & $\begin{array}{l}\text { - RF - mild oxidation, } 0.63 \% \text { maximum } \\
\text { capacity degradation per chemical cycle } \\
\text { - IE-911 - susceptible to aluminosilicate } \\
\text { deposition with unstable feeds }\end{array}$ \\
\hline acceptable physical stability confirmed & Y & $\mathrm{Y} / \underline{\mathbf{U}}$ & $\begin{array}{l}\text { - RF - mild bed expansion with oxidation, no } \\
\text { process impact anticipated } \\
\text { - IE-911 - mild clumping/binding associated } \\
\text { with aluminosilicate formation in unstable } \\
\text { feeds, binding/hardening/fluidization of } \\
\text { ground material after storage in supernate } \\
\text { unknown }\end{array}$ \\
\hline acceptable radiolytic stability confirmed & $\mathrm{Y}$ & $\mathrm{Y}$ & $\begin{array}{l}\text { - } \mathrm{RF}-\sim 0.5 \% \text { capacity degradation per } 1 \mathrm{Mrad} \\
\text { exposure, marginal stability for some } \\
\text { processing cases where only } 1-2 \text { cycles are } \\
\text { expected before resin replacement } \\
\text { - IE-911 - no radiolytic effects observed } \\
\end{array}$ \\
\hline $\begin{array}{c}\text { acceptable downstream impacts confirmed for } \\
\text { column effluent }\end{array}$ & $\mathrm{Y} / \underline{\mathbf{U}}$ & $\mathrm{Y}$ & $\begin{array}{l}\text { - RF - mild resin dissolution associated with } \\
\text { oxidation and radiolytic degradation, given } \\
\text { effluent process volumes expected organic } \\
\text { leaching not expected to impact final waste } \\
\text { form, processing scheme for handling nitric } \\
\text { acid eluate stream needs development } \\
\text { - IE-911 - initial leaching of elemental } \\
\text { components can lead to downstream } \\
\text { precipitation, though impact should be small } \\
\text { due to dilution in column effluent, CST fines } \\
\text { can contribute to effluent dose in some cases }\end{array}$ \\
\hline acceptable safety performance confirmed & $\mathrm{Y}$ & $\mathrm{Y}$ & $\begin{array}{l}\text { - RF - inherent hazards associated with organic } \\
\text { resins and nitric acid leading to off-gassing, } \\
\text { potential for bed compression due to resin } \\
\text { swelling, acceptable mitigation strategies } \\
\text { developed for each hazard } \\
\text { - IE-911 - handling highly loaded solids and } \\
\text { managing hydrogen off-gas }\end{array}$ \\
\hline large scale performance demonstration & $\underline{\mathbf{N}}$ & $\mathrm{Y}$ & $\begin{array}{l}\text { - IE-911 - } 12 \text { in ID, } 38 \text { L columns (lead/lag), } 4 \\
\text { campaigns treated }>30,000 \text { gallons Melton } \\
\text { Valley W-27 supernate }\end{array}$ \\
\hline $\begin{array}{l}\text { spent resin suitability for SRS disposal } \\
\text { confirmed }\end{array}$ & $\underline{\mathbf{N}}$ & Y & $\begin{array}{l}\text { - RF - not yet confirmed, depends upon final } \\
\text { waste form specified } \\
\text { - IE-911 - optimized frit recipes containing } \\
\text { loaded/ground material suitable for DWPF } \\
\text { may require additional development }\end{array}$ \\
\hline
\end{tabular}

Legend: $\mathrm{Y}=$ yes, $\mathrm{N}=$ no, $\mathrm{U}=$ unknown 


\subsection{Current Technology Gaps and Recommendations for Additional Studies for RF and CST}

Perceived gaps in the current characterization data and additional recommended testing for each technology are provided in Table 6-1. Other gaps may be identified as part of the Consolidated Hazard Assessment that is currently underway. 
Table 6-1. Gaps in the Characterization of Spherical RF and IONSIV IE-911 (CST) and Potential Additional Testing

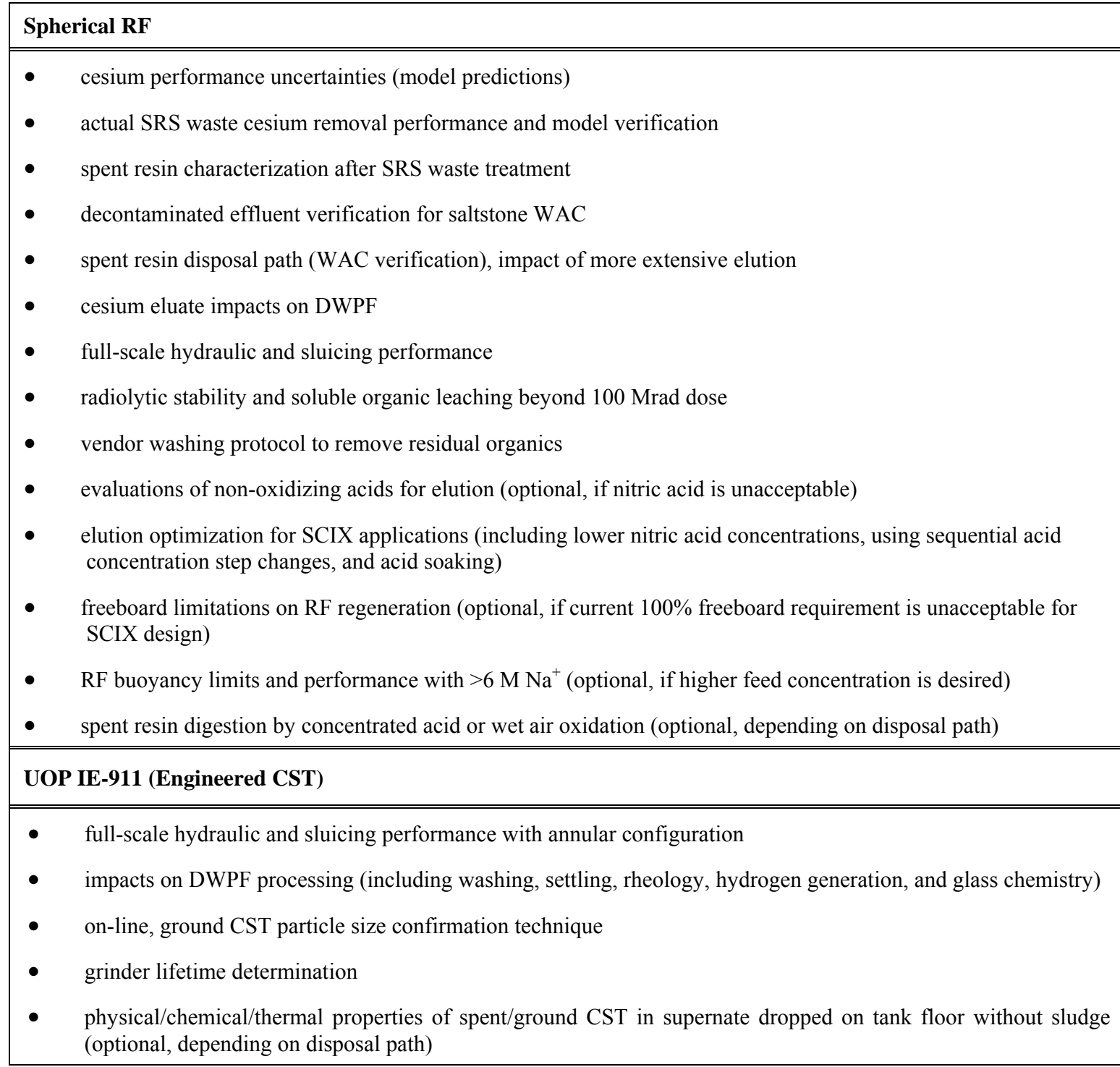




\subsection{Conclusions}

Spherical RF resin and IE-911 (granular CST) are both quite effective at cesium removal from radioactive waste solutions. Scale up production batches of both media have been prepared, though less documentation and characterization is available for the large-scale IE911 batches. The two media have similar capacities for cesium on a mass basis, though the significantly lower density of RF resin results in lower cesium loading on a volumetric basis. IE-911 is also more selective for cesium over potassium. The mean particle diameters of the engineered forms are each in the range 300 to $500 \mu \mathrm{m}$. RF resin beads undergo volume changes during transitions between caustic and acidic conditions. Asreceived IE-911 beads require the removal of fines prior to use. For each material the solids are well-behaved, fairly easily fluidized, and exhibit good settling behavior, though the settling rate of ground IE-911 particles has not been reported. Packed RF and IE-911 beds exhibit similar and acceptable hydraulic performance with regard to pressure drop across the bed. Careful upflow regeneration of spherical RF beds is required after cesium elution to avoid compacting the resin and pressurizing the column during conversion from the lowvolume acid form to the high-volume sodium form. Removal of fines and adequate homogenization of the particle size distribution within the bed are needed for IE-911 column processing to avoid generation of areas of low permeability within the bed. This is normally not an issue if adequate fines removal is conducted prior to column packing. Lower cesium loading on RF columns results in lower radiation exposure during waste processing and lower hydrogen offgassing from the columns. However, spherical RF resin is composed of an organic polymer which is susceptible to radiolytic and oxidative degradation. These characteristics limit RF resin lifetime during processing. IE-911 exhibits little susceptibility to radiolytic damage, but is not elutable and requires particle grinding and disposal after each cesium loading cycle. IE-911 particles have been shown to clump and bridge when exposed to unstable feeds due to the deposition of aluminosilicate solids, which could lead to hydraulic issues and difficulty in removing the media from the columns. This feature is not expected to be an issue with dissolved saltcake because it should not be supersaturated with silicon. Spent spherical RF resin passed TCLP leachate analysis testing for disposal after contact with Hanford simulants and actual waste. IE-911 passed TCLP testing after contact with SRS waste. Spherical RF has not been tested for TCLP after contact with SRS waste.

The physical, chemical, and performance properties of the two media are quite good. Technology selection will likely be weighted toward downstream impacts and dealing with secondary waste streams generated. For example, consideration will be given to the impact of the nitric acid eluate stream and the spent resin disposal path for RF, and the impact of spent IE-911 on SRS waste vitrification operations at DWPF. Based on the technology selected, engineering evaluations will determine whether column processing will involve a single column or two columns operated in a variety of potential configurations including series, parallel and other options. Additional testing is recommended for each technology in response to the characterization gaps identified in Table 6-1. 


\subsection{References}

Adamson, D. J., M. D. Fowley, J. L. Steimke, T. J. Steeper, M. Williams, C. E. Duffey, and F. Fondeur, 2006. "Pilot-Scale Hydraulic Testing of Resorcinol Formaldehyde Ion Exchange Resin,”WSRC-TR-2005-00570 (SRNL-RPP-2006-00013), Rev. 0, (March).

Aleman, S. E., L. L. Hamm, and F. G. Smith, 2007. "Ion Exchange Modeling of Cesium Removal from Hanford Waste Using Spherical Resorcinol-Formaldehyde Resin," WSRC-STI-2007-00030, Rev. 0, (July).

Anthony, R. G., R. G. Dosch, D. Gu, and C. V. Philip, 1994. "Use of Silicotitanates for Removing Cesium and Strontium from Defense Waste", Ind. Eng. Chem. Res., Vol. 33, pp. 2702-2705.

Anthony, R. G., R. G. Dosch, and C. V. Philip, 2002. "Silico-titanates and Their Methods of Making and Using" U.S. Patent \#6,479,427 (November 12).

Arm, S. T., D. L. Blanchard, K. P. Brooks, B. J. Cook, J. M. Cuta, S. K. Fiskum, Z, Hontz, C. Isaakson, A. A. Schlepmoes, D. E. Wallace, 2005. "Progress Report on Laboratory Scale Hydraulic Testing of Spherical Resorcinol Formaldehyde Ion Exchange Resin", Battelle-Pacific Northwest Report, WTP-RPT-138, Rev 0 (August).

Baich, M. A., 2000. “CST/Water Slurry Mixing and Resuspendion” WSRC-TR-2000000370, Rev. 0 (September 20).

Beasley, M. H., A. D. Coleman, B. H. Croy, S. D. Fink, R. A. Jacobs, and D. D. Walker, 2001. "IONSIV IE-911 Performance in Savannah River Site Radioactive Waste" WSRC-TR-2000-0052, Rev. 0 (April 10).

Berge, A., T. Nilsen, and J. Ugelstad, 1997. "Process for Preparing a Dispersion and for Preparing Polymer Particles" U.S. Patent \#5,677,373 (October 14).

Bibler, J. P., and R. M. Wallace, 1995. "Cesium-specific Phenolic Ion Exchange Resin" U.S. Patent \#5,441,991 (August 15).

Bickford, D. F., G. D. Creech, D. C. Beam, 2005. "Confirmation of Small Column Ion Exchange Crystalline Silicotitanate (CST) Grinder Configuration and Estimation and Treatment Cycle (U)" WSRC-TR-2005-000282, Rev. 0 (March).

Cherry, B. R., M. Nyman, and T. M . Alam, 2004. "Investigation of Cation Environment and Framework Changes in Silicotitanate Exchange Materials using Solid-State ${ }^{23} \mathrm{Na}$, ${ }^{29} \mathrm{Si}$ and ${ }^{133}$ Cs MAS NMR", J. Solid State Chem., Vol. 177, pp. 2079-2093.

Crawford, C. L., N. E. Bibler, and J. P. Bibler, 1994. "An Investigation of the Radiolytic Stability of a Resorcinol-Formaldehyde Ion Exchange Resin" Waste Management 1994 Proceedings, Volume 1, Editor R. G. Post, pp. 701-708.

Duffey, C. E., and D. D. Walker, 2006. "Radiolytic, Thermal, and Physical Degradation Testing of Spherical Resorcinol-Formaldehyde Resin (U)" WSRC-TR-2005-00075 (SRNL-RPP-2005-00008), Rev. 0 (July).

Duignan, M. R., 2007. "Small Column Ion Exchange Hydraulic Test” WSRC-TR-200700325, Rev. 0 (July).

Ebra, M. A., and R. M. Wallace, 1983. "Phenolic Cation Exchange Resin Material for Recovery of Cesium and Strontium” U.S. Patent \#4,423,159 (December 27). 
Fiskum, S. K., S. T. Arm, M. S. Fountain, M. J. Steele, and D. L. Blanchard, Jr., $2006 a$. "Spherical Recorcinol-Formaldehyde Resin Testing for ${ }^{137}$ Cs Removal from Simulated and Actual Hanford Waste Tank 241-AP-101 Diluted Feed (Envelope A) Using Small Column Ion Exchange," Battelle-Pacific Northwest Report, WTP-RPT-134, Rev 0 (February).

Fiskum, S. K., M. J. Steele, and D. L. Blanchard, Jr., 2006b. "Small Column Ion Exchange Testing of Spherical Resorcinol-Formaldehyde Resin for ${ }^{137} \mathrm{Cs}$ Removal from Pretreated Hanford Tank 241-AN-102 Waste (Envelope C)", Battelle-Pacific Northwest Report, WTP-RPT-135, Rev 1 (April).

Fiskum, S. K., I. E. Burgeson, O. T. Farmer, III, L. R. Greenwood, C. Z. Soderquist, M. J. Steele, and M. P Thomas, 2006c. "Spherical Resorcinol-Formaldehdye Resin Analysis Following Actual Hanford Tank Waste Processing" Battelle-Pacific Northwest Report, WTP-RPT-144, Rev 0 (May).

Fiskum, S. K., S. T. Arm, W. C. Buchmiller, T. Trange-Le, J. E. Martinez, J. Matyas, M. J. Steele, K. K. Thomas, and D. L. Blanchard, Jr., 2006d. "Comparison Testing of Multiple Spherical Resorcinol-Formaldehyde Resins for the River Protection Project-Waste Treatment Plant", Battelle-Pacific Northwest Report, WTP-RPT-143, Rev 0 (November).

Fondeur, F. F., M. L. Crowder, W. D. King, S. W. McCollum, and M. A. Pettis, 2006. "Spherical Resorcinol-Formaldehyde Resin Reactivity with Nitric Acid and Other Hanford RPP-WTP Process Solutions" WSRC-TR-2005-00228 (SRNL-RPP-200500033), Rev. 1 (September).

Fowley, M. D., D. J. Adamson, C. A. Nash, M. A. Shadday, S. E. Aleman, J. L Steimke, L. L. Hamm, M. L. Restivo, T. J. Steeper, and W. D. King, 2004. "Ion Exchange Testing with SuperLig ${ }^{\circledR} 644$ Resin” WSRC-TR-2003-00514 (SRNL-RPP-2003-00233), Rev. 0 (July).

Hamm, L. L., T. Hang, D. J. McCabe, and W. D. King, 2002. "Preliminary Ion Exchange Modeling for Removal of Cesium from Hanford Waste Using Hydrous Crystalline Silicotitanate Material," WSRC-TR-2001-00400 (SRT-RPP-2001-00134), Rev. 0 (July).

Hamm, L. L., S. E. Aleman, B. J. Hardy, W. D. King, and C. E. Duffey, 2003. "Ion Exchange Modeling for Removal of Cesium from Hanford Waste Using SuperLig ${ }^{\circledR} 644$ Resin,”WSRC-TR-2003-00555 (SRT-RPP-2003-00242), Rev. 0 (February).

Hendrickson, D. W. , 1997. "Hanford Salt Cake Cesium Removal Using Crystalline Silicotitanate", SGN Eurisys Services Corporation, SESC-EN-RPT-006, Rev. 0, September).

Lee, S. Y., 2007. "Heat Transfer Analysis for Fixed CST and RF Columns" WSRC-STI2007-00345, Rev. 0 (July).

Marsh, S. F., Z. V. Svitra, and S. M. Bowen, 1997. "Distribution of 14 Elements on 63 Absorbers from Three Simulant Solutions (Acid-Dissolved Sludge, Acidified Supernate and Alkaline Supernate) for Hanford HLW Tank 102-SY”, LA-12654, Rev. 1, (August).

Mattus, A. J., T. E. Kent, and P. A. Taylor, 2001. "Study of the Potential Impact of Gamma-Induced Radiolytic Gases on Loading of Cesium Onto Crystalline Silicotitanate Sorbent at ORNL's High Flux Isotope Reactor", ORNL/TM-2000/362, Rev. 0, (January).

McCabe, D. J., 2004a. "Calculation of the Pressure Drop Across the Small Column Ion Exchange Bed" WSRC-RP-2004-00590, Rev. 0. 
McCabe, D. J., 2004b. "Calculation of the Hydrogen Gas Generation in Small CesiumRemoval Columns Containing Crystalline Silicotitanate" WSRC-RP-2004-00164, Rev. 0, (February).

McCabe, D. J., 2005. "High Level Waste System Impacts from Small Column Ion Exchange Implementation” WSRC-TR-2005-00034, Rev. 0, (August).

MSDS, 2002. "Material Safety Data Sheet for IONSIV IE-911 CW 30x60", UOP LLC and UOP M.S. S.r.l., MSDS\# 27089, Rev. 2 (February).

MSDS, 2005. "Safety Data Sheet for Resorcinol-Formaldehyde Polymer", Microbeads AS, MSDS\# 36589, Rev. 1 (December, 22).

Nash, C. A., 2004. "Hanford RPP-WTP Alternate Resin Program - Protocol P1-RF: Spherical Resin Sampling from Containers, Resin Pretreatment, F-factor, and Resin Loading to Column", SRNL-RPP-2004-00058, Rev. 0 (July).

Nash, C. A., M. R. Duignan, and C. E. Duffey, 2006. "Batch, Kinetics, and Column Data from Spherical Resorcinol-Formaldehyde Resin," WSRC-STI-2006-00071 (SRT-RPP2006-00024), Rev. 0 (December 18).

Nash, C. A., and M. D. Fowley, 2007. "Toxic Leaching Procedure and Totals Analyses of Spherical Resorcinol-Formaldehyde Resin" WSRC-STI-2007-00213 (SRT-RPP-200600029), Rev. 0 (July).

Olson, J. W. and M. L. Stewart, 2002. "System Description for Cesium Removal Using Ion Exchange - System CSP”, 24590-PTF-3YD-CXP-00001, Rev. B (May 3).

Sherman, J. D., R. R. Willis, R. L. Bedard, A. S. Behan, and P.Connolly, 1999. "Shaped Articles and Process for Preparing the Article" U.S. Patent \#5,925,284 (July 20).

Smith, F. G., 2007. "Modeling of Ion-Exchange for Cesium Removal from Dissolved Saltcake in SRS Tanks 1-3, 37 and 41" WSRC-STI-2007-00315, Rev. 0 (July).

Su, Y., L. Li, J. S. Young, M. L. Balmer, 2001. "Investigation of Chemical and Thermal Stabilities of Cs-Loaded UOP IONSIV ${ }^{\circledR}$ IE-911 Ion Exchanger (Final Report)" PNNL13392-2 (March).

Taylor, P. A., and C. H. Mattus, 1999a. "Thermal and Chemical Stability of Crystalline Silicotitanate Sorbent” ORNL/TM-1999/233, Rev. 0 (October).

Taylor, P. A., J. D. Hewitt, T. D. Hylton, and T. E. Kent, 1999b. "Transport and Storage Properties if CST Slurries for the Savannah River Site" ORNL/TM-13727, Rev. 0 (April).

Taylor, P. A., and C. H. Mattus, 2000. "Thermal and Chemical Stability of Baseline and Improved Crystalline Silicotitanate" ORNL/TM-2001/165, Rev. 0 (December).

Taylor, P. A., H. L. Jennings, and J. F. Walker, 2003. "Letter Report - Clumping Behavior and Cesium Loading Results for Crystalline Silicotitanate and Zeolite in SRS Dissolved Salt Simulants" PER/ORNL/NTEL-IX-003 (August 28).

Thorson, M., 2006. "Basis for Recommendation of Spherical Resorcinol Formaldehyde Resin as the Approved Equivalent to SuperLig ${ }^{\circledR}$ 644", 24590-WTP-RPT-RT-06-001, Rev. 0 (November 14).

Walker, D. D., 1999. "Cesium Removal from Savannah River Site Radioactive Waste Using Crystalline Silicotitanate Ionsiv IE-911” WSRC-TR-99-00308, Rev. 0 (September $18)$. 
Walker, J. F., Jr., P. A. Taylor, R. L. Cummins, B. S. Evans, S. D. Heath, J. D. Hewitt, R. D. Hunt, H. L. Jennings, J. A. Kilby, D. D. Lee, S. Lewis-Lambert, S. A. Richardson, and R. F. Utrera, 1998. "Cesium Removal Demonstration Utilizing Crystalline Silicotitanate Sorbent for Processing Melton Valley Storage Tank Supernate: Final Report" ORNL/TM-13503 (March).

Welch, T. D., K. K. Anderson, D. A. Bostick, T. A. Dillow, M. W. Geeting, R. D. Hunt, R. Lenarduzzi, A. J. Mattus, P. A. Taylor, W. R. Wilmarth, 2000. "Hydraulic Performance and Gas Behavior of a Tall Crystalline Silicotitanate Ion-Exchange Column" ORNL/TM-1999/103 (February).

Wilmarth, W. R., J. T. Mills, V. H. Dukes, and F. F. Fondeur, 2000a. "Effect of Sodium Hydroxide Pretreatment of UOP IONSIV IE-911 Crystalline Silicotitonate Sorbent" WSRC-TR-2000-00167, Rev. 0.

Wilmarth, W. R., J. T. Mills, and V. H. Dukes, 2000b. "Results of Sorption/Desorption Experiments with IONSIV IE-911 Crystalline Silicotitanate" WSRC-TR-2000-00394, Rev. 0, (January).

Wilmarth, W. R., J. T. Mills, and V. H. Dukes 2004. "Reactivity of Crystalline Silicotitanate (CST) and Hazardous Metal/Actinide Loading during Low Curie Salt Use” WSRC-TR-2004-00588, Rev. 0 (November 30).

Zheng, Z., C. V. Philip, R. G. Anthony, J. L. Krumhansi, D. E. Trudell, and J. E. Miller, 1996. "Ion Exchange of Group 1 Metals by Hydrous Crystalline Silicotitanate", Ind. Eng. Chem. Res., Vol. 35, pp. 4246-4256.

Zheng, Z., R. G. Anthony, and J. E. Miller, 1997. "Modeling Multicomponent Ion Exchange Equilibrium Utilizing Hydrous Crystalline Silicotitanates by a Multiple Interactive Ion Exchange Site Model”, Ind. Eng. Chem. Res., Vol. 36, No. 6, pp. $2427-$ 2434. 